Universidad de Lima

Facultad de Ingeniería y Arquitectura

Carrera de Ingeniería Industrial

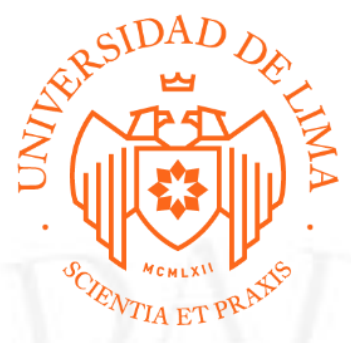

\title{
MEJORA DE PROCESOS MEDIANTE LA IMPLEMENTACIÓN DE UN SISTEMA DE GESTIÓN PARA EL DESARROLLO DE LOS ESTUDIOS DE INGENIERÍA EN UNA EMPRESA AEROPORTUARIA
}

Trabajo de suficiencia profesional para optar el Título Profesional de Ingeniero Industrial

ANDREA PATRICIA ARIAS MENESES

Código 20052460

Asesor

Carlos Urbina Rivera

Lima - Perú

Noviembre del 2019 


\section{PROCESS IMPROVEMENT THROUGH THE}

IMPLEMENTATION OF A MANAGEMENT SYSTEM FOR THE DEVELOPMENT OF ENGINEERING STUDIES IN AN AIRPORT COMPANY 


\section{TABLA DE CONTENIDO}

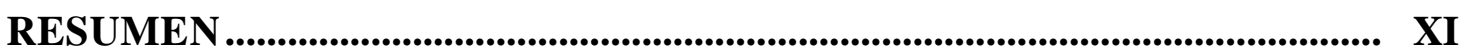

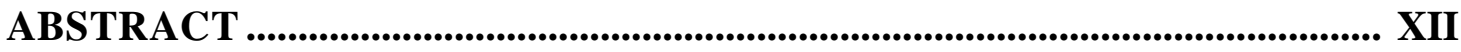

CAPÍTULO I: CONSIDERACIONES GENERALES DE LA

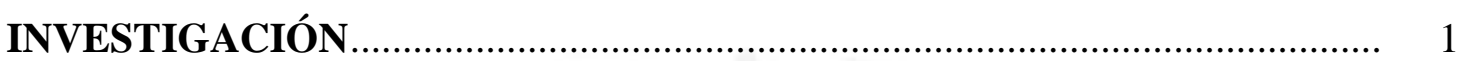

$1.1 \quad$ Antecedentes de la empresa .................................................................... 1

1.1.1 Breve descripción de la empresa y reseña histórica.................................... 1

1.1.2 Descripción y características principales ................................................. 2

1.1.3 Descripción del Sector ..................................................................... 7

1.1.4 Descripción de la problemática actual …................................................ 7

1.2 Objetivos de la investigación ................................................................ 10

1.2.1 Objetivo general ............................................................................. 10

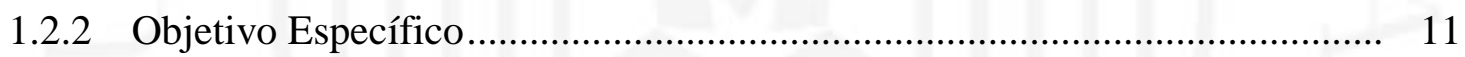

1.3 Alcance y limitaciones de la investigación ............................................. 11

1.4 Justificación de la investigación .............................................................. 11

CAPÍTULO II. ANÁLISIS SITUACIONAL DE LA EMPRESA Y SELECCIÓN

DEL SISTEMA O PROCESO A SER MEJORADO ....................................... 15

2.1 Análisis Externo de la Empresa.............................................................. 15

2.1.1 Análisis del entorno global ................................................................... 15

2.1.2 Análisis del entorno competitivo ......................................................... 17

2.1.3 Identificación y evaluación de las oportunidades y amenazas del entorno ...... 20

2.2 Análisis Interno de la Empresa................................................................... 23

2.2.1 Análisis del direccionamiento estratégico: visión, misión y objetivos

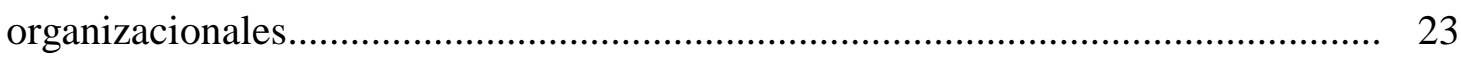

2.2.2 Análisis de la estructura organizacional................................................. 24 
2.2.3 Identificación y evaluación de las fortalezas y debilidades de la empresa.... 26

CAPÍTULO III: DIAGNÓSTICO DEL SISTEMA O PROCESO OBJETO DE ESTUDIO

3.1 Análisis del sistema o proceso objeto de estudio ........................................ 30

3.2 Análisis del FODA de la Gerencia de Ingeniería ...................................... 31

3.2.1 Análisis de los indicadores específicos de desempeño del sistema o proceso (metas, resultados actuales, tendencias, brechas, comparativos) ............................ 31

3.3 Determinación las causas raíz de los problemas hallados ............................. 34

CAPÍTULO IV: DETERMINACIÓN DE LA PROPUESTA DE SOLUCIÓN 37

4.1 Planteamiento de alternativas de solución................................................. 37

4.2 Selección de alternativas de solución .......................................................... 38

4.2.1 Determinación y ponderación de criterios evaluación de las alternativas ..... 38

4.2.2 Evaluación cualitativa y/o cuantitativa de alternativas de solución............... 39

4.2.3 Priorización y selección de soluciones....................................................... 39

CAPÍTULO V: DESARROLLO, PLANIFICACIÓN Y RESULTADOS ESPERADOS DE LA SOLUCIÓN .............................................................................. 41

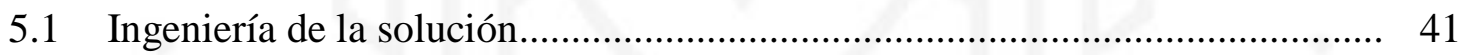

5.1.1 Definición de Macro procesos y Procesos .................................................... 42

5.1.2 Desarrollo de flujogramas y procedimientos........................................... 42

5.1.3 Elaboración de formatos estandarizados .................................................. 47

5.1.4 Definir y adquirir recursos (HW, SW y recursos) para el proceso de mejora.. 50

5.1.5 Implementación del Project Online ..................................................... 50

5.1.6 Plan de capacitación para el uso del sistema de gestión................................... 51

5.2 Plan de implementación de la solución ...................................................... 51

5.2.1 Elaboración del presupuesto requerido para la ejecución de la solución....... 51

5.2.2 Actividades y cronograma de implementación de la solución...................... 53

5.3 Evaluación económica de la solución ........................................................ 54 
CONCLUSIONES

RECOMENDACIONES .

REFERENCIAS.

60

BIBLIOGRAFÍA 61 


\section{ÍNDICE DE TABLAS}

Tabla 1.1 Ubicación de los Aeropuertos ................................................................ 2

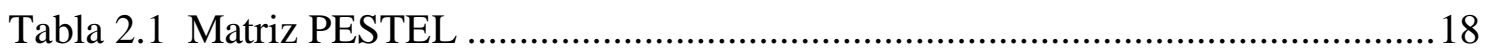

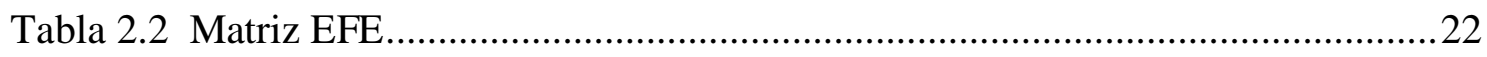

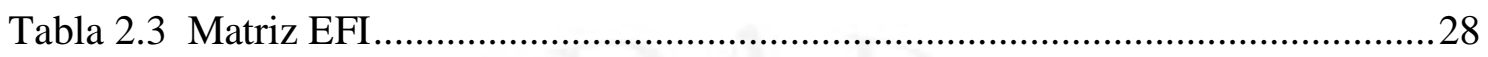

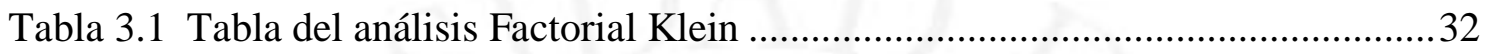

Tabla 3.2 Tabla del Análisis FODA en la G. Ingeniería............................... 35

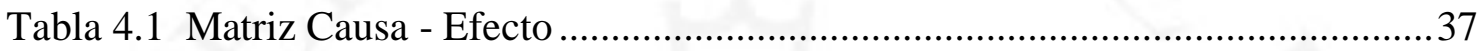

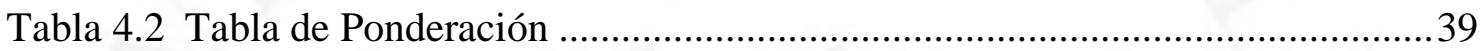

Tabla 4.3 Matriz Cuantitativa de Planificación Estratégica (MCPE) ............................40

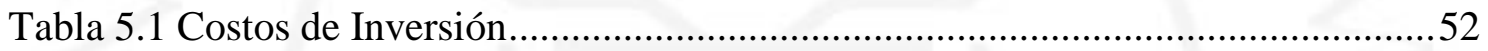

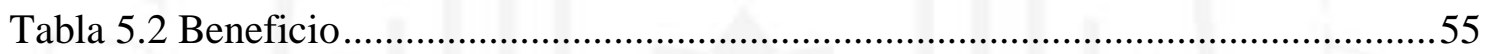

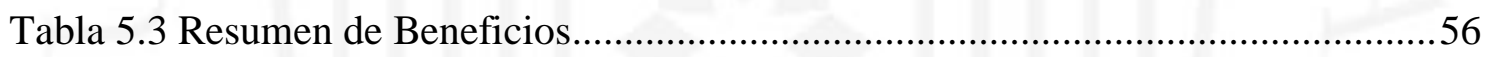

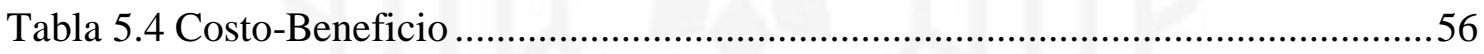




\section{ÍNDICE DE FIGURAS}

Figura 1.1 Mapa Aeropuertos del Perú ....................................................................... 1

Figura 1.2 Empresa del Grupo Sandoval .............................................................

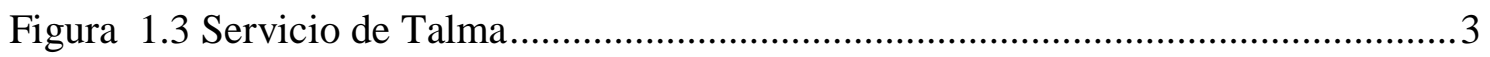

Figura $1.4 \%$ Utilización Inversiones AdP / Fideicomiso LAP .....................................5

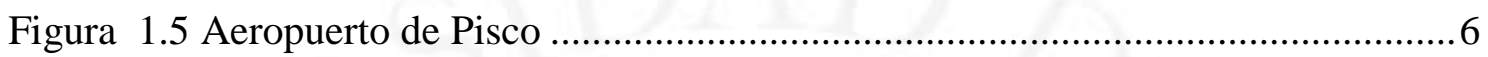

Figura 1.6 Pasajeros (MM) AdP 2007 - 2018 ....................................................... 6

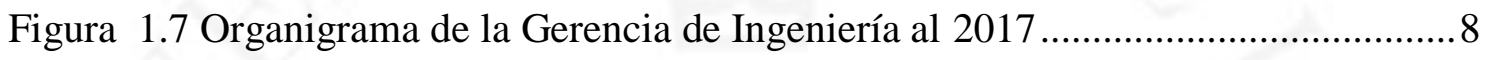

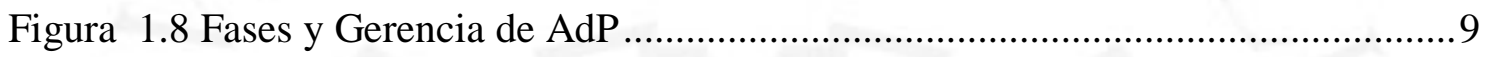

Figura 1.9 Estructura de Portafolio al 21017 .......................................................... 10

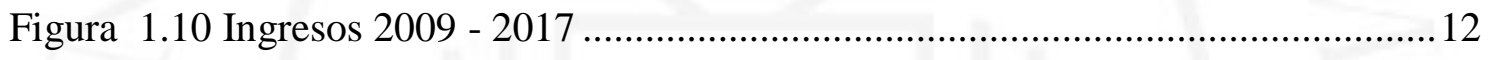

Figura 1.11 Cofinanciamiento - Pasajeros ............................................................ 13

Figura 1.12 Proceso de Gestión de Inversiones según el PMI.................................... 14

Figura 2.1 Evolución de la cuota de mercado de las aerolíneas de bajo costo ...............16

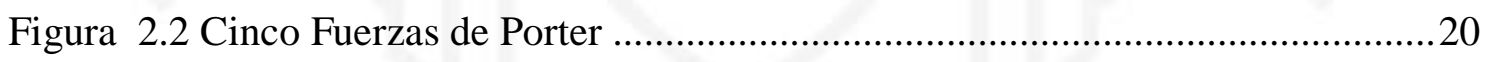

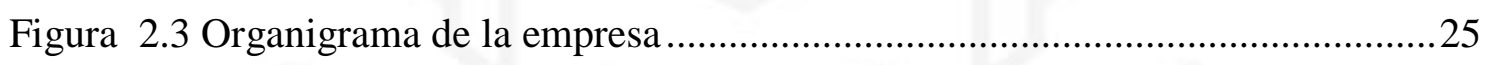

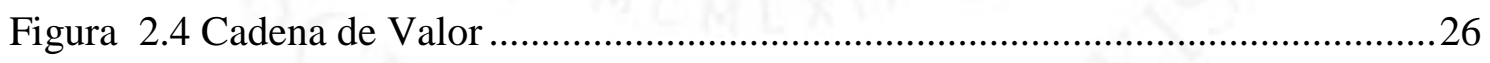

Figura 3.1 Macro procesos de la Gerencia de Ingeniería .......................................... 30

Figura 3.2 Análisis de indicadores de desempeño en días (Estimado vs. Real) para el desarrollo de los Estudios de Ingeniería del Proyecto PRMLA CIX. .............................33

Figura 3.3 Análisis de indicadores de desempeño número de versiones y observaciones de documentos para el desarrollo de los Estudios de Ingeniería de proyecto PRMLA CIX

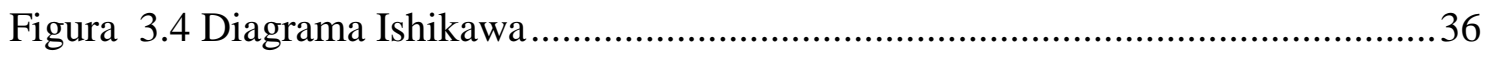

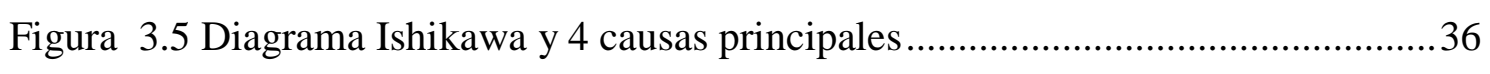


Figura 5.1 Método de trabajo

Figura 5.2 Planificación y control de Proyectos ...........................................................42

Figura 5.3 Diagrama de Flujo para desarrollar el cronograma ....................................43

Figura 5.4 Diagrama de flujo para controlar el cronograma.......................................4

Figura 5.5 Diagrama de flujo para el control de valorizaciones en la Gerencia de Ingeniería 45

Figura 5.6 Diagrama de flujo para la configuración de entorno para gestión de correspondencia y entregable .46

Figura 5.7 Formato para el control de valorizaciones en la Gerencia de Ingeniería .....47

Figura 5.8 Formato de Lista Maestra para el Control de Costos de Servicios .48

Figura 5.9 Formato de Listado Maestro de Concursos .................................................49

Figura 5.10 Página Principal del Project Online.......................................................50

Figura 5.11 Página Principal del Power BI...............................................................51

Figura 5.12 Cronograma de Actividades para desarrollar el Sistema de Gestión de Estudios de Ingeniería .53 


\section{RESUMEN}

El presente proyecto fue iniciado hacia el año 2017 para desarrollar con eficiencia la gestión de proyectos en la empresa aeroportuaria “Aeropuertos del Perú", debido que se venía trabajando de una manera empírica sobre los proyectos existentes y, además, anualmente hay un incremento de proyectos en la cartera de inversiones.

Trayendo como consecuencia una notable mejora en el control de los proyectos aeroportuarios, por una adecuada gestión de los estudios definitivos de ingeniería. La implementación del proyecto viene siendo liderada por la jefatura de Programación y Control de Proyectos, que tiene un impacto transversal en varias áreas de la empresa pero que actualmente pertenece al área de Ingeniería.

Para lograr el impacto esperado se utilizó las herramientas de Ingeniería Industrial compatibles con los objetivos de la empresa, como la matriz PESTEL, las cinco fuerzas de Porter, la matriz EFI y EFE, la matriz FODA para el caso de la Gerencia de Ingeniería, la matriz Ishikawa y la matriz cuantitativa de planificación estratégica (MCPE).

Se puede evidenciar que este proyecto aportó en el desarrollo del sistema de gestión que permitió optimizar el tiempo, costo y alcance de los estudios de ingeniería para lograr la modernización de los aeropuertos, lográndose la inclusión y desarrollo de nuevos procesos, flujogramas, procedimientos y uso del software Project Online a modo de optimizar la gestión y por ende el control del portafolio de proyectos.

Por lo antes expuesto se ha demostrado que el resultado es totalmente positivo, ya que, se logró ahorrar evitando el incremento de los costos de consultoría, se continúan mejorando los procesos para evitar reprocesos y con ello garantizar un control de gestión de los estudios, sobre todo una mejora en el orden y comunicación de la organización.

Palabras clave: Proyectos aeroportuarios, Ingeniería, Procesos, Flujogramas y Gestión de Proyectos. 


\begin{abstract}
The present project was initiated towards 2017 to efficiently develop project management in the airport company "Aeropuertos del Perú", due to the increase of the annual investment portfolio and, in addition, that it had been working in an empirical way on existing projects.

Therefore, there was a notable improvement in the control of airport projects, due to an adequate management of the definitive engineering studies. The mentioned implementation of the project is being led by the head of Programming and Control of Projects, which has a transversal impact in several areas of the company but currently belongs to the area of Engineering.

To achieve the expected impact, Industrial Engineering tools compatible with the company's objectives were used, such as the PESTEL matrix, Porter's five forces, the EFI and EFE matrix, the SWOT matrix for Engineering Management, the Ishikawa matrix and the quantitative strategic planning matrix (MCPE).

It can be evidenced that this project contributed to the development of the management system that allowed optimizing the time, cost and scope of the engineering studies to achieve the modernization of the airports, achieving the inclusion and development of new processes, flowcharts, procedures and use of Project Online software in order to optimize the management and therefore the control of the project portfolio.

Due to the above, it has been shown that the result is totally positive, since savings were achieved by avoiding the increase in consulting costs, processes continue to be improved to avoid reprocesses and thus ensure a management control of the studies, especially an improvement in the order and communication of the organization.
\end{abstract}

Keywords: Airport projects, Engineering, Process, Flowcharts and Project Management. 


\section{CAPÍTULO I: CONSIDERACIONES GENERALES DE LA INVESTIGACIÓN}

\subsection{Antecedentes de la empresa}

\subsubsection{Breve descripción de la empresa y reseña histórica}

El 17 de julio de 2006, el estado pone a concesión el Primer Grupo de Aeropuertos, conformado por 12 aeropuertos del norte y nor-oriente del país.

El 18 de agosto de 2006, el gobierno adjudicó la concesión del primer paquete de aeropuertos, por un plazo de 25 años a Consorcio GBH-Swissport Aeropuertos.

Aeropuertos del Perú (AdP) fue constituida el 30 de octubre de 2006. En diciembre del 2006, nos entregan el primer grupo de aeropuertos de provincias y fue adquirida por el grupo Sandoval en diciembre del 2010.

AdP es una Asociación Pública Privada cofinanciada por el Estado Peruano, esta empresa es concesionaria tiene a cargo los Aeropuertos: Tumbes, Talara, Piura, Cajamarca, Chiclayo, Chachapoyas, Tarapoto, Trujillo, Anta (Huaraz), Iquitos y Pucallpa; además del nuevo aeropuerto de Pisco. Tiene como visión contar para el año 2031 con una moderna infraestructura aeroportuaria, gestionada de manera segura y eficiente.

Figura 1.1

Mapa Aeropuertos del Perú

aDP

\section{MAPA}

\section{AEROPUERTOS}

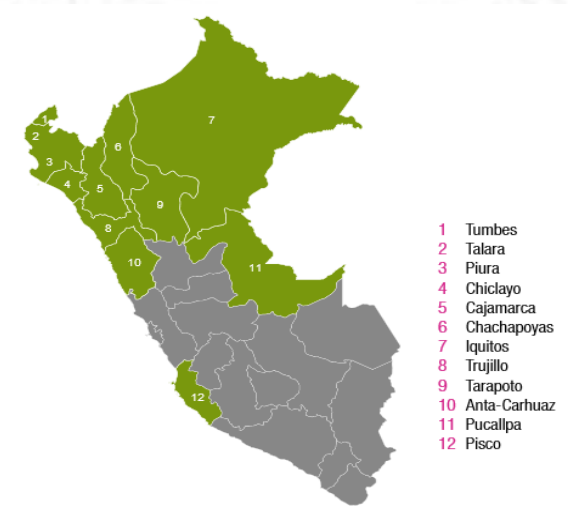

Fuente: Aeropuertos del Perú (2017) 
Tabla 1.1

Ubicación de los Aeropuertos

\begin{tabular}{|c|c|c|c|}
\hline ITEM & CIUDAD & $\begin{array}{l}\text { NOMBRE DEL } \\
\text { AEROPUERTO }\end{array}$ & DIRECCIÓN \\
\hline 1 & Cajamarca & $\begin{array}{c}\text { Aeropuerto Mayor General FAP } \\
\text { Armando Revoredo Iglesias }\end{array}$ & $\begin{array}{c}\text { Av. Hoyos Rubio S/N, Cajamarca } \\
\text { - Perú }\end{array}$ \\
\hline 2 & Chachapoyas & Aeropuerto Chachapoyas & $\begin{array}{c}\text { Jr. Aeropuerto S/N, Chachapoyas } \\
\text { - Amazonas, Perú }\end{array}$ \\
\hline 3 & Chiclayo & $\begin{array}{c}\text { Aeropuerto Internacional } \\
\text { Capitán FAP José A. Quiñones }\end{array}$ & $\begin{array}{c}\text { Av. Fiscarral S/N cruce con Av. } \\
\text { Bolognesi S/N Chiclayo - } \\
\text { Lambayeque }\end{array}$ \\
\hline 4 & Huaraz/Anta & $\begin{array}{l}\text { Aeropuerto comandante FAP } \\
\text { Germán Arias Grazini }\end{array}$ & $\begin{array}{c}\text { Carretera Huaraz - Caraz km.23 } \\
\text { Anta - Carhuaz - Ancash }\end{array}$ \\
\hline 5 & Iquitos & $\begin{array}{c}\text { Aeropuerto Internacional } \\
\text { Coronel FAP Francisco Secada } \\
\text { Vignetta }\end{array}$ & $\begin{array}{c}\text { Av. Abelardo Quiñones Km. } 6 \\
\text { S/N - San Juan Bautista Iquitos - } \\
\text { Perú }\end{array}$ \\
\hline 6 & Pisco & $\begin{array}{c}\text { Aeropuerto Capitán FAP Renán } \\
\text { Elías Olivera }\end{array}$ & $\begin{array}{c}\text { Calle Ica 6ta cuadra S/N Pisco - } \\
\text { Perú }\end{array}$ \\
\hline 7 & Piura & $\begin{array}{c}\text { Aeropuerto Internacional } \\
\text { Capitán FAP Guillermo Concha } \\
\text { Ibérico }\end{array}$ & $\begin{array}{c}\text { Av. Corpac } \mathrm{N}^{\circ} 274 \text {, Castilla, } \\
\text { Piura }\end{array}$ \\
\hline 8 & Pucallpa & $\begin{array}{c}\text { Aeropuerto Internacional } \\
\text { Capitán FAP David Abensur } \\
\text { Rengifo }\end{array}$ & $\begin{array}{c}\text { Carretera Federico Basadre S/N } \\
\text { Pucallpa - Perú }\end{array}$ \\
\hline 9 & Tarapoto & $\begin{array}{c}\text { Aeropuerto Cadete FAP } \\
\text { Guillermo del Castillo Paredes }\end{array}$ & $\begin{array}{c}\text { Jr. Jorge Chávez } 1899 \text { Tarapoto - } \\
\text { San Martín }\end{array}$ \\
\hline 10 & Trujillo & $\begin{array}{c}\text { Aeropuerto Internacional } \\
\text { Capitán FAP Carlos Martínez } \\
\text { de Pinillos }\end{array}$ & $\begin{array}{c}\text { Av. Aviación S/N Huanchaco- } \\
\text { Trujillo }\end{array}$ \\
\hline 11 & Tumbes & $\begin{array}{c}\text { Aeropuerto Capitán FAP Pedro } \\
\text { Canga Rodríguez }\end{array}$ & $\begin{array}{c}\text { Carretera Panamericana norte km. } \\
1276 \text { Tumbes - Perú }\end{array}$ \\
\hline 12 & Talara & $\begin{array}{c}\text { Aeropuerto Internacional } \\
\text { Capitán FAP Víctor Montes } \\
\text { Arias }\end{array}$ & $\begin{array}{c}\text { Talara alto S/N Pariñas - Talara - } \\
\text { Piura }\end{array}$ \\
\hline
\end{tabular}

Fuente: Aeropuertos del Perú (2017)

Elaboración propia.

\subsubsection{Descripción y características principales}

Aeropuertos del Perú pertenece al Grupo Sandoval, el cual tiene empresas con vasta experiencia en el sector aeroportuario tales como Talma y Lima Cargo City (Inmobiliaria Koricancha). 
Figura 1.2

Empresa del Grupo Sandoval

\section{S GrupoSandoval}

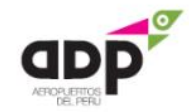
Concesionaria
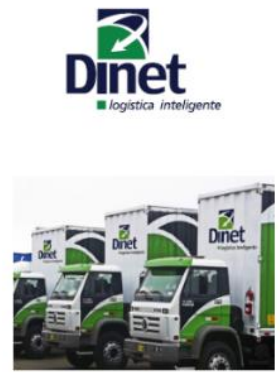

Logistica integral

(3PL)

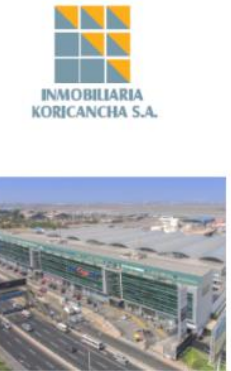

Gestión inmobiliaria

\section{Talma}

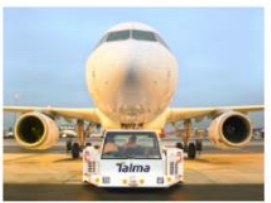

Servicios Aeroportuarios

Fuente: página web Grupo Sandoval (2017)

Talma, es la empresa con más experiencia en el grupo aeroportuario, esta empresa brinda servicios de carga aérea, servicio de rampa, servicios de aviación ejecutiva, operaciones de vuelo y atención a pasajeros desde hace más de 25 años. A partir del 2007 inauguró la primera escuela IATA de habla hispana en Sudamérica: Talma Training School.

Figura 1.3

Servicio de Talma

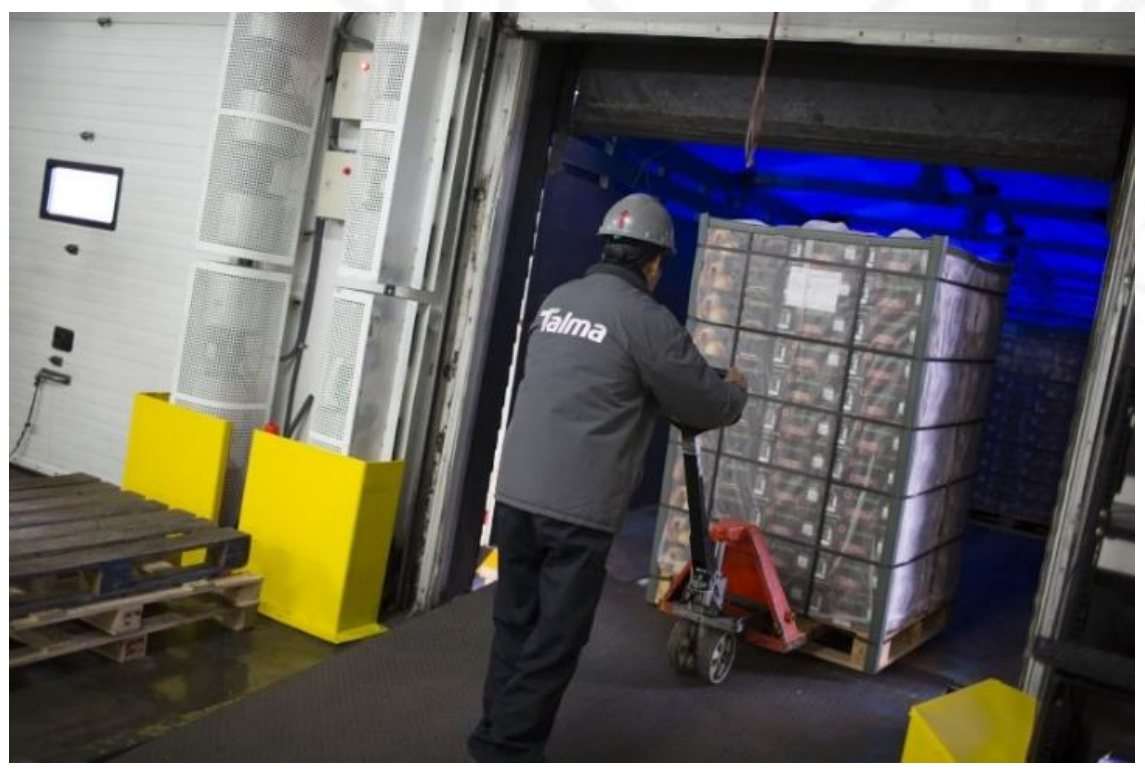

Fuente: página web Grupo Sandoval (2017)

La concesión de Aeropuertos del Perú tiene como características principales: 


\section{$\underline{\text { Vigencia de la concesión }}$}

La vigencia de la Concesión cofinanciada es por 25 años, la cual tuvo inicio con las operaciones en diciembre del 2006.

$\underline{\text { Alcance del cofinanciamiento: }}$

La empresa tiene como parte de su alcance y modo de financiamiento los siguientes términos:

El PAMO: Pago por Administración de Mantenimiento y Operación

Término del contrato de concesión que hace referencia a la suma del dinero expresado en dólares americanos requerido por el concesionario para el mantenimiento, con la excepción del mantenimiento periódico y operación de los aeropuertos. Este importe ha sido consignado en la propuesta económica presentada por el concesionario y será reajustado por inflación anualmente y revisado cada 5 años.

El PAO: Pago por Obra

Término del contrato de concesión que hace referencia al pago trimestral en dólares que el concedente realizará a favor del concesionario por la construcción de infraestructura, adquisición de equipamiento y mantenimiento periódico, efectuadas tanto en el periodo inicial como en el periodo remanente.

\section{$\underline{\text { Fuente de Recursos }}$}

Los montos de las inversiones a ser ejecutadas por AdP no provienen del presupuesto estatal, sino del Fideicomiso administrado por El Banco de Desarrollo del Perú (COFIDE), cuya fuente de ingresos es la retribución pagada al Estado por Lima Airport Partner (LAP).

La Retribución que LAP paga al Estado por la concesión del Aeropuerto Internacional Jorge Chávez (AIJCh) equivale al 46.511\% de sus Ingresos Brutos. Esta retribución de LAP, en los últimos 6 años, ascendió a USD 639 millones de dólares.

En la figura 1.4. se puede apreciar el porcentaje incremental por año en relación a lo consumido por AdP del fideicomiso LAP en sus inversiones. 
Figura 1.4

$\%$ Utilización Inversiones AdP / Fideicomiso LAP

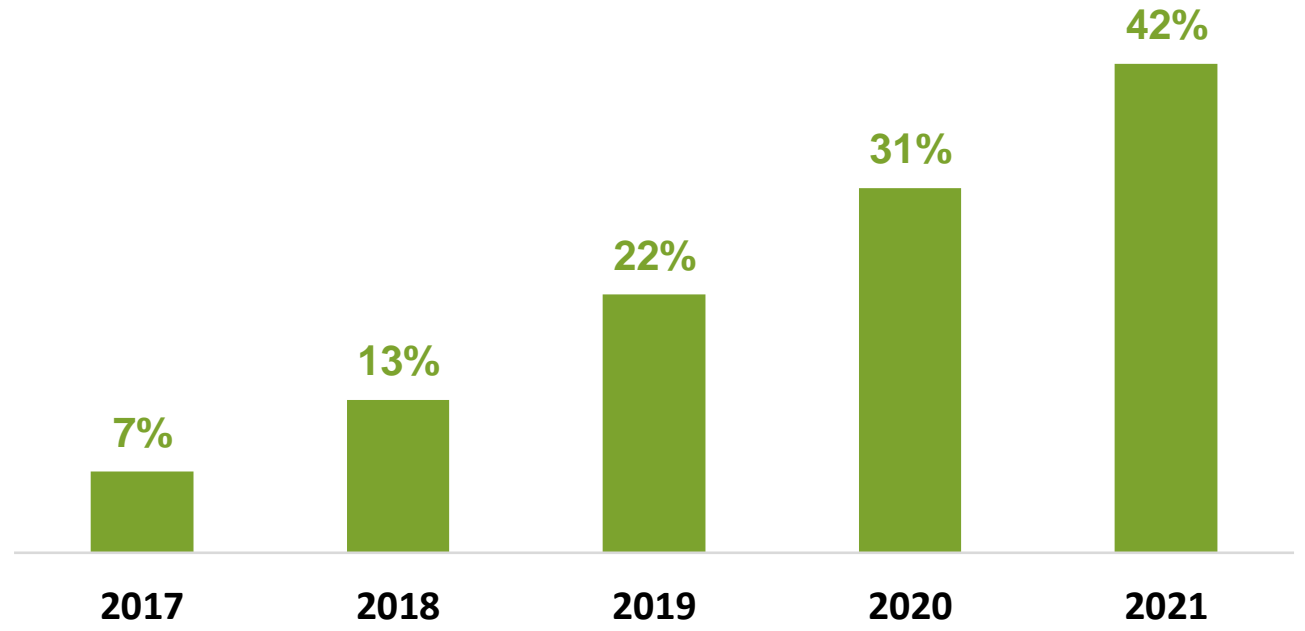

Fuente: Aeropuertos del Perú (2017)

Ejecución de Inversiones

Los proyectos de inversión en curso se gestionan dentro del marco del Sistema Nacional de Inversión Pública (SNIP), los nuevos proyectos bajo el marco del Invierte.pe

\section{$\underline{\text { Obligaciones del concesionario }}$}

DBFOT: Diseño, Construcción, Financiamiento, Operación y Transferencia de la infraestructura, a excepción de los servicios de aeronavegación que continúan a cargo del Estado.

\section{$\underline{\text { Regulador }}$}

Organismo Supervisor de la Inversión en Infraestructura de Transporte de uso Público (OSITRAN).

El primer reto de construcción de gran envergadura, lo asumió con el Aeropuerto Internacional de Pisco en el 2012, el cual conllevó trabajos de gestión y diseño previo a su construcción. El alcance para este proyecto incluyó obras de rápido impacto, de seguridad y ampliación y remodelación del terminal de pasajeros y terminal de carga; la inversión para este proyecto ascendió a los 45 millones de soles. 
Figura 1.5

Aeropuerto de Pisco

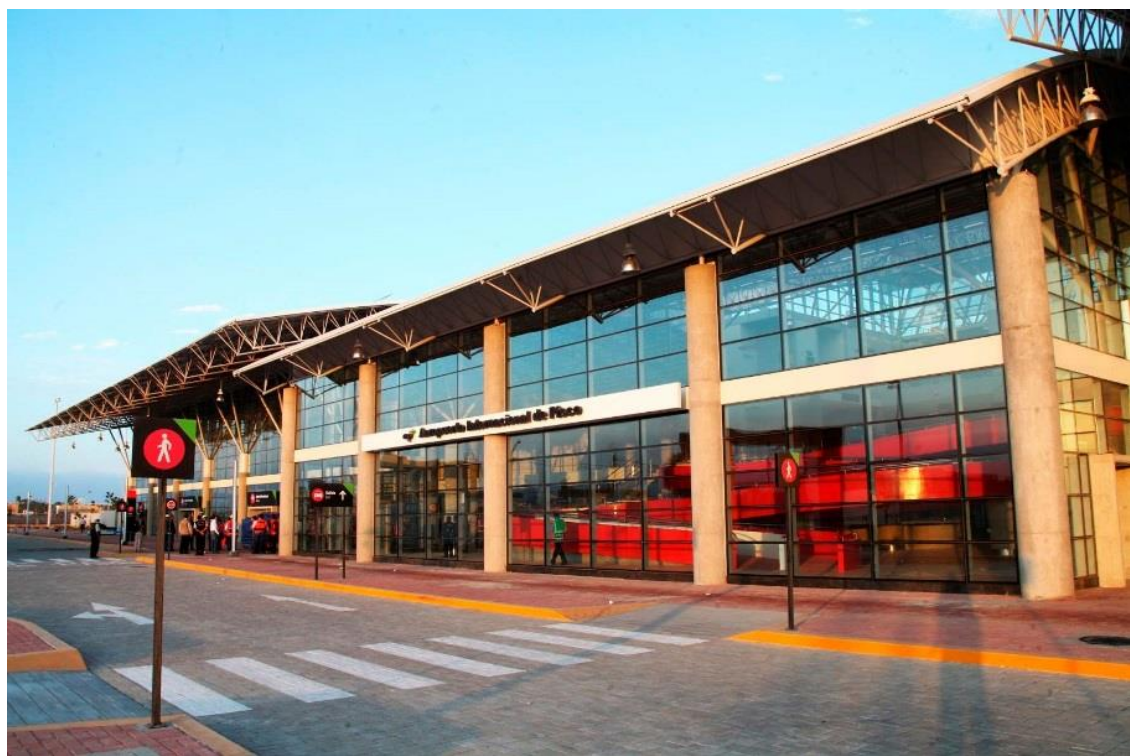

Fuente: Aeropuertos del Perú (2017)

Asimismo a partir de que Aeropuertos del Perú asumió el primer grupo de la concesión gestionando proyectos referidos a la operación y mantenimiento de sus aeropuertos, lleva a un incremento anual de pasajeros.

Figura 1.6

Pasajeros (MM) AdP 2007 - 2018

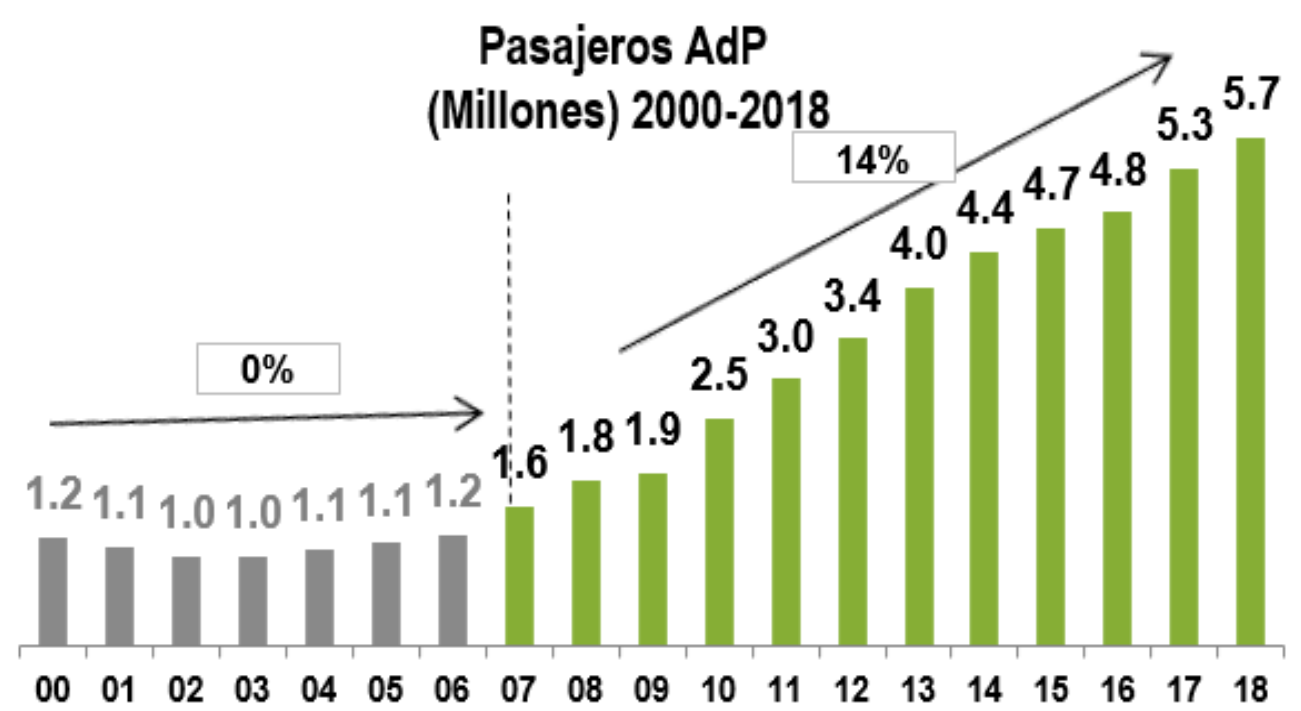

Fuente: Aeropuertos del Perú (2017) 


\subsubsection{Descripción del Sector}

Actualmente en el Perú el sector aeroportuario cuenta con tres concesiones, la primera es la concesión del Aeropuerto Internacional Jorge Chávez (AIJCH) la cual inicia en el 2000 asumiendo la responsabilidad de la operación y desarrollo. La segunda concesión otorgada a Aeropuertos del Perú (AdP) convirtiéndose en el concesionario del primer grupo de aeropuertos regionales del Perú y la tercera otorgada a Aeropuertos Andinos del Perú (AAP)

Las últimas dos concesiones se realizaron con una modalidad de contrato de tipo Asociación Público-Privada (APP) distinta a la primera concesión el cual es de tipo autofinanciada.

\subsubsection{Descripción de la problemática actual}

Para cumplir con el contrato de concesión, AdP deberá desarrollar un portafolio de proyectos de \$4000’MM, lo cual implica necesariamente implementar sistemas de gestión de proyectos y estructura organizacional para ejecutar el desarrollo de la infraestructura aeroportuaria hasta el 2031, año que finaliza la concesión de AdP.

Desde diciembre del 2006 que inició la concesión hasta el año 2019, la empresa viene invirtiendo aproximadamente \$193.4' MM; lo cual significa un promedio anual de inversiones del orden de $\$ 16.12$ ' MM. Entre las obras más importantes que se han ejecutado en los aeropuertos durante los primeros 3 años de la concesión, se encuentran las Obras de Rápido Impacto (ORI), con un monto de inversión de \$46.5’MM y la modernización del aeropuerto de Pisco por \$ 52’MM.

El objetivo de la concesión es modernizar toda la red de aeropuertos, invirtiendo en los programas de inversión del Plan Maestro de Desarrollo (PMD) y Programa de Rehabilitación y Mejoramiento del Lado Aire (PRMLA), \$ 3600’ MM en los PMD para los próximos 10 años y \$ 400' MM para el PRMLA los próximos 6 años. Es por ello, que la gestión de los estudios de pre - inversión y definitivos de ingeniería (Expedientes Técnicos), desde su origen hasta su aprobación por las entidades de gobierno, juega un papel protagónico, ya que, es la base técnica para la inversión de los proyectos y además representan entre el 5\% y $7 \%$ de los montos de inversión de los programas antes mencionados. 
Según lo antes mencionado se ha identificado la necesidad de plantear y llevar a cabo un sistema de gestión de estudios de ingeniería acorde a las necesidades del amplio portafolio de proyectos de la Gerencia de Ingeniería de AdP.

Organigrama de la Gerencia de Ingeniería:

En el año 2013 AdP toma la decisión de crear una gerencia de Ingeniería que se dedique íntegramente al desarrollo de los estudios técnicos previos y permisos previos a la ejecución de las inversiones en obra y en equipamiento. Es así como para el año 2017 la Gerencia de Ingeniería estuvo conformada por nueve personas; cuyo organigrama se muestra en la Imagen 1.6

Figura 1.7

Organigrama de la Gerencia de Ingeniería al 2017

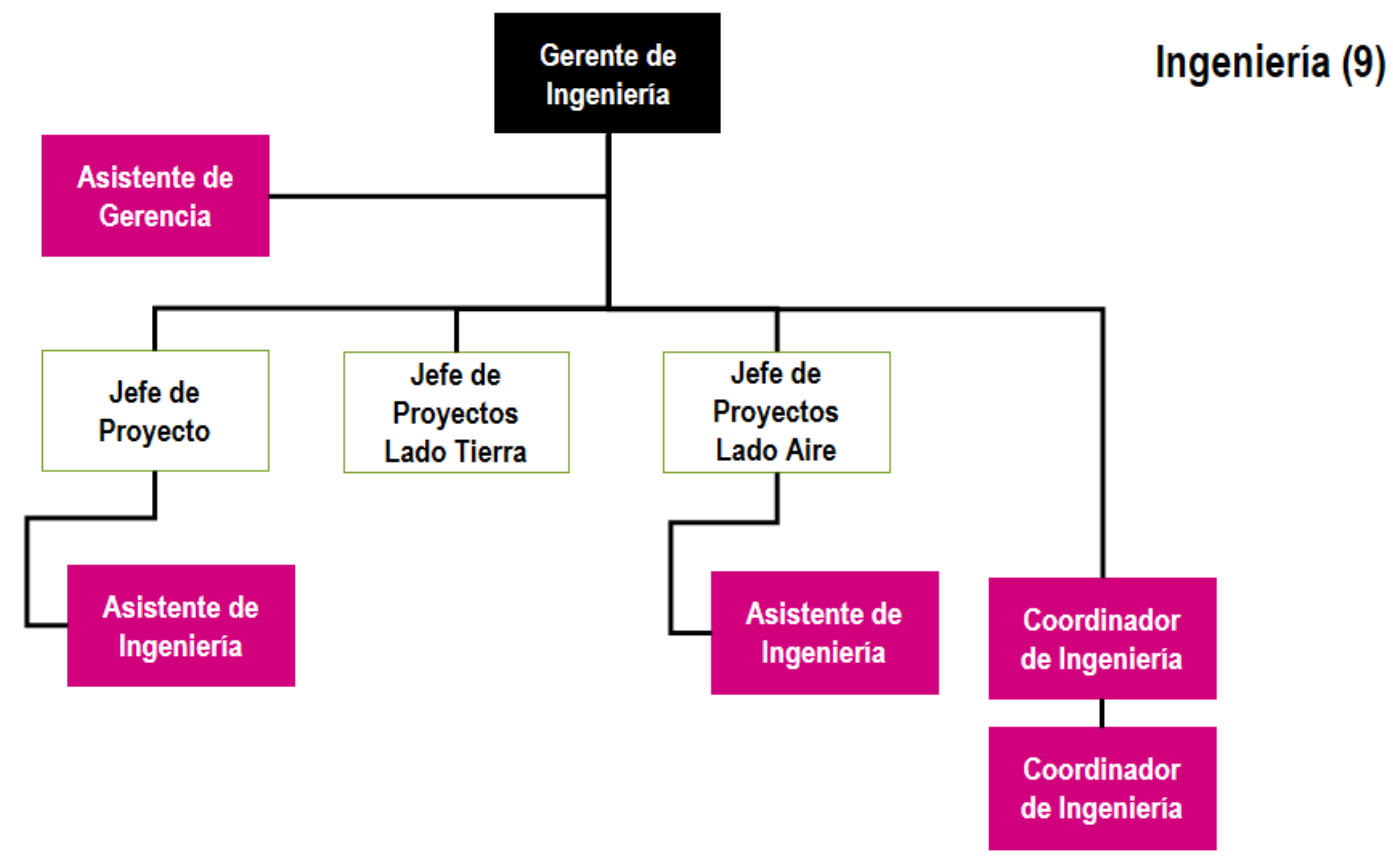

Elaboración propia

\section{Proyectos en Gestión:}

La Gerencia de Ingeniería se encarga de gestionar el desarrollo de los estudios de ingeniería, las actualizaciones y permisos y el proceso de revisión y aprobación de los estudios con las diferentes entidades de gobierno entre las cuales prevalece el OSITRAN como organismo regulador y el Ministerio de Transporte como el concedente. 
El proceso de gestión de los proyectos y el propio desarrollo de la ingeniería en los diferentes niveles de Perfil, Factibilidad y Expediente Técnico, se enmarcan en la normativa del SNIP (Sistema Nacional de Inversión Pública; es un instrumento del Estado que permite la mejor utilización de los recursos públicos destinados a la inversión) que estuvo vigente hasta fines del 2017.

En la figura 1.7, se muestra las fases del ciclo del proyecto con las diferentes gerencias involucradas, resaltando la fase de ingeniería donde se centra la presente investigación.

Figura 1.8

Fases y Gerencia de AdP

\section{FASES Y GERENCIAS I AEROPUERTOS DEL PERÚ}
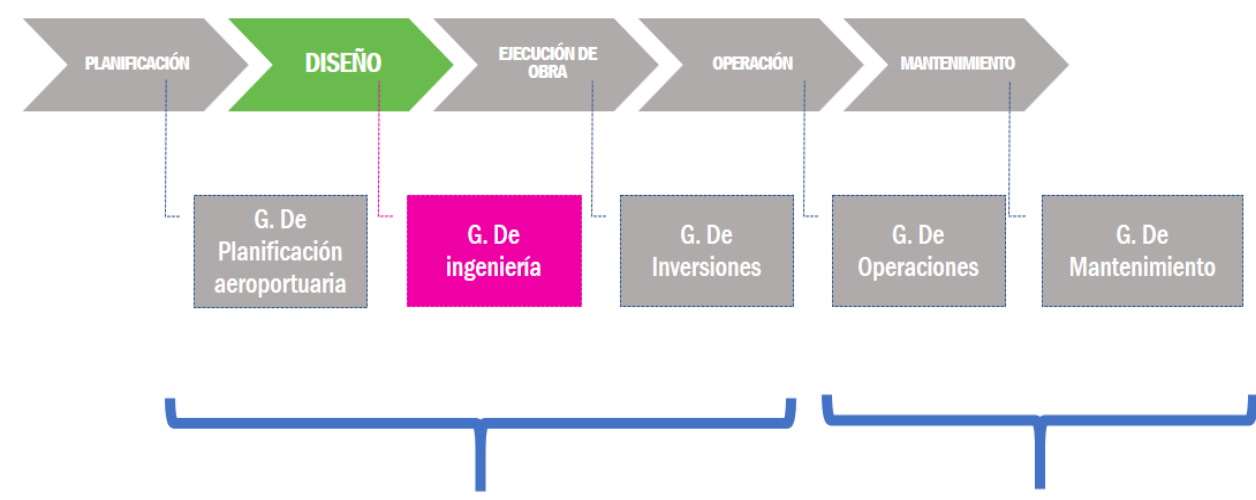

GESTIÓN DE PROYECTOS

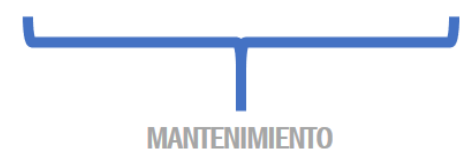

Fuente: Aeropuertos del Perú (2017)

El portafolio al 2017 estaba estructurado en cuatro programas. En el PRMLA estaba constituido por seis proyectos gestionados por un Jefe de Proyectos del lado aire y su asistente, en el PMD constituido por cuatro proyectos y lo gestionaba el jefe de proyectos de lado tierra. El programa de Plan de Inversiones de Equipamiento (PIE) estaba constituido por dos proyectos por un jefe de proyectos y su asistente. Por último, el programa PIP Menor, estaba constituido por dos proyectos de los cuales los responsables eran los dos coordinadores y el jefe de proyecto lado tierra. Cabe mencionar que el trabajo de los coordinadores también se daba de manera transversal a todos los proyectos según el requerimiento de cada jefe. 
La asistente de la gerencia realizaba diversas labores entre las cuales estaba incluido asistir a la gerencia y a los jefes de proyectos, control de proyectos y control comunicaciones de la gerencia.

Figura 1.9

Estructura de Portafolio al 21017

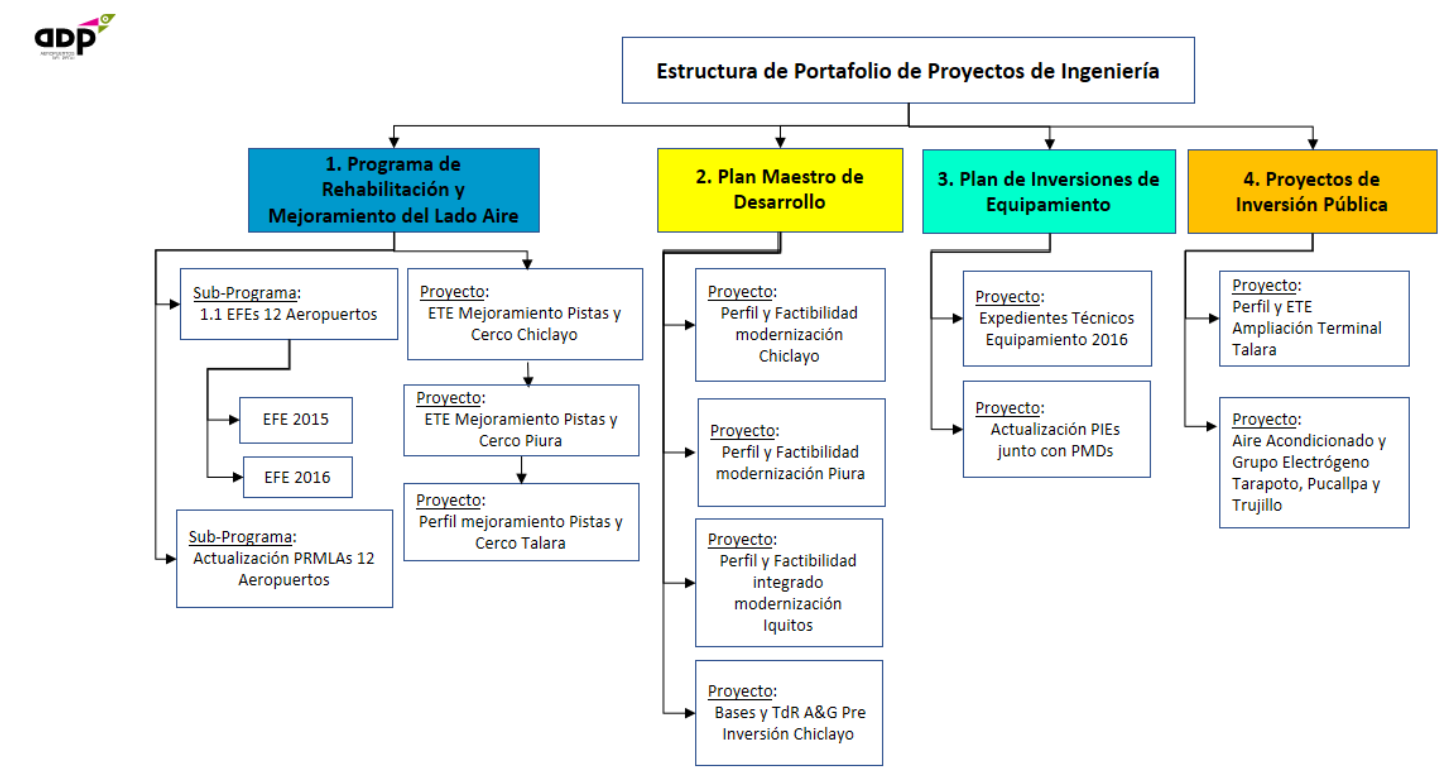

Elaboración propia

\subsection{Objetivos de la investigación}

\subsubsection{Objetivo general}

El objetivo general de la presente investigación es implementar un sistema de gestión que acelere la gestión de la cartera de proyectos de la Gerencia de Ingeniería en una empresa aeroportuaria.

El sistema de gestión desarrollado responde a la identificación de procesos, flujos, formatos y procedimientos que mejoren la eficiencia del desarrollo de los proyectos, el cual permitirá la aprobación por parte del MTC en el tiempo determinado según el Programa Multianual de Inversiones (PMI). Este proyecto se ha desarrollado mediante el uso de herramientas de la Ingeniería Industrial en sus distintas fases. 


\subsubsection{Objetivo Específico}

- Identificar y definir los procesos, formatos, flujos y procedimientos a llevar a cabo en la Gerencia de Ingeniería para el seguimiento y control de los proyectos.

- Definir y adquirir recursos para el proceso de mejora creando sub - áreas de diseño y control documentario

- Identificar por medio de herramientas de la Ingeniería Industrial y hacer uso de la mejor solución para los procesos de la Gerencia de Ingeniería.

- Definir el Project Online como el Software para la gestión de los proyectos desarrollando un plan de capacitación y definición de plantillas para su uso adecuado en los proyectos.

- Definir un plan de capacitaciones para el conocimiento de todo el personal de la Gerencia de Ingeniería del nuevo sistema de gestión de proyectos.

\subsection{Alcance y limitaciones de la investigación}

El proyecto se desarrolla en el año 2017 dentro de la empresa Aeropuertos del Perú en la Gerencia de Ingeniería donde se crea la sub - área de Programación y Control de Proyectos, debido a la activación de una serie de proyectos que incrementaron la cartera de inversiones, razón por la que se requirieron alternativas para definir mejoras en la gestión.

Dentro de estas alternativas se identificó la necesidad de definir un sistema de gestión, programación y control de los proyectos que sea eficiente en el sentido de que nos permita ahorrar reduciendo los tiempos y costos. La mejora en términos generales se relaciona directamente con la implementación del sistema antes mencionado convirtiéndose en el alcance principal del presente proyecto.

\subsection{Justificación de la investigación}

\section{Técnica:}

La proyección de gestionar la mayor cantidad de proyectos hace necesario contar con flujogramas, procesos, procedimientos y formatos definidos; ya que esto:

- Facilita a los usuarios encargados la coordinación con las áreas involucradas en el proceso y permite determinar detalle las actividades para culminarla. 
- Muestra de una manera sencilla y gráfica toda la transacción que se debe realizar en cada proceso identificado.

- El hecho de mostrar gráficamente el desarrollo de cada proceso permite estudiar y analizar mejor las actividades; lo cual permite además realizar mejoras continuas.

- Permite llevar mejor control de los proyectos y supervisión de la gestión.

\section{Económica}

Mediante un análisis de rentabilidad del primer grupo de concesión del Perú, se demuestra en la figura 1.10 que AdP al pasar los años ha ido sumando mayores ingresos lo cual se verifica que para el 2009 el cofinanciamiento del gobierno llegaba a un 51\% mientras que al 2017 tan solo llega a ser el 9\%, por lo tanto, se demuestra que es una empresa rentable.

Figura 1.10

Ingresos 2009 - 2017

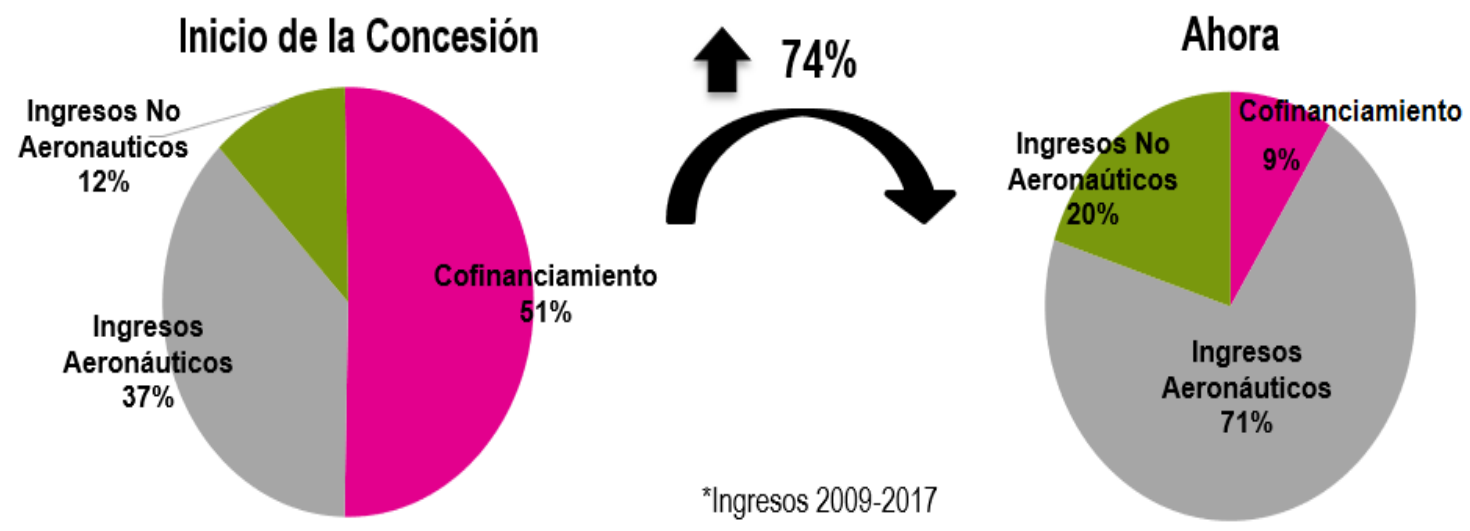

Fuente: Aeropuertos del Perú (2017)

Esta variación de la distribución de los ingresos ha hecho que AdP sea una empresa más independiente del cofinanciamiento del estado que cuando comenzó la concesión, a lo largo de los años se han ido incrementando los ingresos aeronáuticos y no aeronáuticos, generando cada vez más esta independización del estado.

Por otro lado, esto también muestra que al transcurrir los años y por la rentabilidad obtenida AdP percibirá menores fondos de fideicomiso convirtiéndose en una empresa más independiente, pero cabe mencionar que el fideicomiso que percibe AdP proviene 
de los fondos, si sucediera el caso de no tener los ingresos LAP según el contrato de concesión el gobierno tiene cubierto el riesgo de pagos de este fideicomiso a AdP. Adicional a esto AdP tiene un sistema de clasificación de riesgos lo cual se realiza cada 3 meses para controlar el riesgo de manera permanente.

Figura 1.11

Cofinanciamiento - Pasajeros

\section{Cofinanciamiento - Pasajeros (Millones)}

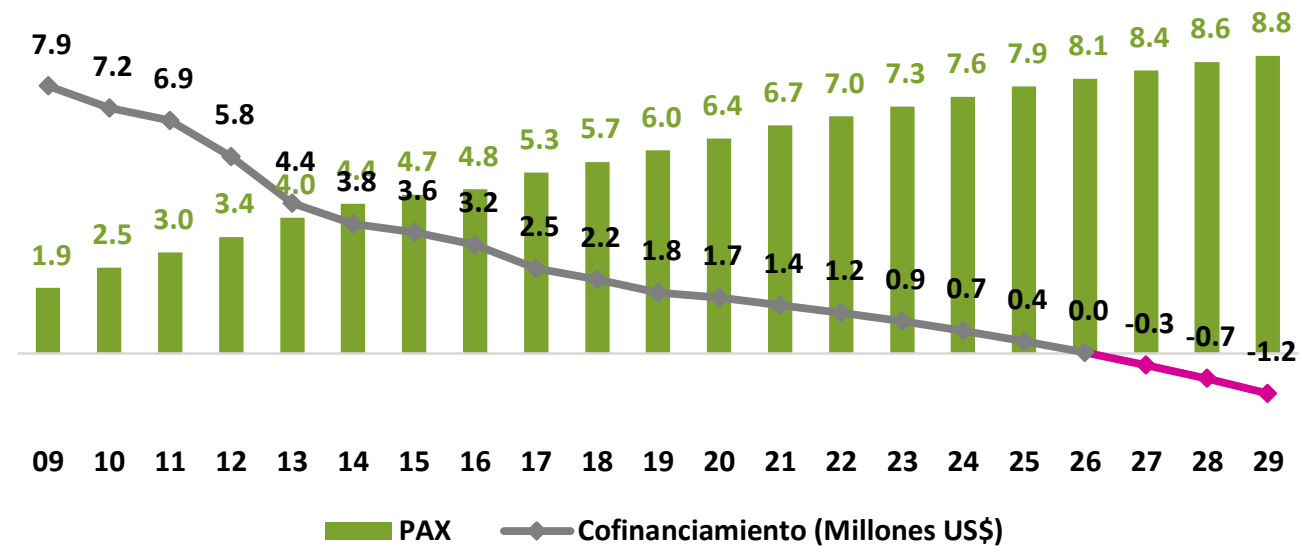

Fuente: Aeropuertos del Perú (2017)

En la gráfica se aprecia como el incremento de pasajeros a lo largo de los años ha ido aumentando, proyectándose al año 2029 tener 8.8' MM de pasajeros anuales, esto genera que AdP pueda reducir su dependencia del cofinanciamiento.

La Gerencia de Ingeniería tiene como objetivo realizar los estudios de manera anual, los cuales abarcan las fases de los Estudios previos a la ejecución de la obra. Según la imagen 1.5 Proceso de Gestión de Inversiones según el Programa Multianual de Inversiones (PMI) se muestran tres etapas, la primera etapa es de planificación, en esta se aprueba el PMI.

El PMI establece el diagnóstico de brechas, la priorización de la cartera, los lineamientos políticos, indicadores y metas anualizados tanto del Ministerio de Transporte y Comunicaciones y las empresas adscritas. 
Figura 1.12

Proceso de Gestión de Inversiones según el PMI

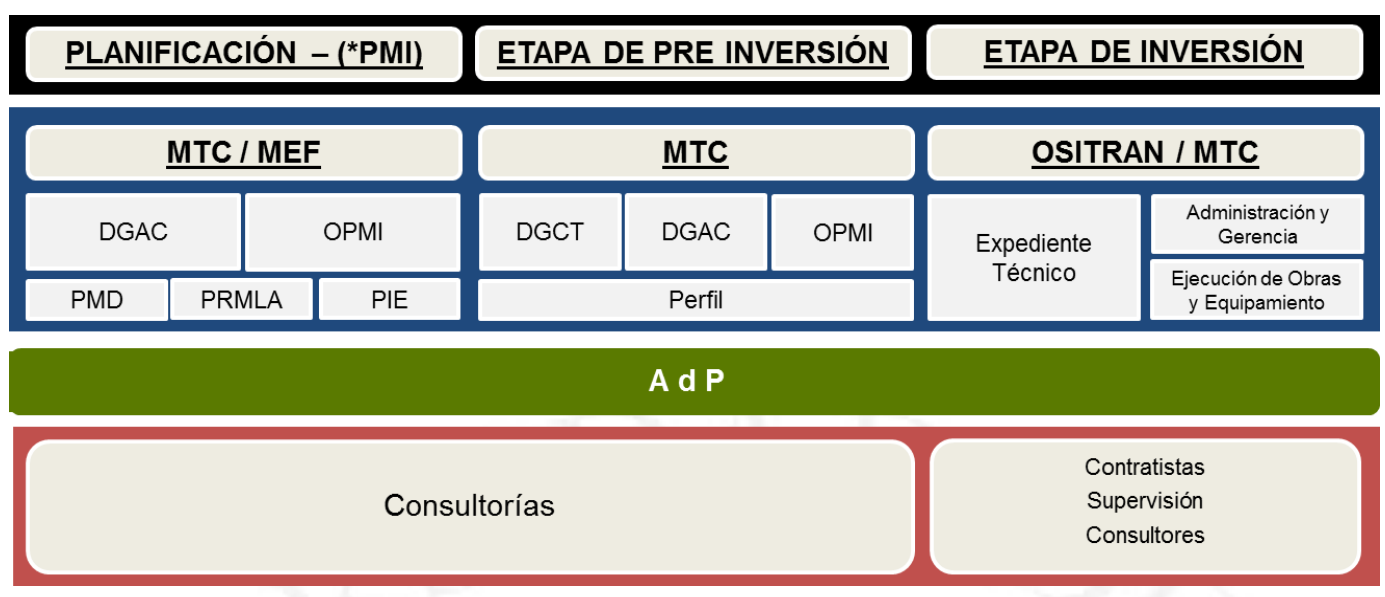

Fuente: Aeropuertos del Perú (2017)

\section{$\underline{\text { Social: }}$}

Como parte de la responsabilidad social, AdP tiene un plan de control medio ambiental, el cual incluye el control de emisiones, desechos sólidos y manejo de líquidos generados por el comercio y las operaciones.

Por otro lado, para los proyectos de inversión AdP tiene un plan de lograr la certificación Leed para los edificios de terminal de pasajeros, lo cual implica la mejor manera de usar recursos, tratando de evitar que el mínimo recurso impacte al medio ambiente, es por ello que esta certificación nos da pie a ser eco amigables.

Asimismo, se aplica la protección de la fauna. El Ministerio de Cultura nos exige tener el certificado de Inexistencia de Restos Arqueológicos, como control para no perjudicar el patrimonio cultural, tenemos responsabilidad en ese sentido de cumplir con todas las normas. 


\section{CAPÍTULO II. ANÁLISIS SITUACIONAL DE LA EMPRESA Y SELECCIÓN DEL SISTEMA O PROCESO A SER MEJORADO}

\subsection{Análisis Externo de la Empresa}

\subsubsection{Análisis del entorno global}

Para poder realizar un análisis estratégico en el entorno global, se realizó el análisis PESTEL, para lo cual se ha identificado los factores más relevantes en cada uno de los aspectos, tal como se muestra en la Tabla 2.1.

Respecto al tema económico se detalla la investigación dada por el Banco de Desarrollo de América Latina - CAF para el sector aeroportuario de América Latina y El Caribe (ALC), esta investigación reveló un crecimiento promedio de $8 \%$ anual en el tráfico de pasajeros en la década 2006-2015; es por ello que se considera que las inversiones estimadas llegarían a aumentar en el periodo entre el 2016 y 2040. (Gestión, 2019) Anunciado el 26 de junio del 2018 por la Agencia Peruana de Noticias.

Las proyecciones del estudio estiman un crecimiento promedio del tráfico aéreo de pasajeros del 5.2\% anual, pasando de 322 millones de pasajeros a 1,100 millones de pasajeros en el periodo de 2016-2040. Para cumplir con esta brecha las inversiones estimadas asciende a un total de US\$ 53,150 millones. . (Gestión, 2019)

La inversión disgregada por países que menciona el estudio sería en: México (US\$ 16,969 millones), Brasil (US\$ 11,389 millones), Colombia (US\$ 8,538 millones), Perú (US\$ 5,404 millones) y Chile (US\$ 3,046 millones). Perú por tanto es uno de los principales países para la inversión en proyectos aeroportuarios. (Gestión, 2019).

Según el “Análisis de Inversiones Portuarias y Aeroportuarias en América Latina y el Caribe (ALC) 2040", en la Figura 2.1 se muestra la evolución de la cuota de mercado de las aerolíneas de bajo costo, identificando el crecimiento de la conectividad que ha experimentado ALC centrándose en los mercados de intra-América-Latina el resto de los continentes. 
Figura 2.1

Evolución de la cuota de mercado de las aerolíneas de bajo costo

\section{$\%$ de la capacidad}

$60 \%$

$50 \%$

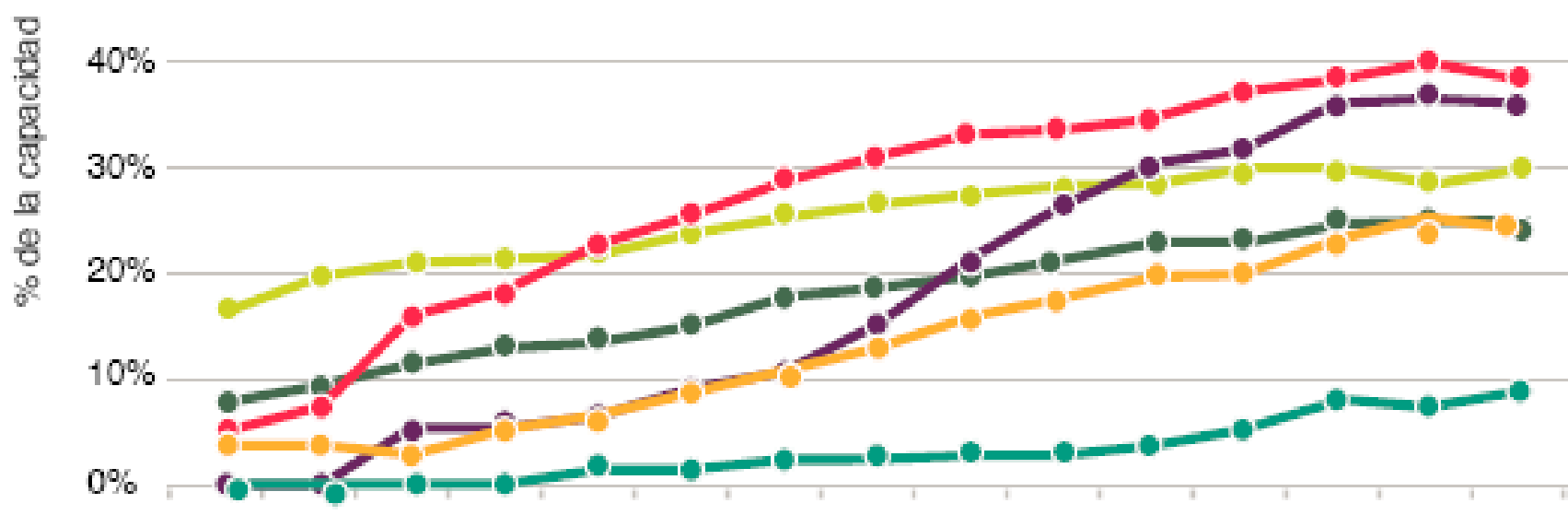

200120022003200420052006200720082009201020112012201320142015

EO Worldwide

$=\mathrm{m}=$ North America

=1 Latin America

EN Europe

$=0=$ Asia-Pacific

=OE ALC w/o Mex/Bra

Fuente: Análisis de inversiones aeroportuarias en América Latina y el Caribe al horizonte 2040, (2019) 
Actualmente la situación del país apunta a un crecimiento en el sector construcción aeroportuaria, como ha sido anunciado en el diario Gestión el 26 de junio del 2018, el sector se vio beneficiado del crecimiento económico en la región, junto con la internacionalización de las economías y la creciente demanda turística de Norteamérica y Europa.

\subsubsection{Análisis del entorno competitivo}

Se utilizará el análisis de las cinco fuerzas de Porter:

Amenaza de nuevos ingresos (Competidores): Alto

- Las concesionarias aeroportuarias internacionales actualmente no participan en este sector aeroportuario del Perú, pero tienen la capacidad de poder competir si se presentan nuevas oportunidades de licitación para obtener un contrato nuevo con los aeropuertos que necesiten una mejora o mantenimiento.

- Las concesionarias LAP y Aeropuertos Andinos, son competidores directos ya que son al igual que AdP gestores aeroportuarias, siendo LAP la concesionaria con mayores movimientos financieros.

Poder de negociación de los clientes (Compradores): Baja

- En el rubro aeroportuario se están dando negociaciones por la llegada de compradores de aerolíneas que ofrecen pasajes a bajo costo.

- Con el desarrollo de nuevos aeropuertos se genera una apertura a mayores compradores para tiendas comerciales. 
Tabla 2.1

Matriz PESTEL

\begin{tabular}{|c|c|c|}
\hline & Factor & Detalle \\
\hline $\begin{array}{l}\stackrel{\circlearrowright}{\Xi} \\
\text { : }\end{array}$ & $\begin{array}{l}\text { Contrato para la modernización de los aeropuertos } \\
\text { Estado promueve conectividad } \\
\text { Rotación de personal político }\end{array}$ & $\begin{array}{l}\text { Se está planteando modernizar aeropuertos en las ciudades más importantes del País } \\
\text { El estado promueve la conectividad por medio del desarrollo de infraestructura vial } \\
\text { Alta rotación de funcionarios públicos, debido a la inestabilidad Política del País que puedan afectar el } \\
\text { flujo de proceso de aprobación de planes de trabajo con el estado }\end{array}$ \\
\hline 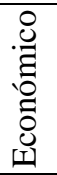 & $\begin{array}{l}\text { Proyección tráfico aéreo } \\
\text { Inversión en proyectos } \\
\text { Plan Multianual de Inversiones (PMI) }\end{array}$ & $\begin{array}{l}\text { Se proyecta un crecimiento anual de } 5.2 \% \text { en el tráfico aéreo de pasajeros (2016-2040) } \\
\text { Según estudio se estima una inversión de \$ } 5404 \text { MM en proyectos aeroportuarios para el Perú } \\
\text { Para desarrollar la modernización de los aeropuertos depende de que se encuentren aprobados dentro del } \\
\text { Plan Multianual de Inversiones (PMI) }\end{array}$ \\
\hline $\begin{array}{l}\cdot \bar{\pi} \\
\text {. } \\
\tilde{8}\end{array}$ & $\begin{array}{l}\text { Aumento de número de colaboradores } \\
\text { Plan de desarrollo de personal } \\
\text { Aumento de número de pasajeros }\end{array}$ & $\begin{array}{l}\text { Anualmente se registra un aumento en el número de colaboradores en la Gerencias que se encuentran } \\
\text { dentro del proceso de la cadena de valor } \\
\text { Falta de un plan de desarrollo de persona: línea de carrera, plan de sucesión, desarrollo de competencias, } \\
\text { capacitación, entrenamiento, etc. } \\
\text { El concesionario aeroportuario y aerolíneas buscan dar mejores servicios a sus clientes }\end{array}$ \\
\hline $\begin{array}{l}\stackrel{8}{0} \\
\frac{0}{00} \\
\frac{0}{0} \\
\stackrel{0}{0} \\
\qquad\end{array}$ & Implementación de Softwares & $\begin{array}{l}\text { Las distintas Gerencias requieren de implementación de tecnología para la optimización y mejora de sus } \\
\text { procesos. }\end{array}$ \\
\hline 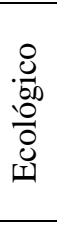 & $\begin{array}{l}\text { Desastres Naturales } \\
\text { Estudios medioambientales } \\
\text { Conciencia ambiental }\end{array}$ & $\begin{array}{l}\text { Existen riesgos en los distintos aeropuertos que podrían ser afectados por los desastres naturales, tales } \\
\text { como: Terremotos, lluvias, inundaciones y heladas. } \\
\text { Riesgo de demora en la ejecución de los proyectos por una mala gestión del desarrollo de los estudios } \\
\text { medioambientales. } \\
\text { se generaron políticas medioambientales para tomar conciencia en el cuidado del medio ambiente en } \\
\text { todos los aeropuertos. }\end{array}$ \\
\hline $\begin{array}{l}\overline{\widetilde{J}} \\
\stackrel{0}{0} \\
. \\
\end{array}$ & $\begin{array}{l}\text { Extensión del Contrato de Concesión } \\
\text { Retención PAMO } \\
\text { Penalidades por incumplimiento del Contrato }\end{array}$ & $\begin{array}{l}\text { Demostrando la buena gestión se puede obtener extensión del contrato con la Entidad Gubernamental } \\
\text { Por incumplimiento de levantamiento de observaciones en los proyectos PAMO } \\
\text { Multa y penalidades por incumplimiento del Contrato de Concesión }\end{array}$ \\
\hline
\end{tabular}

Nota: Datos obtenidos de la empresa Aeropuertos del Perú

Elaboración propia 
Poder de negociación de los Proveedores: Media

- Por la cantidad de proyectos que se están activando se está generando una red de consultorías y contratistas para el sector aeroportuario.

- Existen pocos consultores especializados en el rubro aeroportuario, por lo cual en algunas oportunidades se contratan consultores internacionales con pericia en el rubro aeroportuario.

Amenaza de Sustitutos: Media

- En algunos de los aeropuertos de la concesión no hay aumento de pasajeros debido al precio de los pasajes, ya que estos no compiten con el bajo costo de pasajes de los buses de transporte público.

- Se genera una competencia con aeropuertos aledaños a los aeropuertos de la concesión, ya que existen usuarios que tienen como destino final una ubicación intermedia entre ambos aeropuertos.

Rivalidad entre los competidores existentes: Baja

- Al finalizar el contrato de concesión se abren las posibilidades para distintos competidores que podrían asumir la continuidad de los aeropuertos de la actual concesión.

Asimismo, se muestra la Figura 2.2 las cinco fuerzas de porter 
Figura 2.2

Cinco Fuerzas de Porter

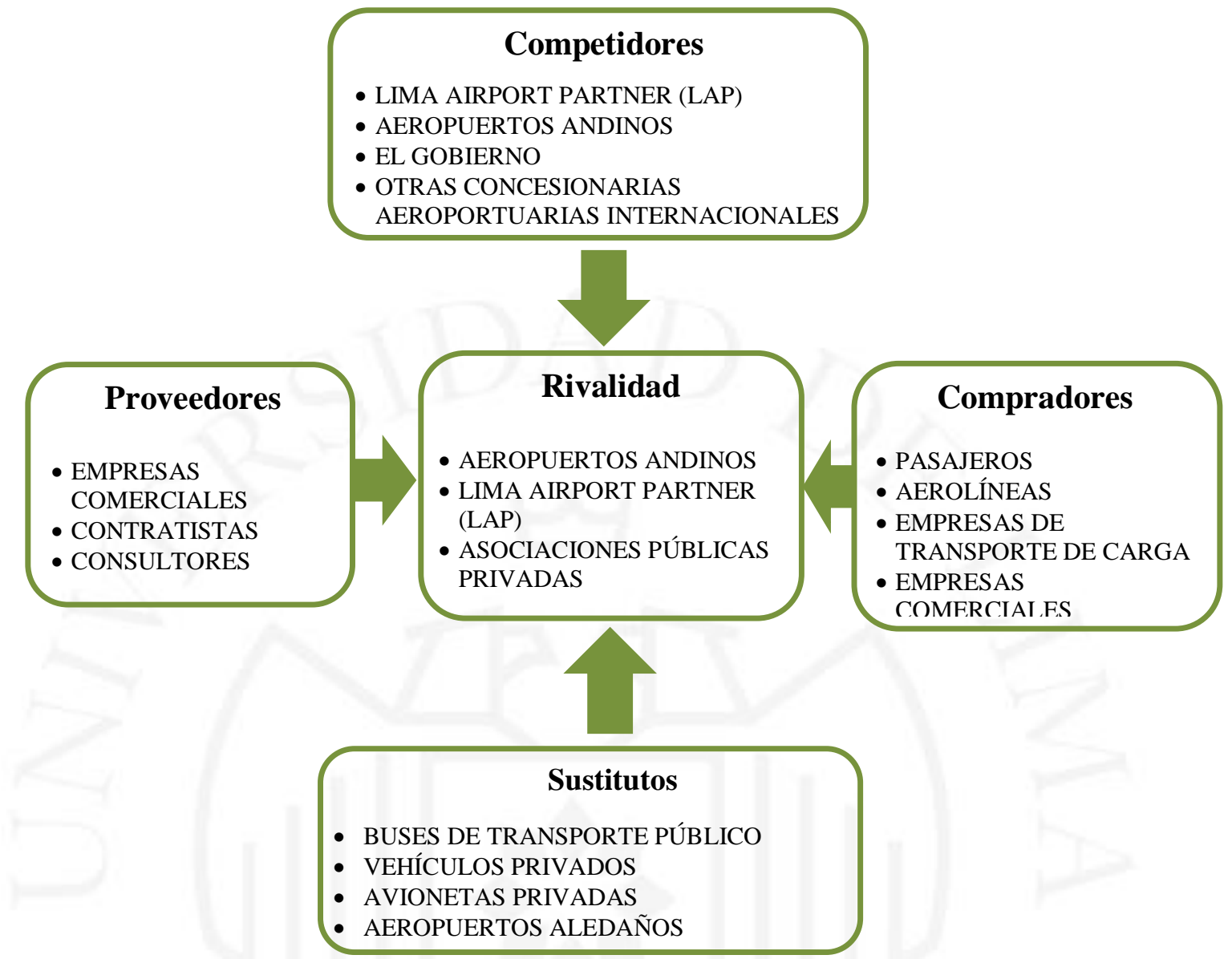

Elaboración propia.

\subsubsection{Identificación y evaluación de las oportunidades y amenazas del entorno}

Oportunidades:

- Incrementar el flujo de pasajeros y el negocio de cargas en los aeropuertos de la concesión.

- Realizar los proyectos en base al financiamiento que se recibe por parte del estado.

- El contrato de concesión no permite cerrar los aeropuertos en su totalidad para la ejecución de los proyectos. Estos deben ser cerrados parcialmente (tiempos y espacio) en coordinación con la DGAC, CORPAC y Aerolíneas.

- El sector aeroportuario tiene una tendencia de crecimiento 
- Interés del Estado en Promover la conectividad y descentralización de las operaciones aeronáuticas a nivel nacional e internacional

- Extensión del Contrato de Concesión.

- Cumplimiento de nuestro Plan de inversiones sujeto al plan multianual de la inversión pública.

- Falta de procedimientos con el Estado para el desarrollo de las inversiones.

Amenazas:

- Las penalidades por incumplimiento o sanciones establecidas en el contrato de concesión.

- Baja confiabilidad de proveedores en provincia.

- Retención del Pago por administración de mantenimiento y operación (PAMO) por incumplimiento de levantamiento de observación al equipamiento e infraestructura de los aeropuertos.

- La corrupción y el poder político podría desvirtuar o limitar la gestión de los proyectos de la concesión.

- Falta de consultoras especializadas en el rubro aeroportuario.

- Existe mucha burocracia en las gestiones de aprobación con OSITRAN/MTC.

- Alta rotación de funcionarios públicos, debido a la inestabilidad Política del País que puedan afectar el flujo de proceso de aprobación de planes de trabajo con el estado.

Según la identificación de las oportunidades y amenazas de la empresa, a continuación, se presenta la matriz de evaluación de factores externos. Esto dio como resultado que una de las oportunidades de mayor peso es "Incrementar el flujo de pasajeros y el negocio de cargas en los aeropuertos de la Concesión”, es por ello la empresa tiene un plan estratégico para la modernización de los aeropuertos y así poder alcanzar esta oportunidad lo cual señala una calificación de 4. El total ponderado de 2.65, indica que esta empresa está justo por encima de la media en su esfuerzo por seguir con estrategias que rentabilicen las oportunidades externas y eviten las amenazas. 
Tabla 2.2

Matriz EFE

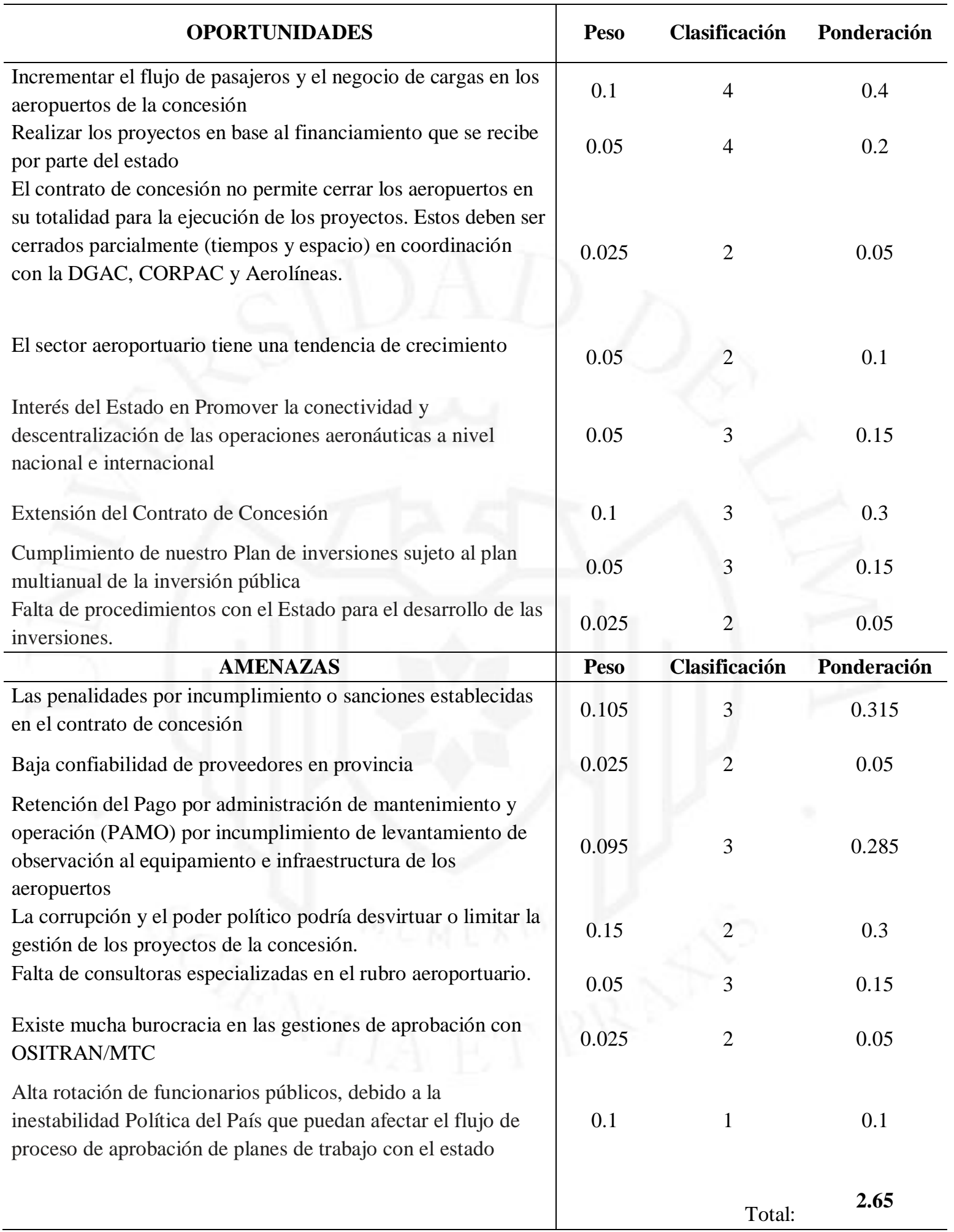

Nota: Pesos y Calificaciones de acuerdo a opinión de la Gerencia de Ingeniería (2017)

Elaboración Propia 


\subsection{Análisis Interno de la Empresa}

\subsubsection{Análisis del direccionamiento estratégico: visión, misión y objetivos organizacionales}

\section{Visión:}

Para el año 2031 contaremos con una moderna infraestructura aeroportuaria gestionada de manera segura y eficiente.

Misión:

Satisfacer las necesidades y expectativas de nuestros clientes:

- Gestionando la planificación, diseño, construcción e implementación de la infraestructura aeroportuaria.

- Manteniendo y operando de manera segura y eficiente los aeropuertos.

- Facilitando el desarrollo de servicios que contribuyan a mejorar continuamente la experiencia del usuario en nuestros aeropuertos.

- Promoviendo la conectividad, integración regional y contribuyendo al desarrollo del comercio y turismo.

- Gestionando el cuidado del Medio Ambiente.

- Cumpliendo con los compromisos contractuales con el Estado Peruano.

\section{Objetivos organizacionales:}

- Satisfacer las necesidades y expectativas de nuestros clientes, promoviendo la mejora continua de nuestros procesos.

- Garantizar la seguridad operacional aeronáutica mediante la gestión de riesgos y el desarrollo de una cultura de notificación voluntaria y confidencial que comprometa la seguridad operacional.

- Proteger la seguridad y salud en el trabajo, promoviendo la participación y consulta de nuestros colaboradores.

- Prevenir la contaminación del medio ambiente, que pueda generarse producto del desarrollo de nuestras actividades y buscar la reducción del uso de energía en nuestras operaciones. 
- Gestionar los riesgos de actos de soborno, lavado de activos, financiamiento del terrorismo, colusión, tráfico de influencias y otros de corrupción a través del Encargado de Prevención, quien actúa con autoridad e independencia, apoyándose en el Comité Operativo de Ética.

\subsubsection{Análisis de la estructura organizacional}

La empresa está conformada por 10 Gerencias, estas son:

1. Gerencia General

2. Gerencia de Planificación aeroportuaria y comercial

3. Gerencia de Ingeniería

4. Gerencia de Inversiones

5. Gerencia de Operaciones

6. Gerencia de Mantenimiento

7. Gerencia de Regulación y legal

8. Gerencia de Seguridad

9. Gerencia de Finanzas y contabilidad

10. Gerencia de Desarrollo de negocios

A continuación, se muestra el organigrama general de la empresa:

La organización de la empresa está estructurada de manera estratégica en una serie de gerencias funcionales con el fin de atender los requerimientos del Contrato de Concesión.

El Sistema Integrado de Gestión de Calidad, SST, Medio Ambiente, Anti soborno y SMS que se muestra a continuación, muestra los macro procesos Estratégicos, Soporte, Partes interesadas y la Cadena de Valor. 
Figura 2.3

Organigrama de la empresa

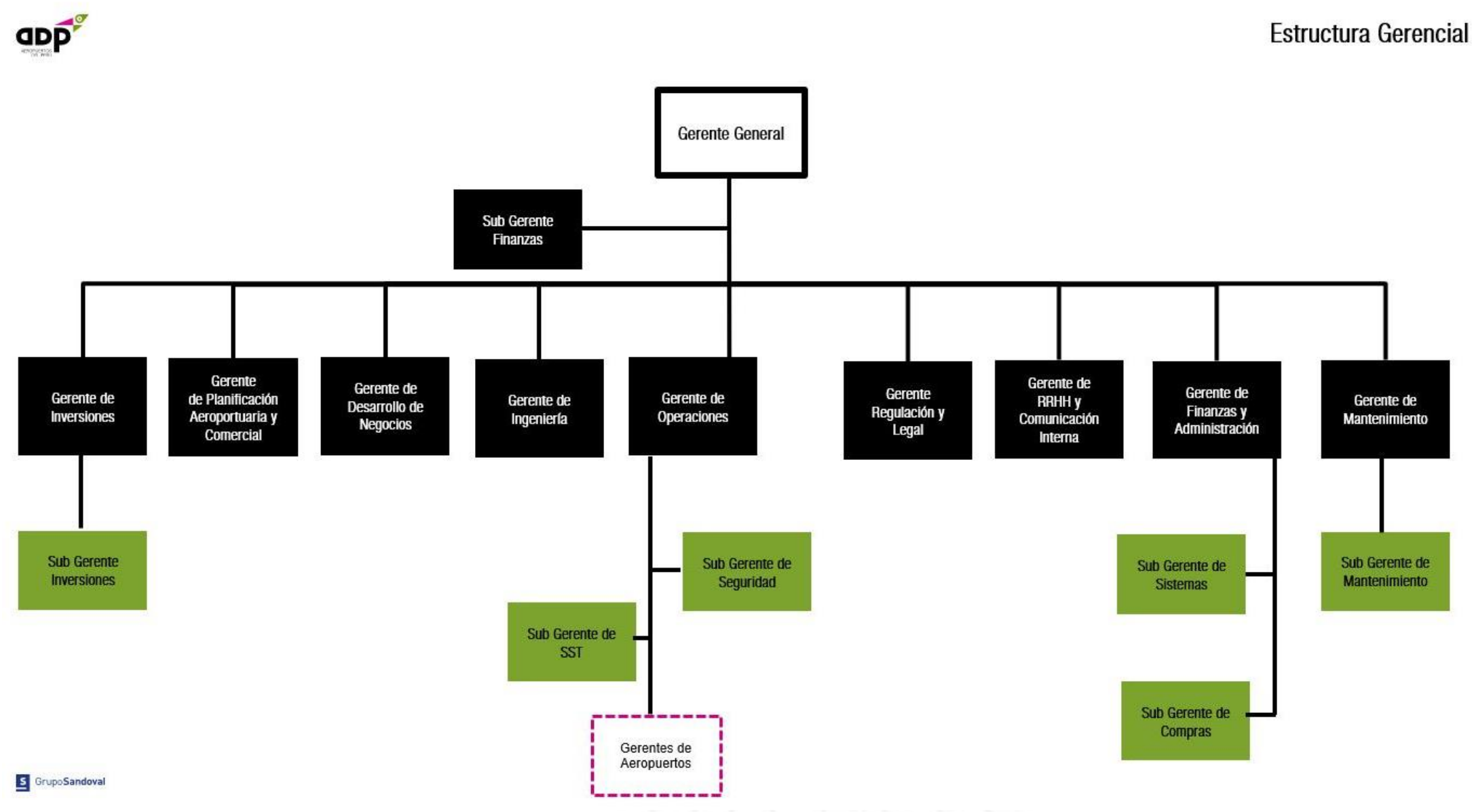

Fuente: Empresa Aeropuertos del Perú, (2017) 
La Cadena de Valor, como se muestra en la Figura 2.3, incluye las inversiones de tipo PAO y PAMO gestionados por la Gerencia de Planificación aeroportuaria, Ingeniería, Inversiones, Operaciones y Mantenimiento, teniendo como proyectos más relevantes a los Programas de Rehabilitación y Mejoramiento del Lado Aire (PRMLA) y a los Plan Maestro (PMD).

Figura 2.4

Cadena de Valor

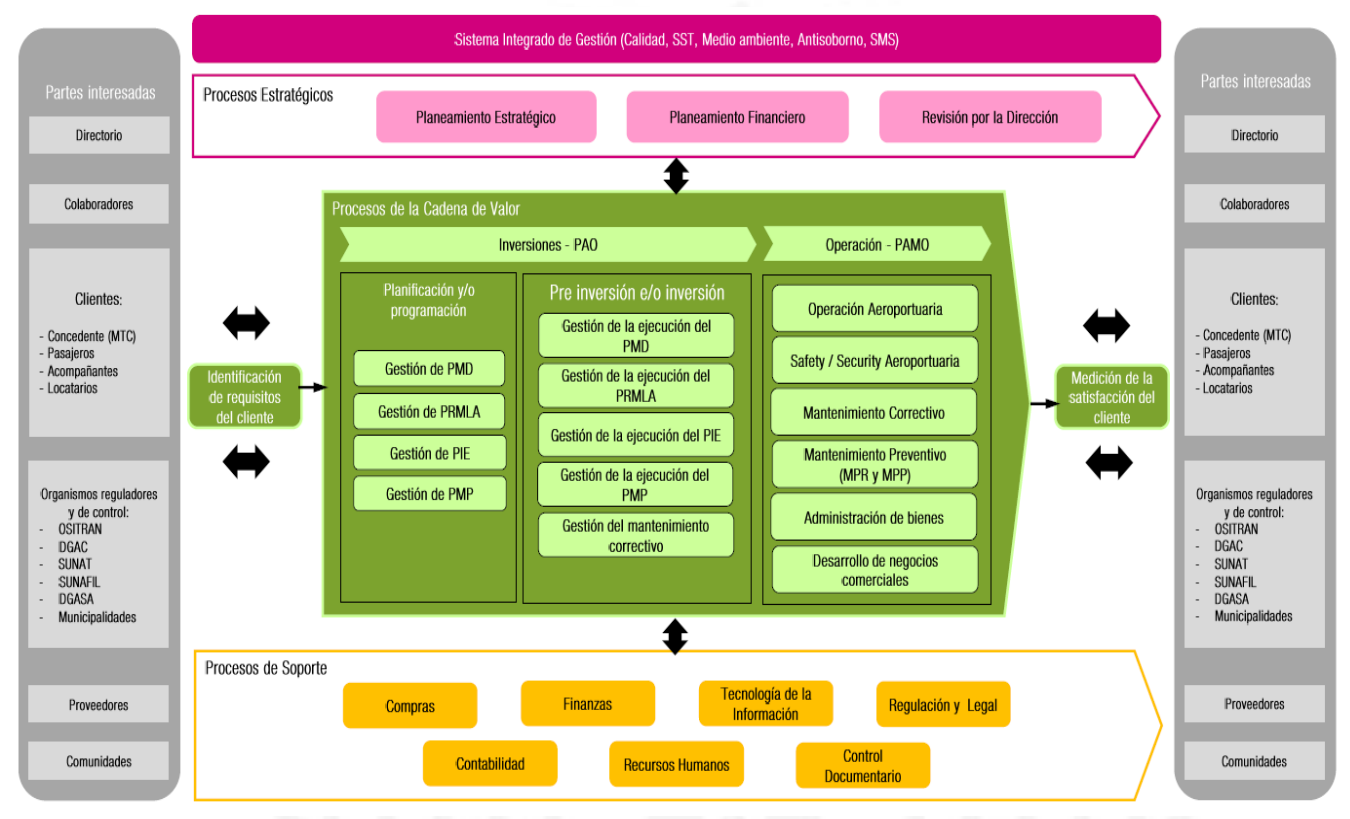

Fuente: Empresa Aeropuertos del Perú (2017)

\subsubsection{Identificación y evaluación de las fortalezas y debilidades de la empresa.}

Fortalezas:

- Aeropuertos del Perú tiene tres ISO: Sist. De Gestión anti soborno (ISO 37001:2016) Sist. De Gestión de Calidad (ISO 9001:2015) Declaración de verificación de gases de efecto invernadero (ISO 14064-1:2006).

- Solides financiera - Disminución de la dependencia del cofinanciamiento del estado.

- Inversiones aseguradas al 2024 por US\$ 984' MM.

- AdP pertenece al sólido grupo empresarial Sandoval.

- Trece años de experiencia en manejo de operación y mantenimiento de los 12 aeropuertos. 
- Contamos con personal competente, capacitado y comprometido para el desarrollo de nuestras actividades.

- Contamos con un Sistema Integrado de Gestión (Calidad, Anti soborno, Modelo de prevención, medio ambiente, seguridad y salud en el trabajo, y SMS), que nos ayuda a garantizar la mejora continua de nuestros procesos.

- Contamos con una cartera de proyectos de alto impacto social.

- Rentabilización de los servicios que ponemos a disposición de nuestros usuarios en los aeropuertos. (áreas comerciales en los diferentes aeropuertos).

- Explotar los espacios comerciales de cada uno de los aeropuertos de la concesión.

- Desarrollo de nuevas alianzas para generar rutas turísticas.

- Margen de rentabilidad asociado a la ejecución de las inversiones.

Debilidades:

- Existen restricciones en las modalidades de contratación con los consultores, lo cual limita la adjudicación.

- Falta de experiencia en desarrollo y ejecución de proyectos de mejora, rehabilitación y/o mantenimiento de la infraestructura aeroportuaria

- Escaso control de proyectos.

- Falta de desarrollo de estudios de mercado para la licitación de concursos.

- La inversión que realizamos para los estudios no retorna hasta el primer hito de la ejecución de la obra, por lo que esta condicionante genera costos financieros que serían evitados si el retorno de la inversión fuera más rápido.

- Mecanismo lento y burocrático para la renovación de infraestructura y equipamiento de los aeropuertos.

- Retención del PAMO por demoras en el levantamiento de observaciones.

- Falta de medición de tiempos de respuesta.

- Riesgo de demora en la ejecución de los proyectos por una mala gestión del desarrollo de los estudios medioambientales

A continuación, se presenta la matriz de evaluación de factores internos: 
Tabla 2.3

\section{Matriz EFI}

\begin{tabular}{|c|c|c|c|}
\hline FORTALEZAS & Peso & Clasificación & Ponderación \\
\hline $\begin{array}{l}\text { Aeropuertos del Perú tiene tres ISO: } \\
\text { Sist. De Gestión anti soborno (ISO 37001:2016) } \\
\text { Sist. De Gestión de Calidad (ISO 9001:2015) } \\
\text { Declaración de verificación de gases de efecto invernadero (ISO 14064-1:2006) }\end{array}$ & 0.045 & 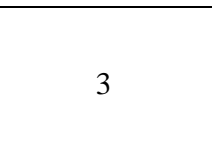 & 0.135 \\
\hline Solides financiera - Disminución de la dependencia del cofinanciamiento del estado & 0.05 & 3 & 0.15 \\
\hline Inversiones aseguradas al 2024 por US\$ 984' MM & 0.095 & 4 & 0.38 \\
\hline AdP pertenece al sólido grupo empresarial Sandoval & 0.025 & 3 & 0.075 \\
\hline Trece años de experiencia en manejo de operación y mantenimiento de los 12 aeropuertos & 0.095 & 4 & 0.38 \\
\hline Contamos con personal competente, capacitado y comprometido para el desarrollo de nuestras actividades. & 0.075 & 4 & 0.3 \\
\hline $\begin{array}{l}\text { Contamos con un Sistema Integrado de Gestión (Calidad, Antisoborno, Modelo de prevención, medio ambiente, seguridad y salud en el trabajo, } \\
\text { y SMS), que nos ayuda a garantizar la mejora continua de nuestros procesos. }\end{array}$ & 0.025 & 3 & 0.075 \\
\hline Contamos con una cartera de proyectos de alto impacto social. & 0.015 & 3 & 0.045 \\
\hline $\begin{array}{l}\text { Rentabilización de los servicios que ponemos a disposición de nuestros usuarios en los aeropuertos. (áreas comerciales en los diferentes } \\
\text { aeropuertos) }\end{array}$ & 0.055 & 4 & 0.22 \\
\hline Explotar los espacios comerciales de cada uno de los aeropuertos de la concesión & 0.025 & 3 & 0.075 \\
\hline $\begin{array}{l}\text { Desarrollo de nuevas alianzas para generar rutas turísticas } \\
\text { Margen de rentabilidad asociado a la eiecución de las inversiones }\end{array}$ & $\begin{array}{l}0.025 \\
0.105\end{array}$ & $\begin{array}{l}3 \\
4\end{array}$ & $\begin{array}{c}0.075 \\
0.42\end{array}$ \\
\hline $\begin{aligned} \text { Margen de rentabilidad asociado a la ejecución de las inversiones } & \text { DEBILIDADES }\end{aligned}$ & Peso & $\begin{array}{c}4 \\
\text { Clasificación }\end{array}$ & $\frac{0.42}{\text { Ponderación }}$ \\
\hline Existen restricciones en las modalidades de contratación con los consultores, lo cual limita la adjudicación & 0.015 & 1 & 0.015 \\
\hline $\begin{array}{l}\text { Falta de experiencia en desarrollo y ejecución de proyectos de mejora, rehabilitación y/o mantenimiento de la infraestructura aeroportuaria } \\
\text { Escaso control de proyectos } \\
\text { Falta de desarrollo de estudios de mercado para la licitación de concursos }\end{array}$ & $\begin{array}{c}0.045 \\
0.1 \\
0.025\end{array}$ & $\begin{array}{l}1 \\
2 \\
1\end{array}$ & $\begin{array}{c}0.045 \\
0.2 \\
0.025\end{array}$ \\
\hline $\begin{array}{l}\text { La inversión que realizamos para los estudios no retorna hasta el primer hito de la ejecución de la obra, por lo que esta condicionante genera } \\
\text { costos financieros que serían evitados si el retorno de la inversión fuera más rápido }\end{array}$ & 0.05 & 1 & 0.05 \\
\hline Mecanismo lento y burocrático para la renovación de infraestructura y equipamiento de los aeropuertos & 0.015 & 1 & 0.015 \\
\hline Retención del PAMO por demoras en el levantamiento de observaciones & 0.075 & 2 & 0.15 \\
\hline Falta de medición de tiempos de respuesta & 0.002 & 2 & 0.004 \\
\hline Riesgo de demora en la ejecución de los proyectos por una mala gestión del desarrollo de los estudios por parte de los consultores & 0.002 & 1 Total: & $\begin{array}{l}0.002 \\
2.836\end{array}$ \\
\hline
\end{tabular}

Nota: Con Pesos y Calificaciones de acuerdo con opinión de la Gerencia de Ingeniería (2017) se elaboró la matriz EFI.

Elaboración Propia. 
Según el valor obtenido en la matriz EFI, el análisis realizado en las fuerzas internas de la organización demuestra favorablemente, ya que tienen un peso ponderado total de 2.33 contra 0.506 de las debilidades, teniendo como valor ponderado total 2.836 , el cual indica que la posición estratégica interna general de la empresa está arriba de la media, es decir está realizando moderadamente bien sus operaciones.

Por otro lado, realizando el análisis sobre la Matriz Interna - Externa (IE) se concluye que los resultados muestran que el estado actual de la empresa, indica que la organización se puede administrar mejor con estrategias para “Retener y Mantener". 


\section{CAPÍTULO III: DIAGNÓSTICO DEL SISTEMA O PROCESO OBJETO DE ESTUDIO}

\subsection{Análisis del sistema o proceso objeto de estudio}

Se realizó el análisis Factorial de Klein para determinar el diagnóstico de los principales procesos en las actividades de la Gerencia de Ingeniería, enfocado a los temas de programación y control de proyectos en el año 2017, liderado por el Gerente del área.

Este análisis que se muestra en la Tabla 3.1, se realizó enfocado en dos puntos, Política y Dirección, y Operaciones; dando como resultado un promedio ponderado de $60 \%$ y $59 \%$ respectivamente.

Este resultado concluye según el Factorial de Klein que los procesos cumplen sus actividades operativas de manera regular pero no en forma ideal.

Este proyecto se enfoca en la importancia del seguimiento y control de los proyectos, lo cual abarca cuatro macro procesos identificados como mejora del trabajo diario en la Gerencia de Ingeniería, estos se muestran en la Figura 3.1.

Figura 3.1

Macro procesos de la Gerencia de Ingeniería

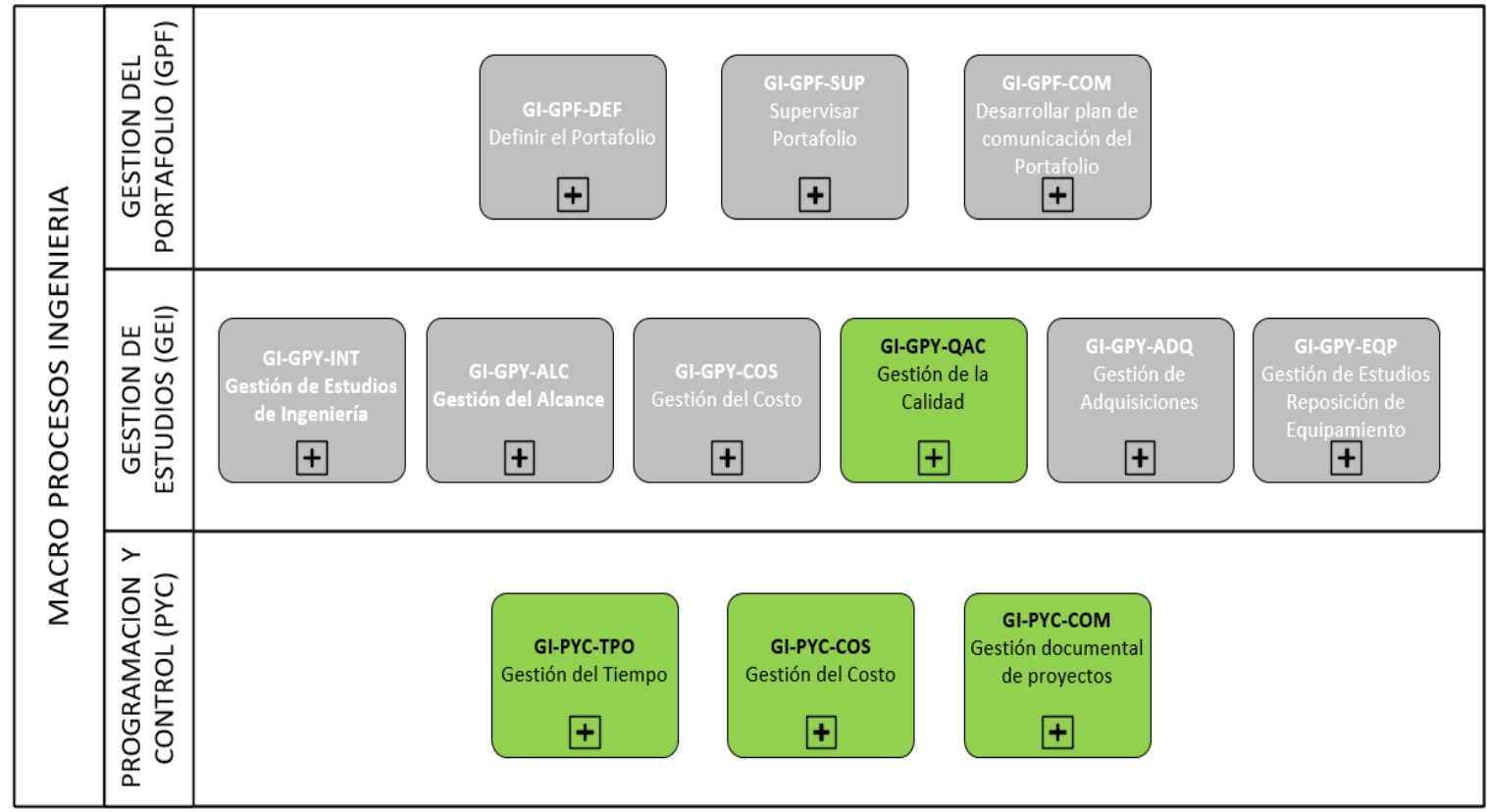

Elaboración propia 
Gestión del Tiempo: según el PMBOK 5, incluye los procesos requeridos para administrar la finalización del proyecto a tiempo.

Gestión del Costo: Incluye los procesos involucrados en estimar, presupuestar y controlar los costos de modo que se complete el proyecto dentro del presupuesto aprobado.

Gestión Documental: comprende un conjunto de procesos que controla de manera eficaz y sistemática los aspectos que se deben relacionar con la organización, almacenamiento, preservación y recuperación de la documentación producida y recibida por una organización que desarrolla sus actividades, es decir, por la dirección de proyectos.

Gestión de la Calidad: Gestión de actividades de la organización que valida la calidad de los entregables para cada proyecto de la Gerencia de Ingeniería a fin de que el satisfaga los alcances determinados.

\subsection{Análisis del FODA de la Gerencia de Ingeniería}

Para obtener las alternativas de solución también se desarrolló el análisis FODA de la Gerencia de Ingeniería que se muestra en la Tabla 3.2.

\subsubsection{Análisis de los indicadores específicos de desempeño del sistema o proceso (metas, resultados actuales, tendencias, brechas, comparativos)}

Para el desarrollo del análisis de indicadores se usó como muestra el proyecto "Programa de Rehabilitación y Mejoramiento del Lado Aire de Chiclayo (PRMLA CIX)", el cual consiste en realizar los estudios de Términos de Referencia (TdR) del Perfil, Perfil, Términos de Referencial de la Factibilidad, Factibilidad, Expediente Técnico, el análisis de indicador de desempeño en días estimado versus el real, se muestra en la Figura 3.2. 
Tabla 3.1

Tabla del análisis Factorial Klein

ANÁLISIS FACTORIAL DE KLEIN AL 2017

GERENCIA DE INGENIERIAA

1.1. Organización

1.1.1 Calificación de los directivos de la empresa

1.1.2 Expectativas de los empleados

1.1.3 Perfeccionamiento de los empleados

1.1.4 Estilo de liderazgo

1.1.5 Sistema para fomentar propuestas de los empleados

1.1.6 Empleo adecuado de la informática

1.2 Control

1.2.1 Administrativo

1.2.2 Financiero

1.2.3 Físico

1.3Personal

1.3.1 Calificación de los empleados

1.3.2 Motivación de los empleados

1.3.3 Capacidad del personal

1.3.4 Nivel de Ausentismo

1.3.5 Ambiente en la empresa

2 OPERACIONES

2.1 Relación con el medio

2.1.1 Relación de la empresa con el público

2.1.2 Conocimiento del grado de satisfacción del cliente

2.1.3 Relación con otras almaceneras

2.1.4 Imagen de la empresa

21.5 . Sistema de reclamos y consultas al cliente

Bueno

Mediano

Malo

Resultado \%

$\begin{array}{ll}1 & 4 \\ 2 & 3 \\ 0 & 0 \\ 3 & 2 \\ 0 & 4 \\ 1 & 4 \\ 7 & 17\end{array}$

0
0
5
0
1
0

$56.67 \%$

1
1
1
1
2

4
3
4
3
3

2
2
1

(1)

6

4
3
4
3
3
3
3
4
3
2
1
33
5
4
3
0
5
17

0
1
0
1
0
0
0
0
0
3
4
9
0
0
0
0
0
0

$57.73 \%$

1

(n)

$66.00 \%$

$60 \%$

$\begin{array}{lc}1 & 3 \\ 1 & 4 \\ 1 & 4 \\ 2 & 3 \\ 1 & 2 \\ 6 & 16\end{array}$

$\begin{array}{cc}3 & 1 \\ 4 & 0 \\ 4 & 0 \\ 3 & 0 \\ 2 & 2 \\ 16 & 3\end{array}$

$59.00 \%$

Nota: Elaboración Factorial Klein con calificaciones de acuerdo con la opinión de la Gerencia de Ingeniería (2017). Escala: 1- Bajo, 2 y 3- Medio, 4- Alto.

Elaboración propia 
Figura 3.2

Análisis de indicadores de desempeño en días (Estimado vs. Real) para el desarrollo de los Estudios de Ingeniería del Proyecto PRMLA CIX.

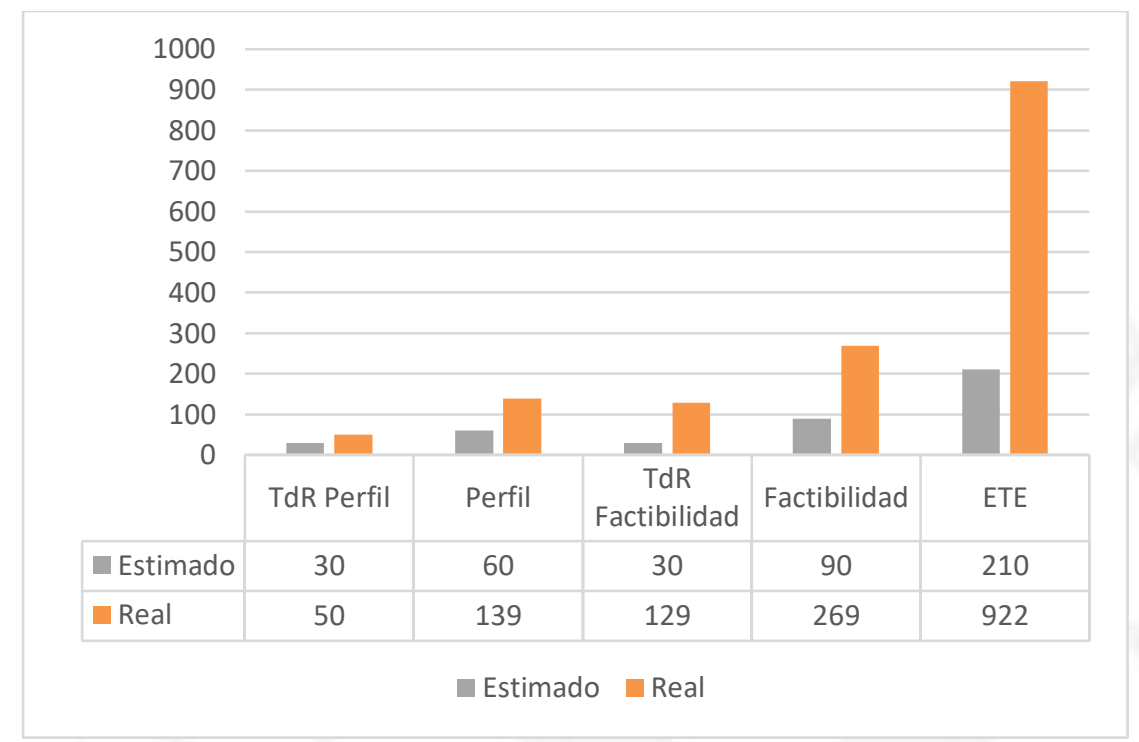

Elaboración propia

Según el análisis del tiempo de desarrollo de los estudios, nos muestra que ya se veía la necesidad de poder implementar algún tipo de mejora. La diferencia del estimado versus el real fue de 3.69 veces más, a lo que debió ser realizado en todas las sub-fases que contempla el proyecto.

Respecto a las sub-fases más relevantes observamos que para el Perfil el tiempo fue de 2.32 veces, para la Factibilidad fue de 2.99 veces y para el Expediente Técnico fue de 4.39 veces a comparación de lo estimado.

Para el desarrollo de análisis de indicadores de desempeño de la gestión documental se usó también como muestra el proyecto PRMLA Chiclayo, en el cual se observa que el desarrollo de la sub-fases del Expediente Técnico contempló la mayor cantidad de versiones (4) y observaciones (314) de todo el proyecto.

Esta información muestra la necesidad de contar con un equipo de revisión para asegurar la calidad y minimizar las observaciones y versiones a los proyectos futuros. 
Figura 3.3

Análisis de indicadores de desempeño número de versiones y observaciones de documentos para el desarrollo de los Estudios de Ingeniería de proyecto PRMLA CIX

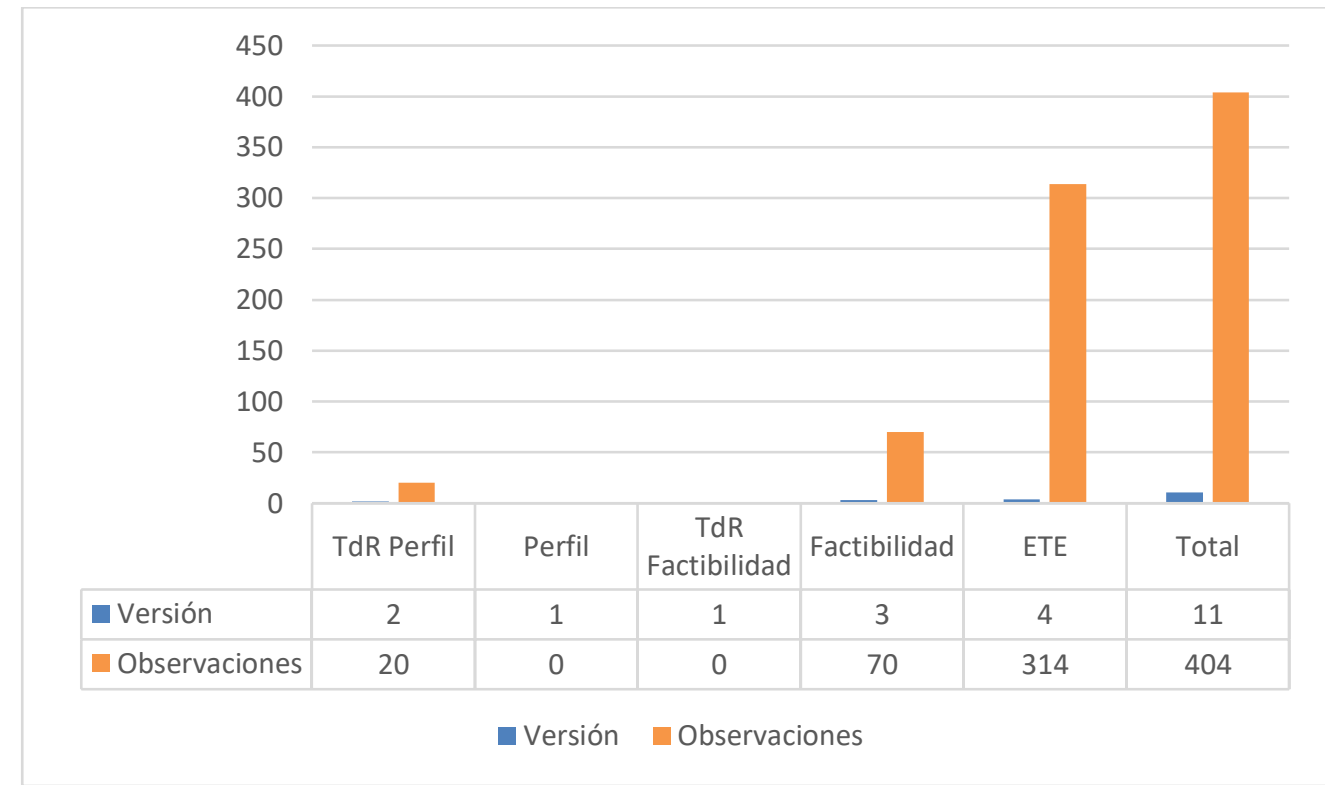

Elaboración propia

\subsection{Determinación las causas raíz de los problemas hallados}

Según el método de construcción del diagrama de Ishikawa se identificaron 11 causas reales, mediante el resultado de insatisfacción del "Escaso control de proyectos", como se muestra en la Figura 3.4. 
Tabla 3.2

Tabla del análisis FODA en la G. Ingeniería

\begin{tabular}{|c|c|c|}
\hline & Fortaleza & Debilidades \\
\hline & 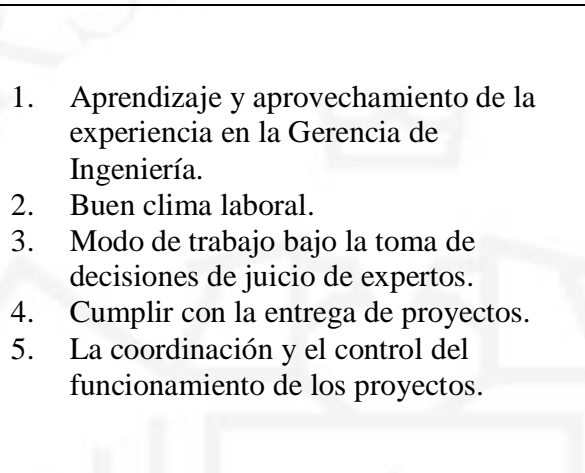 & $\begin{array}{l}\text { 1. Reprocesos, utilizando mayor tiempo y esfuerzo para lograr los objetivos. } \\
\text { 2. El Sistema de aprobación de los estudios de ingeniería no reduce plazos de } \\
\text { entrega. } \\
\text { 3. No se cuenta con flujogramas definidos y personal que controle la calidad } \\
\text { de la Ingeniería. } \\
\text { 4. Falta identificar los procesos internos de la gestión de estudios. } \\
\text { 5. Control de la gestión de riesgos de los proyectos. } \\
\text { 6. Existe mucha burocracia para obtener la aprobación la validación y } \\
\text { aprobación de los estudios de ingeniería. } \\
\text { 7. No se cuenta con un número necesario de recursos (HW, SW, Humanos) } \\
\text { para la gestión de proyectos. } \\
\text { 8. Bajo nivel de digitalización de los entregables de los estudios de ingeniería } \\
\text { 9. Entrega de los estatus de avance de los proyectos fuera de tiempo. }\end{array}$ \\
\hline Oportunidades & Estrategia FO & Estrategia DO \\
\hline $\begin{array}{l}\text { 1. Mayor cantidad de proyectos en la cartera de inversiones } \\
\text { 2. Ventaja competitiva en la gestión aeroportuaria }\end{array}$ & $\begin{array}{l}\text { FO1 } \mathrm{F} 1 ; \mathrm{F} 3 ; \mathrm{F} 4, \mathrm{~F} 5 \quad \mathrm{O} 1 ; \mathrm{O} 2 \text { Manejar el } \\
\text { incremento de la cartera de proyectos de } \\
\text { manera óptima. }\end{array}$ & $\begin{array}{l}\text { DO1 D1;D3;D4,D7 O2 Plantear un Sistema Integrado de Gestión de Proyectos } \\
\text { orientado en la superación de las debilidades. } \\
\text { D8,D9 O1 Desarrollar canales virtuales de distribución de entregables } \\
\text { de los estudios de ingeniería. }\end{array}$ \\
\hline Amenazas & Estrategia FA & Estrategia DA \\
\hline $\begin{array}{l}\text { 1. No existe tiempo límite de respuesta de aprobación por } \\
\text { parte de la DGAC para los estudios. } \\
\text { 2. Falta de priorización por parte de la entidad para realizar } \\
\text { los proyectos. } \\
\text { 3. Falta de consultoras especializadas en el rubro } \\
\text { aeroportuario. } \\
\text { 4. Entrega de los estudios de ingeniería sin cumplir con el } \\
\text { alcance, costo y tiempo determinado. } \\
\text { 5. Consultores abandonan el Proyecto. }\end{array}$ & $\begin{array}{l}\text { FA } 1 \mathrm{~F} 1 ; \mathrm{F} 5, \mathrm{~A} 3 \text { Definir procesos de mejora } \\
\text { a desarrollar los estudios de ingeniería de } \\
\text { manera interna para no depender de } \\
\text { consultores. }\end{array}$ & $\begin{array}{l}\text { DA 1 D4; D5 A4 Establecer los procesos para el desarrollo y control de los } \\
\text { estudios de ingeniería. } \\
\text { D6, A5 Establecer procesos de negociación en la gestión de los estudios de } \\
\text { ingeniería con el consultor para la continuidad de los proyectos. } \\
\text { D2,A1;A2 Establecer convenios con la entidad }\end{array}$ \\
\hline
\end{tabular}

Nota: Elaboración FODA de acuerdo a opinión de la Gerencia de Ingeniería (2017).

Elaboración propia 
Figura 3.4

Diagrama Ishikawa

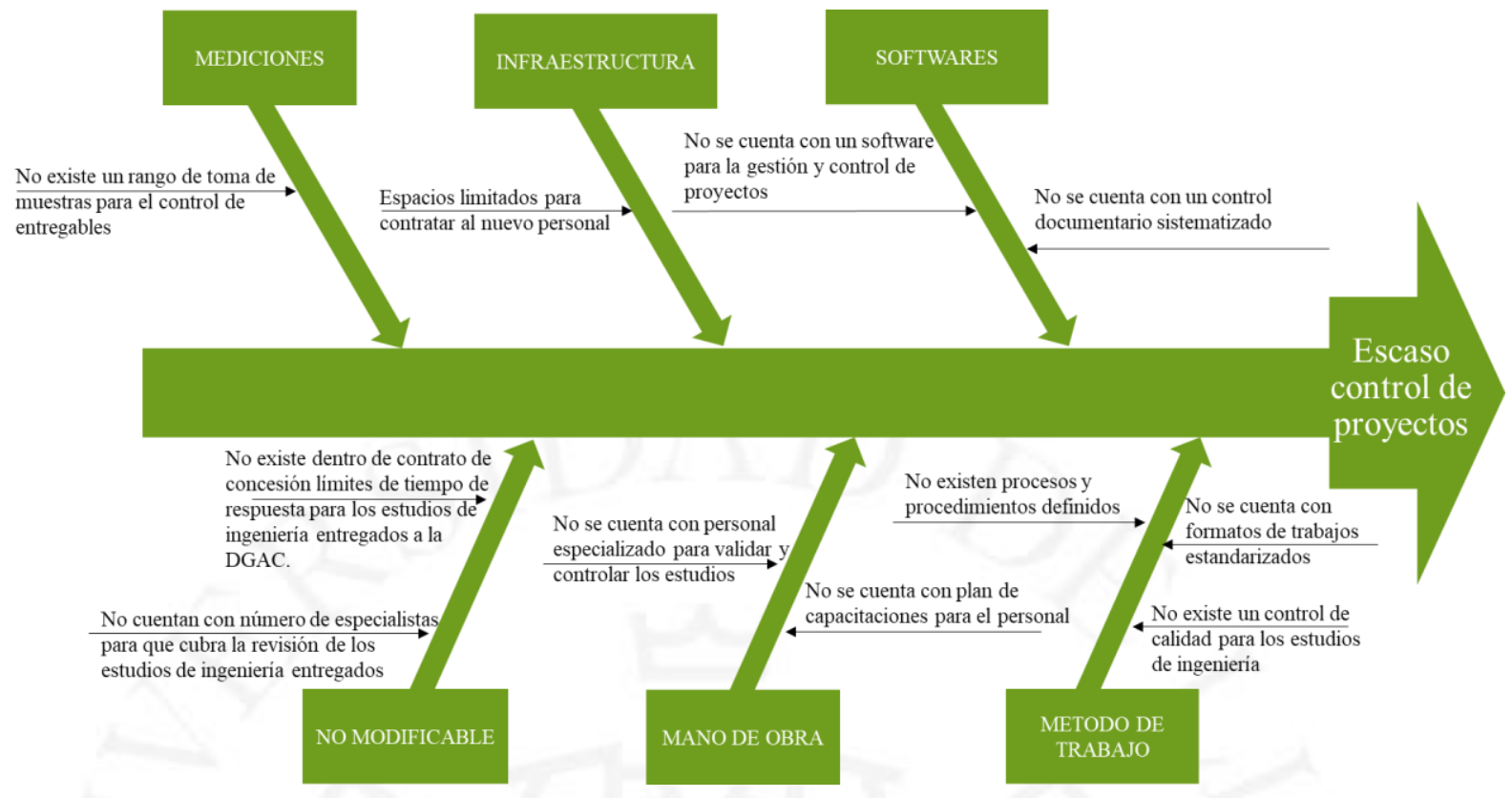

Elaboración propia

En el análisis de este Diagrama se valoraron 4 causas principales, las cuales se encuentran resaltadas, estas se determinaron por medio de la identificación de grados de impacto en el problema principal y reuniones de consensos con la Gerencia de Ingeniería.

Figura 3.5

Diagrama Ishikawa y 4 causas principales

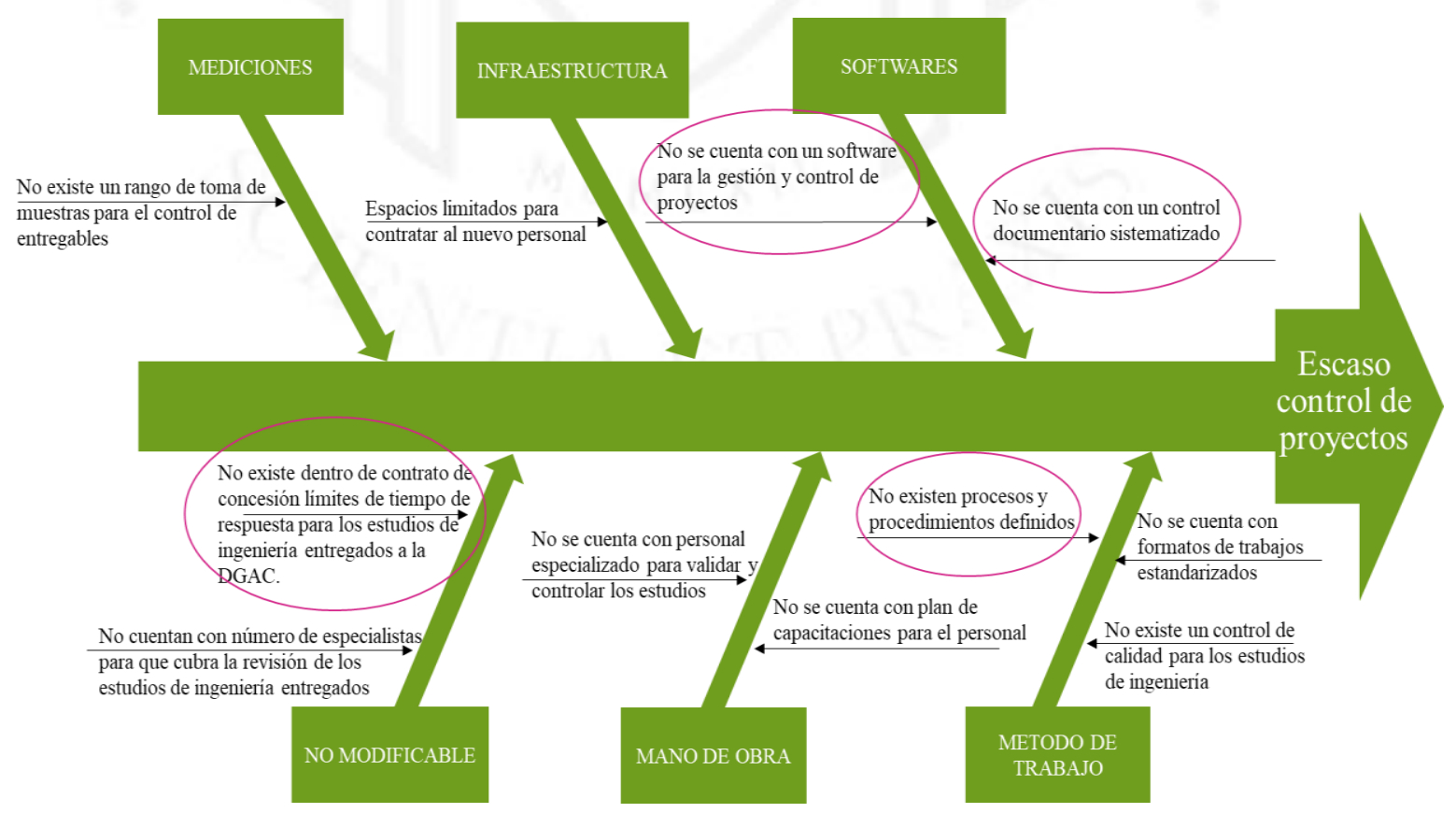

Elaboración propia 


\section{CAPÍTULO IV: DETERMINACIÓN DE LA PROPUESTA DE SOLUCIÓN}

\subsection{Planteamiento de alternativas de solución}

En base al problema y habiendo determinado las principales causas raíz, se han identificado posibles soluciones, las cuales no son excluyentes.

\section{Tabla 4.1}

Matriz Causa - Efecto

\begin{tabular}{|l|llll|}
\hline $\mathbf{N}^{\circ}$ & \multicolumn{1}{|c}{ Causas } & \multicolumn{1}{|c|}{ Posibles Soluciones } \\
\hline 1 & $\begin{array}{l}\text { No existen procesos y procedimientos } \\
\text { definidos. }\end{array}$ & $\begin{array}{l}\text { Elaborar un manual de procesos y } \\
\text { procedimientos en la Gerencia de Ingeniería. }\end{array}$ \\
3 & $\begin{array}{l}\text { No se cuenta con un control documentario } \\
\text { sistematizado. }\end{array}$ & $\begin{array}{l}\text { Desarrollar canales virtuales de distribución de } \\
\text { documentos para los estudios de ingeniería. }\end{array}$ \\
4 & $\begin{array}{l}\text { Nontrol de proyectos. } \\
\text { No existe dentro del contrato de concesión } \\
\text { límites de tiempo de respuesta para los } \\
\text { Estudios de Ingeniería entregados a la DGAC. }\end{array}$ & $\begin{array}{l}\text { Establecer convenios con la entidad para reducir } \\
\text { tiempos de aprobación de los estudios de } \\
\text { ingeniería. }\end{array}$ \\
\hline
\end{tabular}

Elaboración propia.

A continuación, se muestran las alternativas de solución detalladas, de las cuales la solución 1 y 3 se integraron ya que eran complementarias:

Alternativa1: Sistema de Gestión de Proyectos en la Gerencia de Ingeniería.

Con este sistema se espera la integración y control de manera estandarizada y sistemática de los procesos en tiempo, costo, documentación y recursos para planificar y dirigir los proyectos de la Gerencia de Ingeniería y así lograr alcanzar los objetivos estratégicos establecidos.

Alternativa 2: Desarrollar canales virtuales de distribución de entregables de los estudios de ingeniería.

Con este canal se espera facilitar la transferencia, registro y revisión de los documentos técnicos facilitando el control y trazabilidad de los entregables.

Alternativa 3: Establecer convenios con la Entidad para reducir tiempos de aprobación del estudio de la ingeniería. 
Con esta alternativa se espera que los acuerdos realizados con la entidad beneficien el proyecto para su ejecución en menores tiempos.

\subsection{Selección de alternativas de solución}

Para determinar la alternativa de solución más viable a implementar, se realizará una priorización de las posibles soluciones identificadas.

\subsubsection{Determinación y ponderación de criterios evaluación de las alternativas}

Para poder realizar los criterios de evaluación se utilizó la matriz cuantitativa de planificación estratégica (MCPE), en el cual se determinó el peso o importancia para el FODA de la Gerencia de Ingeniería.

Fortalezas

- Aprendizaje y aprovechamiento de la experiencia en la Gerencia de Ingeniería.

- Buen clima laboral.

- Modo de trabajo bajo la toma de decisiones de juicio de expertos.

- Cumplir con la entrega de proyectos.

- La coordinación y el control del funcionamiento de los proyectos.

Debilidades

- Reprocesos, utilizando mayor tiempo y esfuerzo para lograr los objetivos.

- El Sistema de aprobación de los estudios de ingeniería no reduce plazos de entrega.

- No se cuenta con flujogramas definidos y personal que controle la calidad de la Ingeniería.

- Falta identificar los procesos internos de la gestión de estudios.

- Control de la gestión de riesgos de los proyectos.

- Existe mucha burocracia para obtener la aprobación la validación y aprobación de los estudios de ingeniería.

- No se cuenta con un número necesario de recursos (HW, SW, Humanos) para la gestión de proyectos.

- Bajo nivel de digitalización de los entregables de los estudios de ingeniería

- Entrega de los estatus de avance de los proyectos fuera de tiempo. 
Oportunidades

- Mayor cantidad de proyectos en la cartera de inversiones

- Ventaja competitiva en la gestión aeroportuaria

Amenazas

- No existe tiempo límite de respuesta de aprobación por parte de la DGAC para los estudios.

- Falta de priorización por parte de la entidad para realizar los proyectos.

- Falta de consultoras especializadas en el rubro aeroportuario.

- Entrega de los estudios de ingeniería sin cumplir con el alcance, costo y tiempo determinado.

- Consultores abandonan el Proyecto.

\subsubsection{Evaluación cualitativa y/o cuantitativa de alternativas de solución}

En base a las alternativas definidas se realizó la evaluación cuantitativa mediante la Matriz Cuantitativa de Planificación Estratégica (MCPE) con el objetivo de seleccionar la mejor alternativa de una manera técnica y analítica utilizando el FODA para la Gerencia de Ingeniería.

\subsubsection{Priorización y selección de soluciones}

El resultado de la evaluación MPCE dio como estrategia adecuada al "Sistema de Gestión de Proyectos" dando como ponderación 6.465, debido que esta opción va más acorde con las necesidades de la Gerencia de Ingeniería y generaría un mayor valor a lo que se requiere implementar.

Tabla 4.2

Tabla de Ponderación

\begin{tabular}{|c|lc|}
\hline ÍTEM & \multicolumn{1}{|c|}{ ESTRATEGIAS } & PONDERACIÓN \\
\hline 1 & Sistema de Gestión de Proyectos & 6.465 \\
2 & $\begin{array}{l}\text { Desarrollar canales virtuales de distribución de } \\
\text { entregables de los estudios de ingeniería } \\
3\end{array}$ & $\begin{array}{l}\text { Establecer convenios con la Entidad para reducir tiempos } \\
\text { de aprobación del estudio de la ingeniería }\end{array}$ \\
\hline
\end{tabular}

Elaboración propia. 
Tabla 4.3

Matriz Cuantitativa de Planificación Estratégica (MCPE)

\begin{tabular}{|c|c|c|c|c|c|c|c|}
\hline \multirow{2}{*}{$\begin{array}{c}\text { FACTORES } \\
\text { FORTALEZAS }\end{array}$} & \multirow[t]{2}{*}{ PESO } & \multicolumn{2}{|c|}{$\begin{array}{l}\text { Estrategia1: Sistema de } \\
\text { Gestión de Proyectos }\end{array}$} & \multicolumn{2}{|c|}{$\begin{array}{l}\text { Estrategia2: Desarrollar } \\
\text { canales virtuales de } \\
\text { distribución de entregables } \\
\text { de los estudios de ingeniería }\end{array}$} & \multicolumn{2}{|c|}{$\begin{array}{c}\text { Estrategia3: Establecer } \\
\text { convenios con la Entidad para } \\
\text { reducir tiempos de aprobación } \\
\text { del estudio de la ingeniería }\end{array}$} \\
\hline & & EC & TCE & EC & TCE & EC & TCE \\
\hline Aprendizaje y aprovechamiento de la experiencia en la Gerencia de Ingeniería & 0.04 & 4 & 0.16 & 0 & 0 & 3 & 0.12 \\
\hline Buen clima laboral & 0.04 & 3 & 0.12 & 0 & 0 & 0 & 0 \\
\hline Modo de trabajo bajo la toma de decisiones de juicio de expertos. & 0.04 & 3 & 0.12 & 4 & 0.16 & 4 & 0.16 \\
\hline Cumplir con la entrega de proyectos. & 0.07 & 4 & 0.28 & 4 & 0.28 & 1 & 0.07 \\
\hline La coordinación y control del funcionamiento de los proyectos. & 0.07 & 3 & 0.21 & 3 & 0.21 & 0 & 0 \\
\hline \multicolumn{8}{|l|}{ DEBILIDADES } \\
\hline Reprocesos, utilizando mayor tiempo y esfuerzo para lograr los objetivos & 0.07 & 3 & 0.21 & 3 & 0.21 & 3 & 0.21 \\
\hline El sistema de aprobación de los estudios de ingeniería no reduce plazos de entrega. & 0.09 & 4 & 0.36 & 4 & 0.36 & 0 & 0 \\
\hline No se cuenta con flujogramas definidos y personal que controle la calidad de la ingeniería. & 0.09 & 4 & 0.36 & 3 & 0.27 & 0 & 0 \\
\hline Falta identificar los procesos internos de la gestión de estudios. & 0.1 & 4 & 0.4 & 3 & 0.3 & 0 & 0 \\
\hline Control de la gestión de riesgos de los proyectos. & 0.09 & 4 & 0.36 & 3 & 0.27 & 0 & 0 \\
\hline Existe mucha burocracia para obtener la aprobación la validación y aprobación de los estudios de ingeniería. & 0.07 & 2 & 0.14 & 3 & 0.21 & 4 & 0.28 \\
\hline No se cuenta con un número necesario de recursos (HW, SW, Humanos) para la gestión de proyectos. & 0.09 & 3 & 0.27 & 3 & 0.27 & 3 & 0.27 \\
\hline Bajo nivel de digitalización de los entregables de los estudios de ingeniería. & 0.07 & 3 & 0.21 & 3 & 0.21 & 3 & 0.21 \\
\hline Entrega de los estatus de avance de los proyectos fuera de tiempo. & 0.07 & 3 & 0.21 & 1 & 0.07 & 3 & 0.21 \\
\hline Total, Fortalezas y Debilidades & 1 & & 3.41 & & 2.82 & & $\mathbf{1 . 5 3}$ \\
\hline \multicolumn{8}{|l|}{ OPORTUNIDADES } \\
\hline Mayor cantidad de proyectos en la cartera de inversiones & 0.5 & 3 & 1.5 & 3 & 1.5 & 0 & 0 \\
\hline Ventaja competitiva en la gestión aeroportuaria & 0.025 & 3 & 0.075 & 3 & 0.075 & 2 & 0.05 \\
\hline \multicolumn{8}{|l|}{ AMENAZAS } \\
\hline No existe tiempo límite de respuesta de aprobación por parte de la DGAC para los estudios. & 0.15 & 4 & 0.6 & 0 & 0 & 4 & 0.6 \\
\hline Falta de priorización por parte de la entidad para realizar los proyectos. & 0.07 & 0 & 0 & 0 & 0 & 4 & 0.28 \\
\hline Falta de consultoras especializadas en el rubro aeroportuario & 0.07 & 3 & 0.21 & 2 & 0.14 & 2 & 0.14 \\
\hline Entrega de los estudios de ingeniería sin cumplir con el alcance, costo y tiempo determinado & 0.15 & 4 & 0.6 & 2 & 0.3 & 2 & 0.3 \\
\hline Consultores abandonan el proyecto & 0.035 & 2 & 0.07 & 0 & 0 & 1 & 0.035 \\
\hline Total, Oportunidades y Amenazas & $\mathbf{1}$ & & $\mathbf{3 . 0 5 5}$ & & 2.015 & & 1.405 \\
\hline Total, Ponderado & & & 6.465 & & 4.835 & & 2.935 \\
\hline
\end{tabular}

Elaboración propia 


\section{CAPÍTULO V: DESARROLLO, PLANIFICACIÓN Y RESULTADOS ESPERADOS DE LA SOLUCIÓN}

\subsection{Ingeniería de la solución}

Se desarrolló en base a una metodología de trabajo, definido desde el diagnóstico de la solución hasta la puesta en marcha del sistema de gestión. El cual se detalla en el diagrama:

Figura 5.1

Método de trabajo

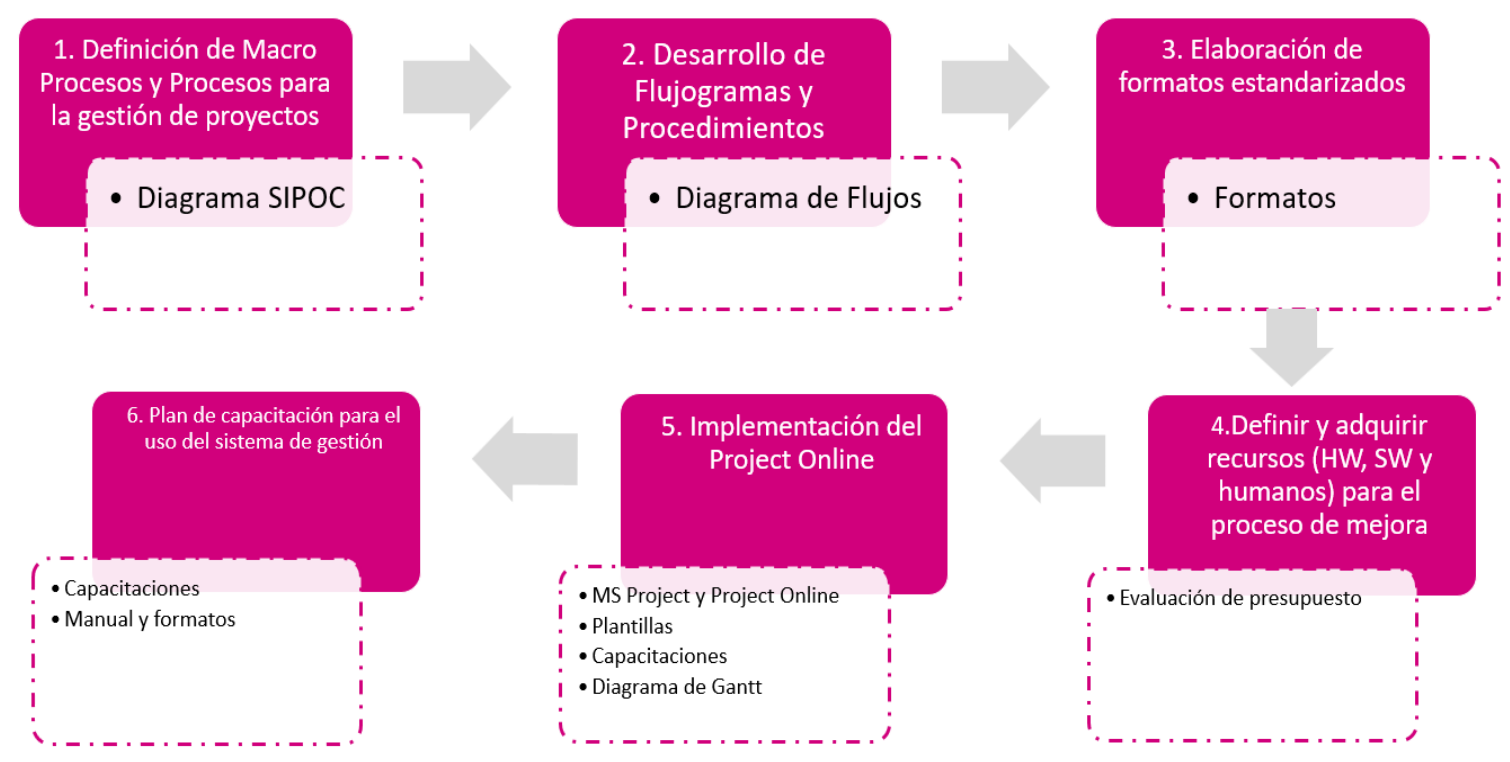

Elaboración propia.

Esta solución incluye seis procedimientos que dirigirán el funcionamiento de este sistema de gestión. 


\subsubsection{Definición de Macro procesos y Procesos}

Figura 5.2

Planificación y control de Proyectos

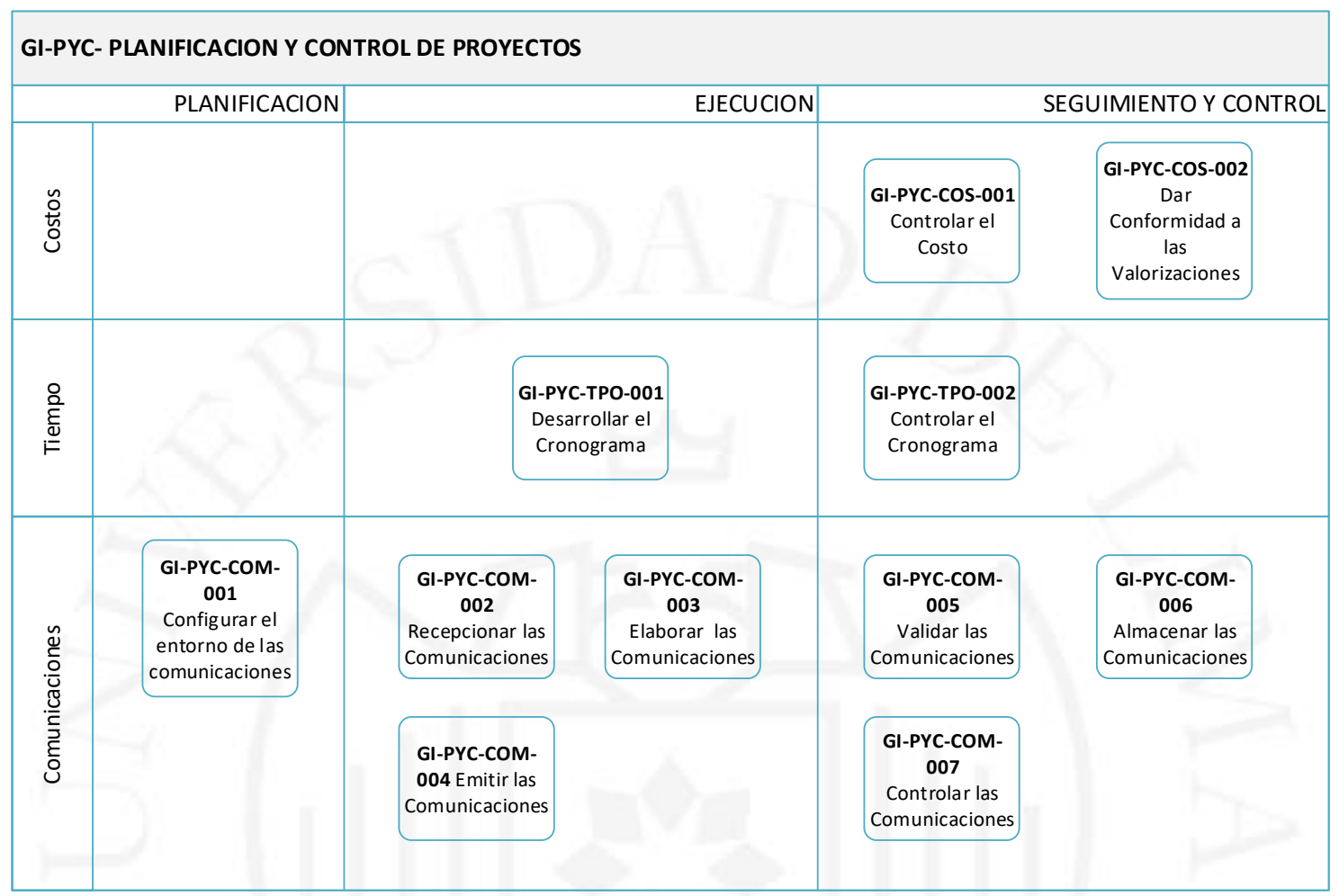

Elaboración propia

\subsubsection{Desarrollo de flujogramas y procedimientos}

En base a los macro procesos definidos se realizó los procesos, flujos y procedimientos mediante reuniones constantes con los juicios expertos, ingenieros y jefes de proyectos además de reuniones con el área de SIG para su integración al sistema.

Gestión del tiempo:

Para la gestión del tiempo se desarrollaron 2 procesos y sus respectivos flujogramas y procedimientos:

- Desarrollar el cronograma 
Figura 5.3

Diagrama de Flujo para desarrollar el cronograma

\section{PYC-TPO-001 - DESARROLLAR EL CRONOGRAMA}

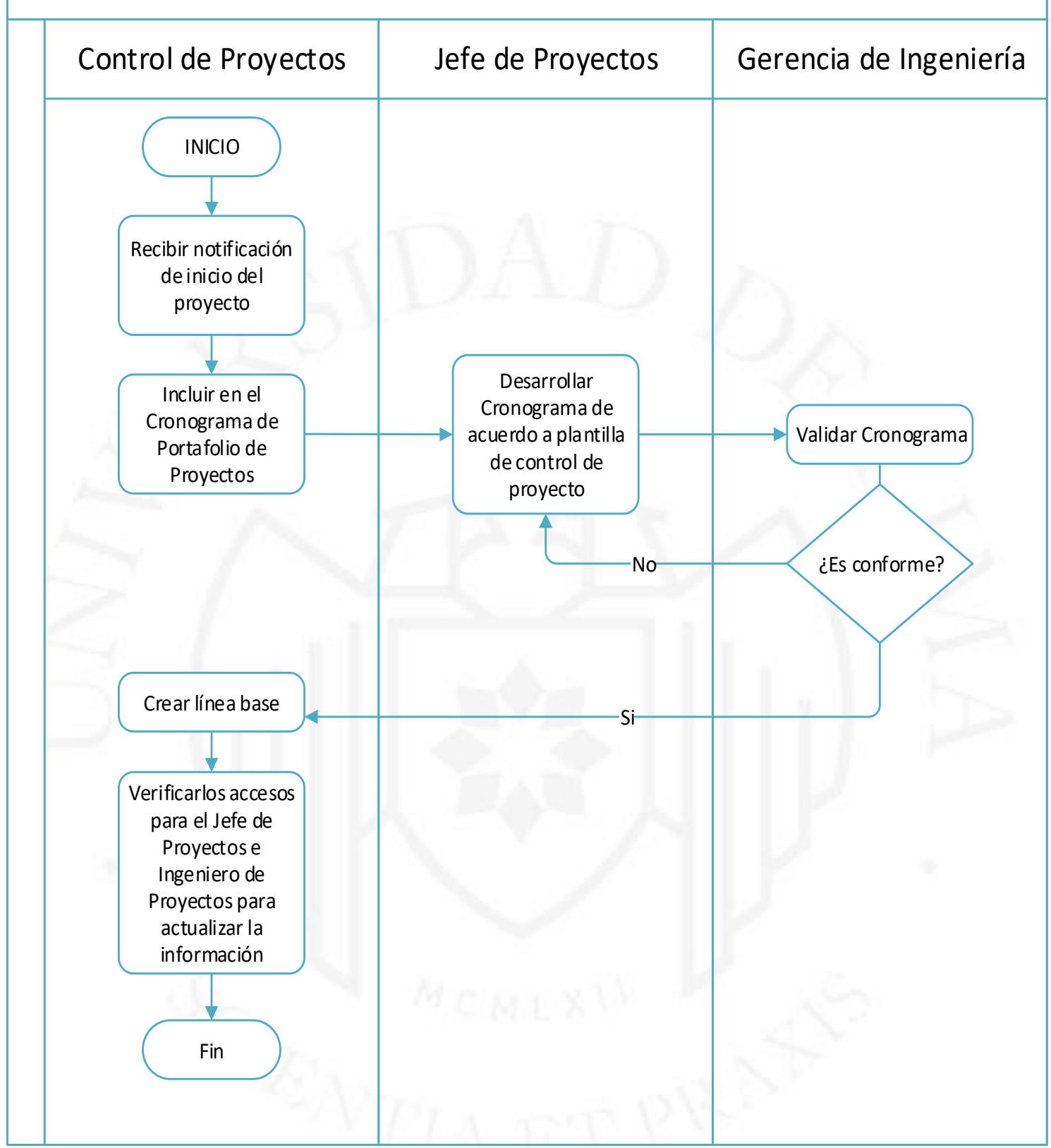

Elaboración propia 
- Controlar el cronograma

Figura 5.4

Diagrama de flujo para controlar el cronograma

\section{PYC-TPO-002 - CONTROLAR EL CRONOGRAMA}

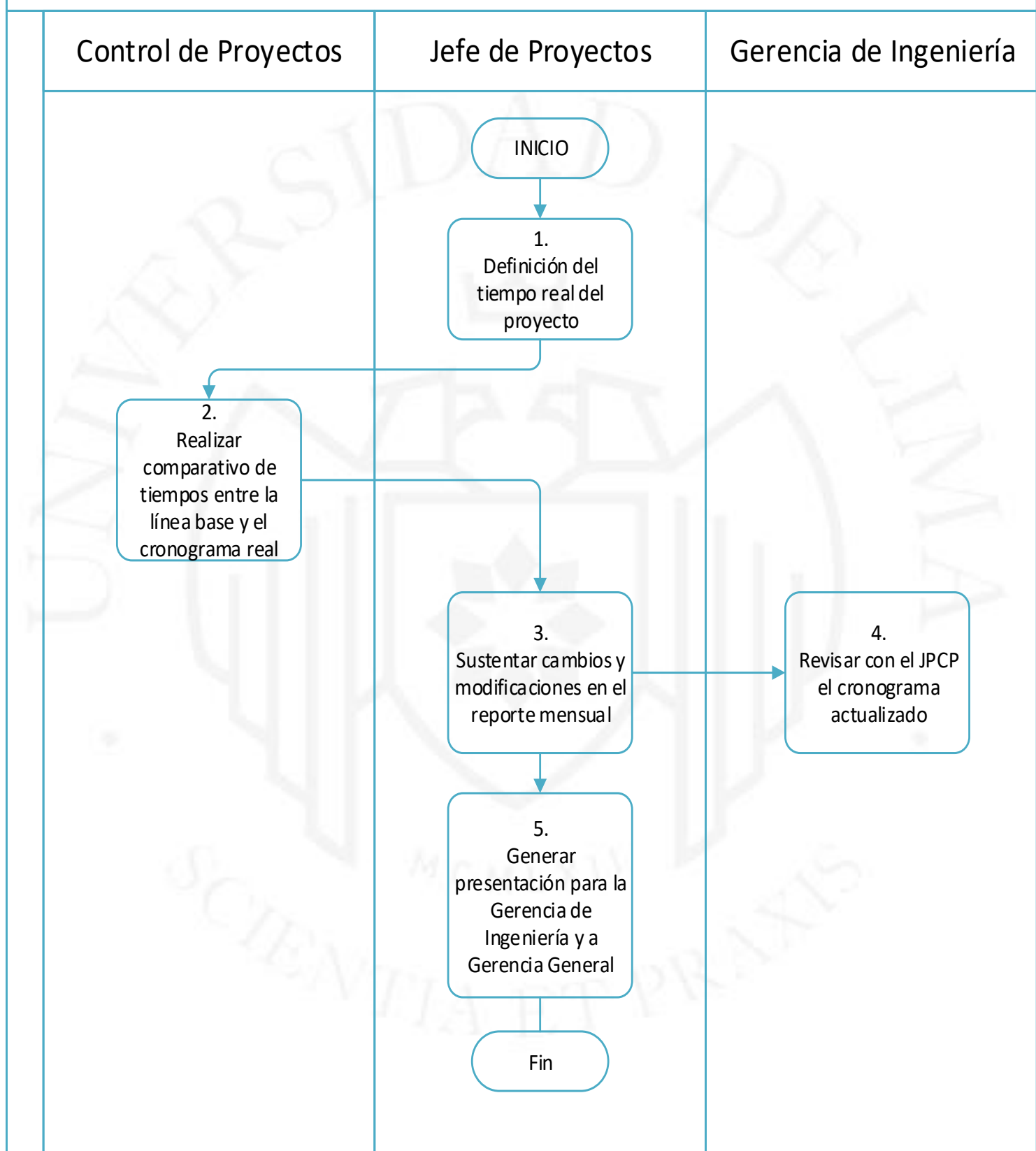

Elaboración propia

Gestión del Costo:

Para la gestión del costo se desarrolló un diagrama de flujo con su respectivo procedimiento. 
Figura 5.5

Diagrama de flujo para el control de valorizaciones en la Gerencia de Ingeniería

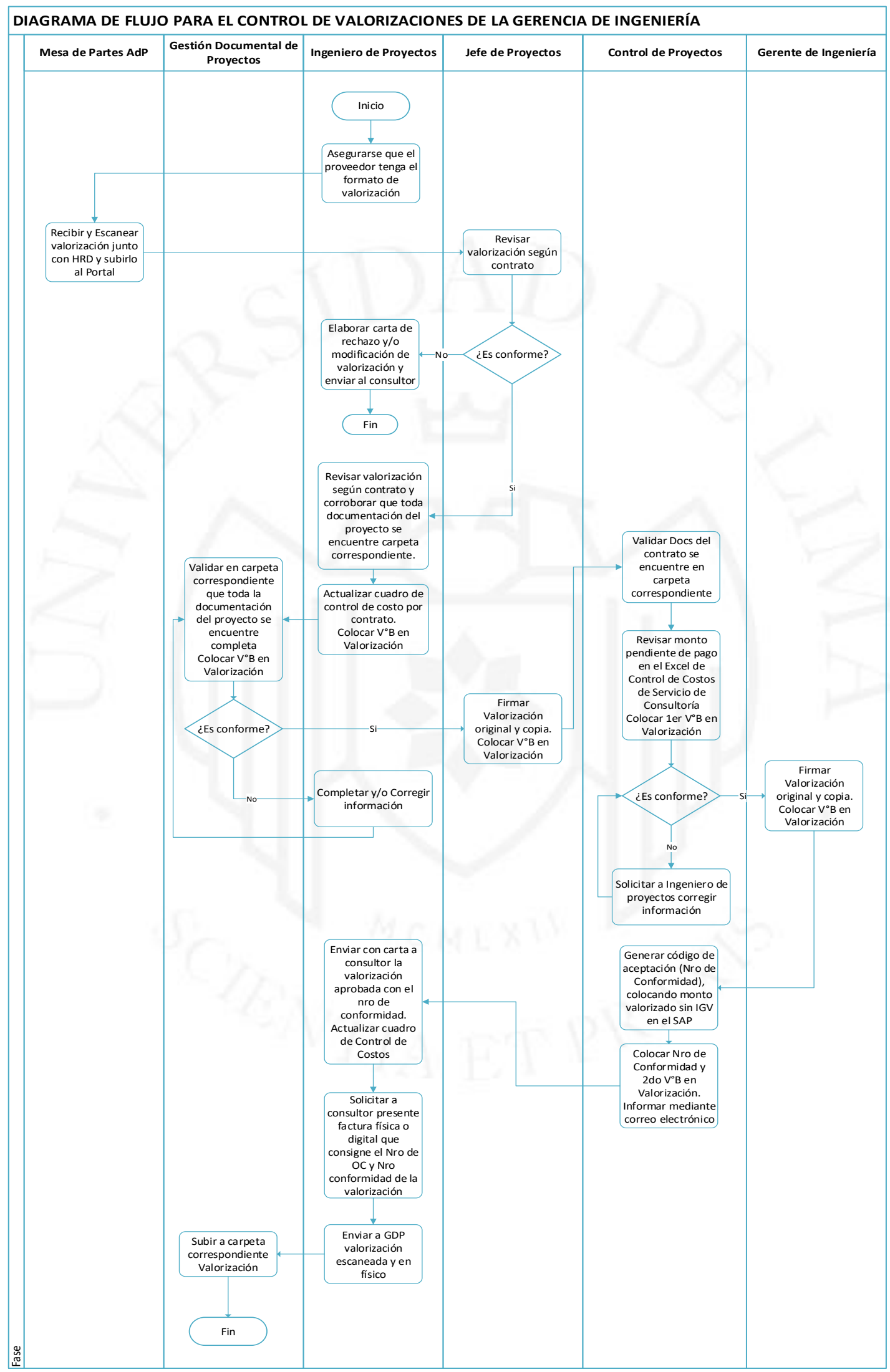

Elaboración propia 


\section{Gestión Documental:}

Para la gestión documental se hicieron siete diagramas de flujos con sus procedimientos respectivos para el mejor trabajo y operatividad interna en AdP y con los consultores.

Figura 5.6

Diagrama de flujo para la configuración de entorno para gestión de correspondencia y entregable

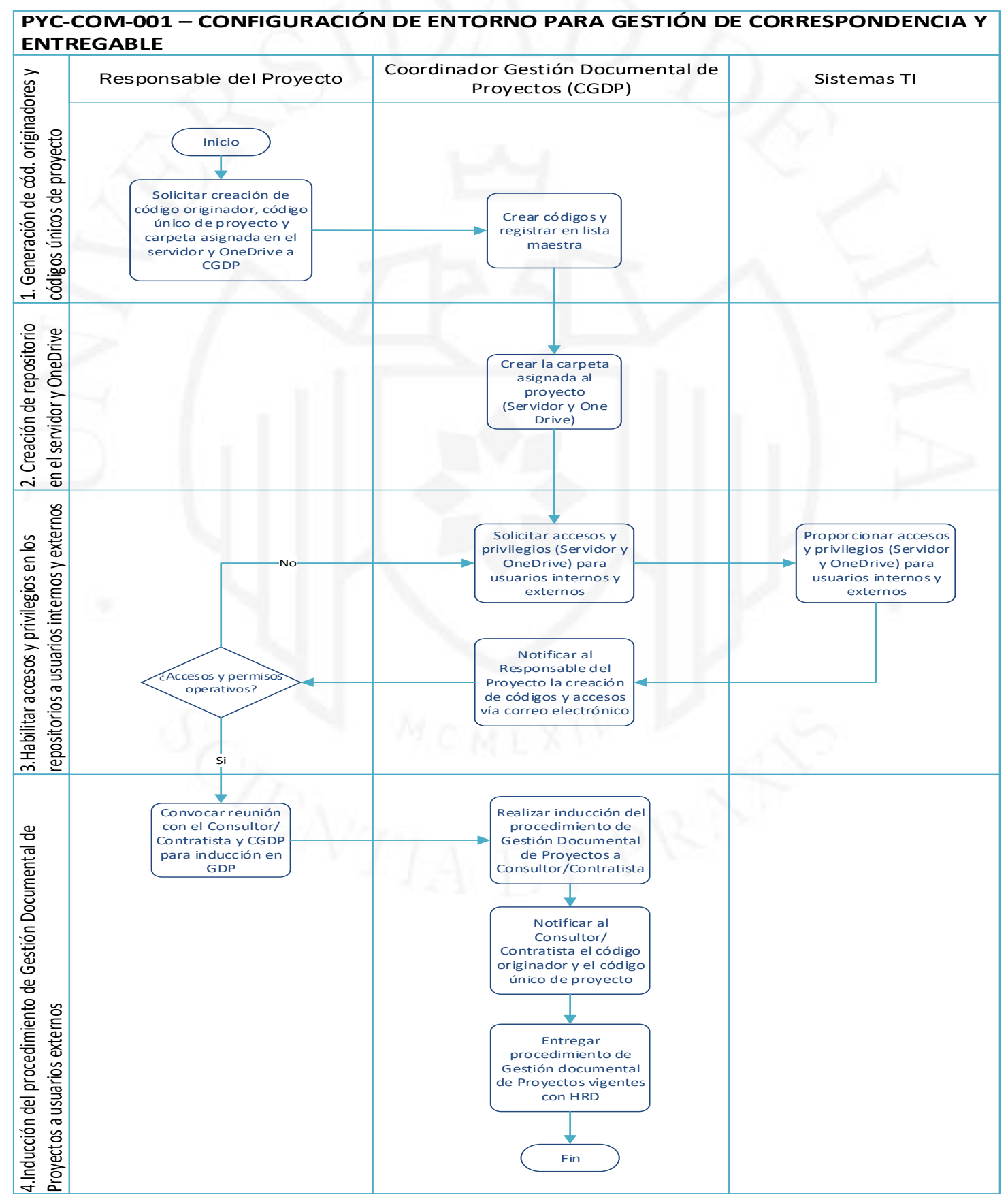

Elaboración propia 


\subsubsection{Elaboración de formatos estandarizados}

La elaboración de los formatos implica el control de la información, con el fin de integrarse de manera eficaz con el sistema de gestión y mediante la elaboración de los formatos distribuir la información a todos los niveles de la organización y consultores.

Figura 5.7

Formato para el control de valorizaciones en la Gerencia de Ingeniería

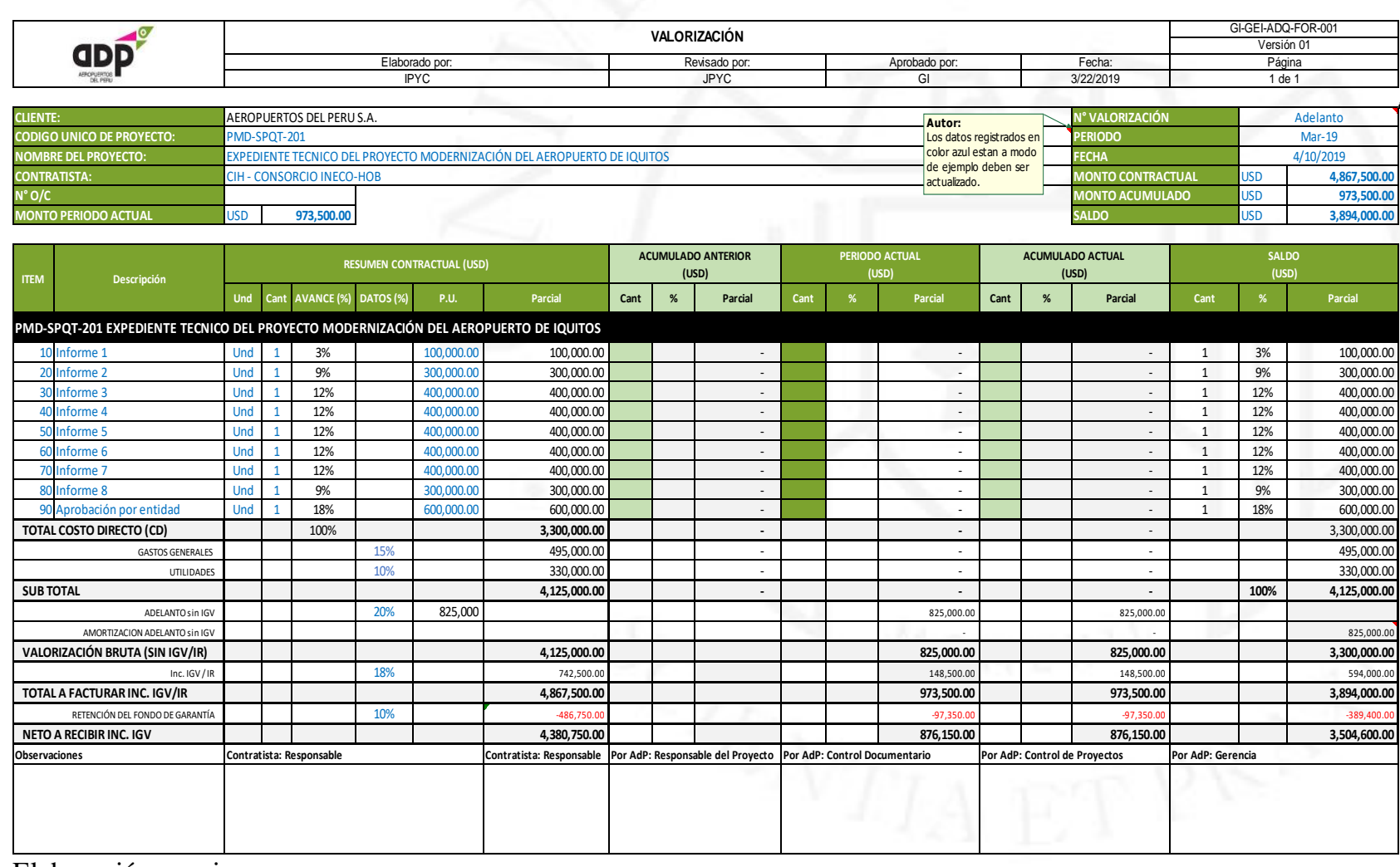

Elaboración propia
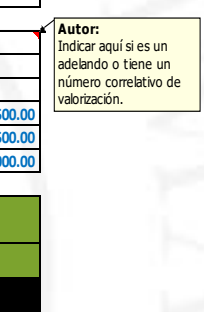
Figura 5.8

Formato de Lista Maestra para el Control de Costos de Servicios

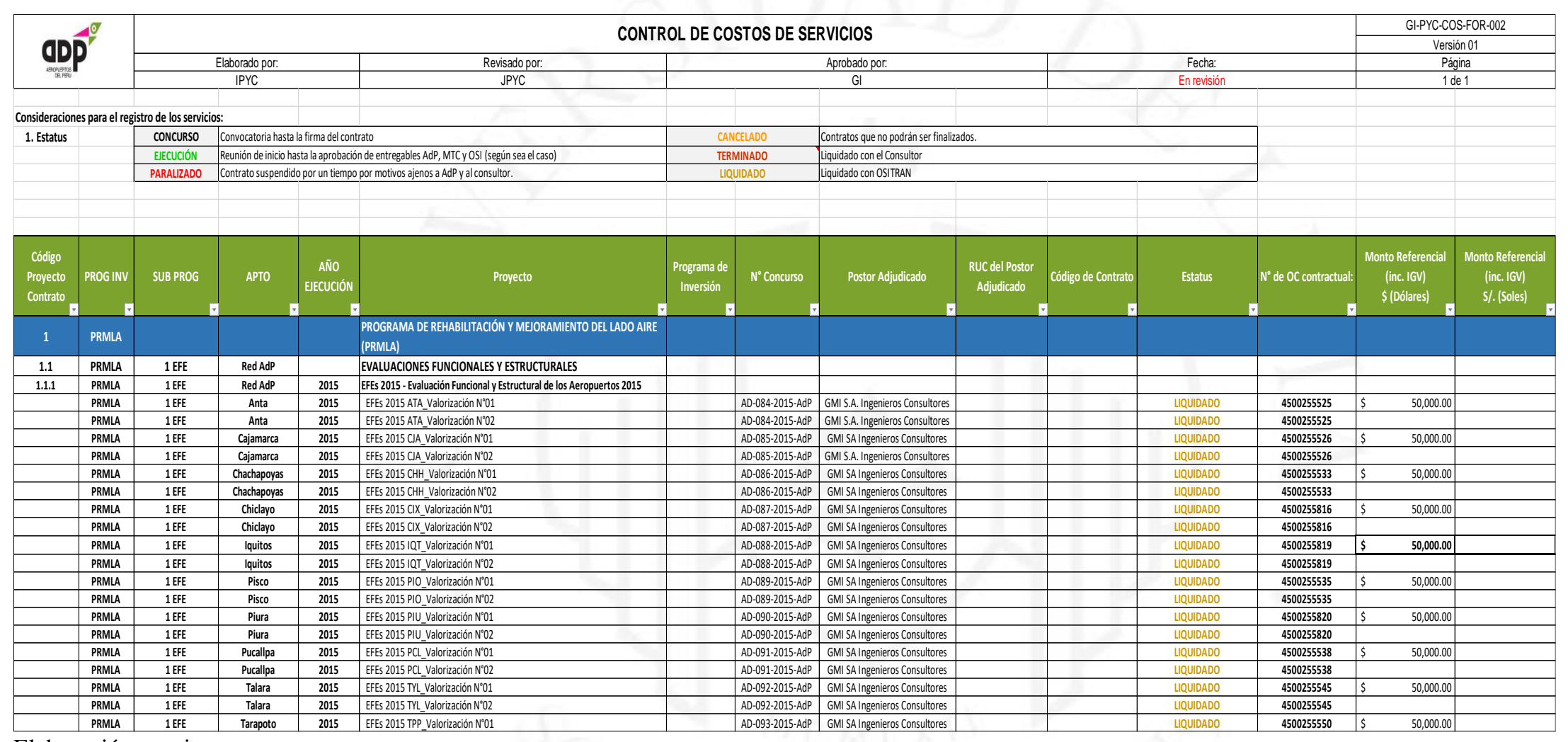

Elaboración propia 
Figura 5.9

Formato de Listado Maestro de Concursos

\begin{tabular}{|c|c|c|c|c|c|c|c|c|c|c|c|c|}
\hline & $\operatorname{ann} 0^{\circ}$ & & & & & & LITADO & AESTRO DE CO & ONCURSOS & & & \\
\hline & P P & & & Elaborado & & & $\begin{array}{lll}\text { Revisado por: } \\
\text { JPYC }\end{array}$ & & forobadop & & $\begin{array}{lll}\text { Fefcha: } \\
4102019\end{array}$ & \\
\hline 1. th & - & thro ae I & & & & & & & & & & \\
\hline & this del concurso & 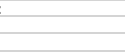 & $\begin{aligned} \text { No INCADO } \\
\text { DESISID } \\
\text { CANCELADO } \\
\end{aligned}$ & & 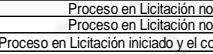 & 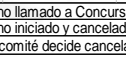 & & $\begin{array}{l}\text { POSTERGABO } \\
\text { ENPDCESO } \\
\text { ADUDOCADO }\end{array}$ & 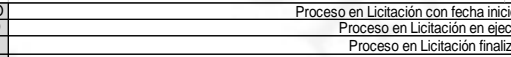 & 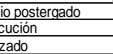 & & \\
\hline & & & DESIERTO & Proceso en el cual nos $\mathrm{s}$ & se concede a ninguno de los que opt & ptan ganar el proceseso & & INCIADO & $\begin{array}{ll}\text { Concurso finalizado - Serviciolob } \\
\end{array}$ & tra hiciado & & \\
\hline iem & MODALIDAD & $\begin{array}{l}\text { COODGOODE } \\
\text { MODALDAD }\end{array}$ & $\begin{array}{l}\text { MODALDAD DE } \\
\text { CONTRATACOÓN }\end{array}$ & ESTATUS Concuiso & AEROPUERTO & AREA & $\begin{array}{l}\text { OBRA/CONSUITORAI } \\
\text { SERVICI/EQUPAMIENTO }\end{array}$ & $\begin{array}{c}\text { INOCACAOR } \\
\text { DE PAGO }\end{array}$ & DESCRPPCIÓN & ETE & $\begin{array}{l}\text { MONTO MAXIMO } \\
\text { REEERENCIAL } \\
\text { (INC. IGV) }\end{array}$ & TIPO DE MONEAA \\
\hline 1 & LPI & IPP-001-2019-AdP & 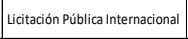 & DESERTO & Tarapoto & Mantenimiento & SeRvicio & PAO-LQ & 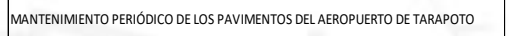 & IMP TPP & $19,482,594.81$ & soles \\
\hline 2 & LPN & LPN-001-2019-AdP & Lictactáion Pública Nacional & DESERTO & Chachapovys & Mantenimiento & SERvICIO & PAO-LIQ & MANTENIMENTO PERRÓOICO DE LOS PAVIIMENTOS DEL LERROPUERTO DE CHACHAPOYAS & . & $9,604,299.90$ & soles \\
\hline 3 & AD & AD-001-2019-AdP & Adjudicación Directa & ADJUDICADO & \begin{tabular}{|l} 
Talara, Trujlilo, Tumbes, Anta, \\
Iquitos Pucallpa
\end{tabular} & Compras & ADQUISICIÓN & PAO-UQ & 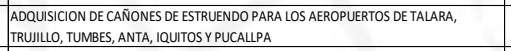 & ETE-ADP-GE-0997 & 12,224.08 & DOLAR \\
\hline 2 & SP & SP-001-2019-AdP & Solicitud de Propuestas & ADJUDICADO & 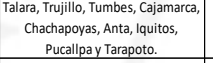 & Compras & ADQUISICIÓN & PAO-LQ & 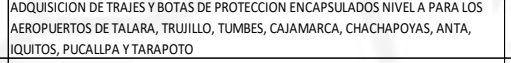 & ETE-ADP-GE-0980 & 95,961.30 & DOLAR \\
\hline 3 & SP & Sp-002-2019-AdP & Solictudd de propuestas & EN Processo & 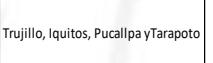 & Compras & ADQUISICIÓN & PAO-ULQ & 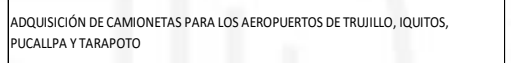 & ETE-ADP-GE-0987 & & \\
\hline 4 & LPN & LPN-002-2019-AdP & Lictactáion Pubblica Nacional & EN Processo & Truillilo Y Tarapoto to & Compras & ADQUUSIIIÓN & PAO-LQQ & 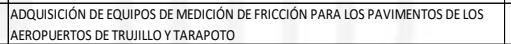 & ETE-ADP-GE-1001 & 322,913.25 & DOCAR \\
\hline 3 & LPI & LP1-002-2019-AdP & |Licitación Pública Internacional | & ADJUDICADO & 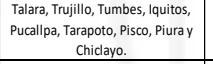 & compras & ADQuisición & PAO-UQ & 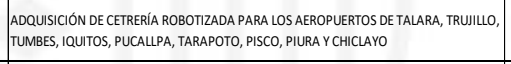 & ETE-ADP-GE-0999 & 1,346,052.17 & DOCAR \\
\hline 4 & LPN & LPN-003-2019-AdP & Lictactáión Pública Nacional & ADJUDICADO & $\begin{array}{c}\text { Pucallila, lquitos, Trujillo, Tumbes, } \\
\text { Cajamarca, , Talara }\end{array}$ & Compras & ADQUISICIÓN & PAO-LQ & 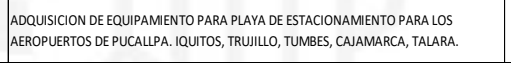 & $\begin{array}{cl}\text { ETE-974-979-977- } \\
971-972-969 \\
\end{array}$ & 923,519.49 & DOLAR \\
\hline 5 & LPN & LPN-004-2019-AdP & Lictactä́n Pública Nacional & EN PROCESO & 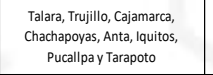 & Compras & ADQUUSIIIÓN & PAO-LQQ & 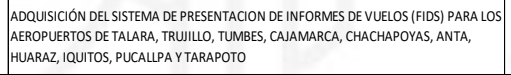 & ETE-ADP-GE-0981 & 328,575.89 & DÓlAR \\
\hline 4 & AD & AD-002-2019-AdP & Adjudicación Directa & ADJUDICADO & Trujilloy Tumbes & compras & ADQuisición & PAO-LIQ & 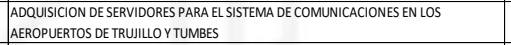 & EEE-ADP-GE-0995 & $31,925.23$ & DOLAR \\
\hline 5 & AD & AD-003-2019-AdP & Adjudicación nirecta & ADJUDICADO & 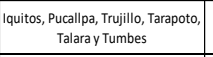 & Compras & ADQUISICIÓN & PAO-UQ & 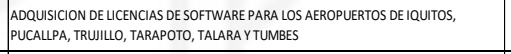 & ETE-AD-GE-1020 & $65,55.64$ & soles \\
\hline 6 & AD & AD-004-2019-AdP & Adjudicación Directa & ADJUDICADO & Chiclayo & Inversiones & AQUIIIIIÓN & PAO-ULQ & 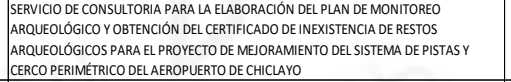 & & $50,000.00$ & USD \\
\hline 5 & AD & AD-005-2019-AdP & Adjudicación Directa & ADJUDICADO & Chiclayo & Mantenimiento & OBRA & PAO-UQ & 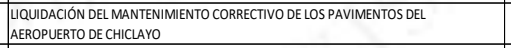 & N.A. & $200,000.00$ & soles \\
\hline 6 & $\mathrm{CPI}$ & CP-001-2019-AdP & Concurso Público Internacional & NO INICIADO & chiclayo & Ingeniería & Consutroría & PAO-UQ & 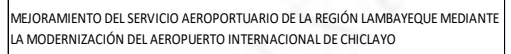 & - & $12,242,40.00$ & uso \\
\hline
\end{tabular}

Elaboración propia 


\subsubsection{Definir y adquirir recursos (HW, SW y recursos) para el proceso de mejora}

Anualmente se realizan evaluaciones de presupuesto para la adquisición de Hardware, Software y/o nuevas contrataciones de personal.

\subsubsection{Implementación del Project Online}

Este software se implementó con el objetivo de apoyo a la gestión del portafolio de proyectos, el cual será utilizado para realizar el seguimiento de costos, tiempos y recursos; teniendo como beneficio centralizar, evaluar y gestionar la información de proyectos en una sola plataforma tecnológica mediante la nube de servicios Microsoft. Por otro lado, también tiene disponibilidad de generar informes, métricas e indicadores en cualquier momento vía la integración Power BI.

Figura 5.10

Página Principal del Project Online

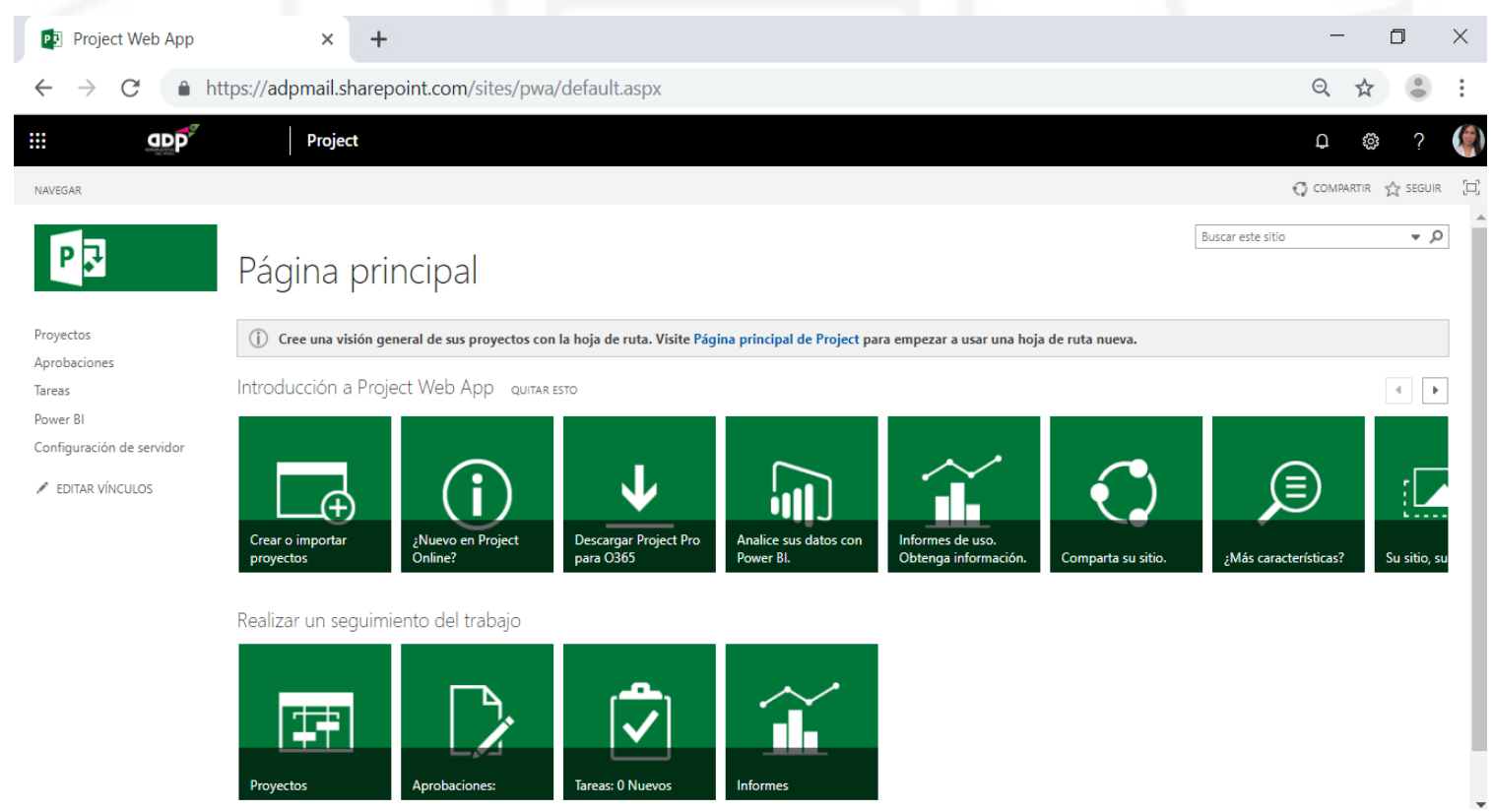

Fuente: Software Project Online (2019) 
Figura 5.11

Página Principal del Power BI

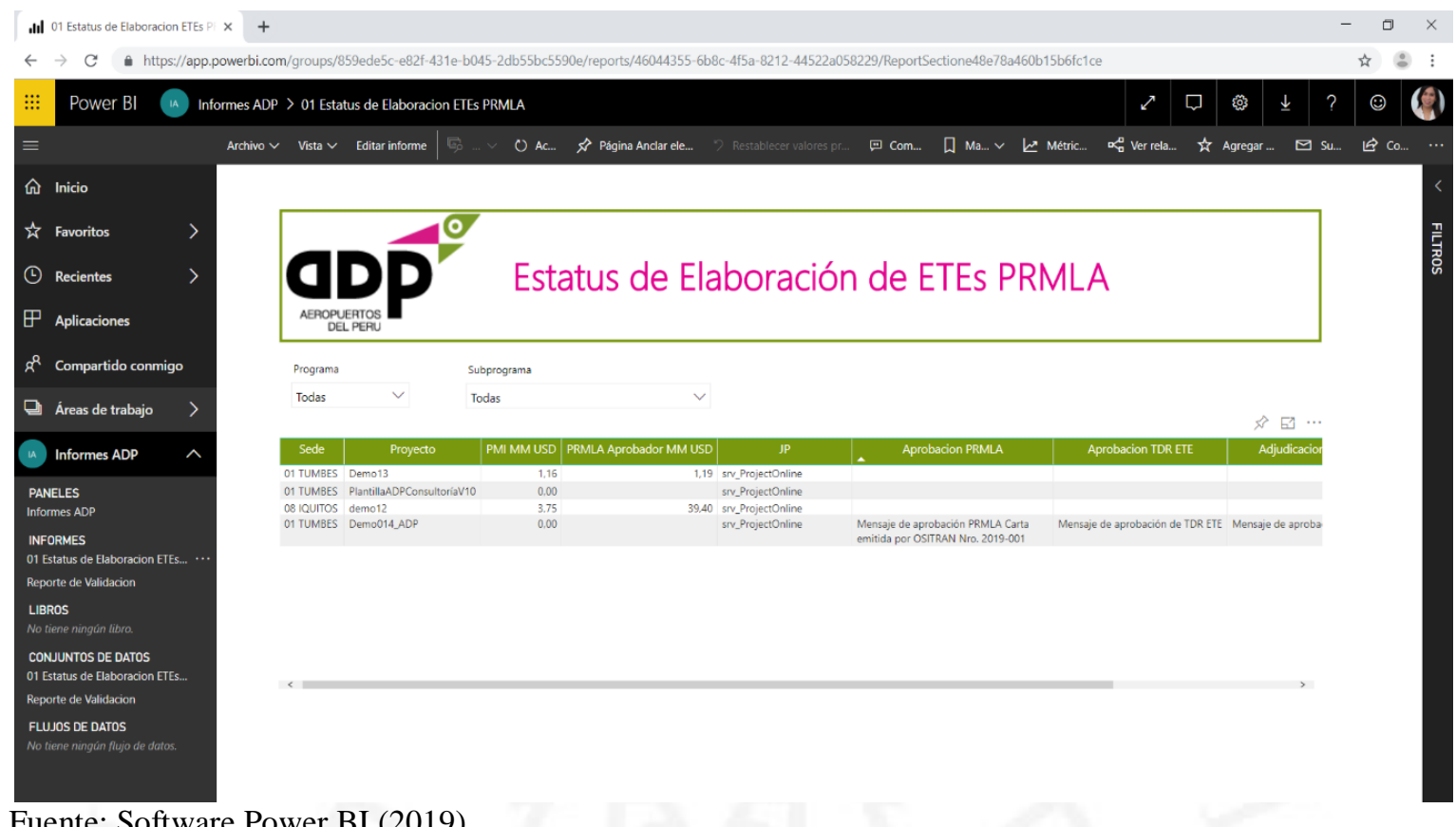

Fuente: Software Power BI (2019)

\subsubsection{Plan de capacitación para el uso del sistema de gestión}

Se emplearon técnicas especializadas y planificadas por medio del cual el colaborador tuvo que recibir conocimientos en las nuevas políticas para el desarrollo de los procesos, procedimientos y uso de los formatos, asimismo el manejo del Project Online.

\subsection{Plan de implementación de la solución}

Desde el punto de vista de la estrategia a nivel corporativo, la implementación de la solución responde a una estrategia de integración hacia adelante, dado que la Gerencia de Ingeniería se encuentra en la búsqueda de la estandarización y del dominio de sus procesos antes de generar la entrega de sus proyectos a su socio estratégico.

\subsubsection{Elaboración del presupuesto requerido para la ejecución de la solución}

Para el desarrollo de la solución, se realizó un presupuesto detallado el cual ascendió a la suma de 1,200,426.90 soles, considerando una inversión paulatina durante el periodo de 2017 al 2020. 
Tabla 5.1

Costos de Inversión

\begin{tabular}{|c|c|c|c|c|}
\hline COSTO DE INVERSION 2017 & MESES & $\begin{array}{c}\text { COSTO } \\
\text { MENSUAL }\end{array}$ & $\begin{array}{c}\text { CANT. } \\
\text { USUARIOS }\end{array}$ & SUBTOTAL \\
\hline \multicolumn{5}{|l|}{ RRHH } \\
\hline Asistente de Programación y Control de Proyectos & 12 & 2500 & 1 & $30,000.00$ \\
\hline Coordinador de Control Documentario de Proyectos & 12 & 5250 & 1 & $63,000.00$ \\
\hline Asistente de Ingeniería & 12 & 3500 & 1 & $42,000.00$ \\
\hline \multicolumn{5}{|l|}{ LICENCIAS } \\
\hline Software Project & 12 & 66 & $\begin{array}{l}2 \\
\text { Total: }\end{array}$ & $\begin{array}{r}1,584.00 \\
\mathbf{1 3 6 , 5 8 4 . 0 0}\end{array}$ \\
\hline COSTO DE INVERSION 2018 & MESES & $\begin{array}{c}\text { COSTO } \\
\text { MENSUAL }\end{array}$ & $\begin{array}{c}\text { CANT. } \\
\text { USUARIOS }\end{array}$ & SUBTOTAL \\
\hline \multicolumn{5}{|l|}{ RRHH } \\
\hline Jefe de Prog. Y Control de Proyecto & 12 & 12000 & 1 & $144,000.00$ \\
\hline Ingeniera de Programación y Control de Proyectos & 12 & 3000 & 1 & $36,000.00$ \\
\hline Coordinador de Control Documentario de Proyectos & 12 & 5000 & 1 & $60,000.00$ \\
\hline Asistente de Control Documentario & 12 & 3500 & 1 & $42,000.00$ \\
\hline \multicolumn{5}{|l|}{ CONSULTORIA } \\
\hline Implementación Project Online & & & & $54,954.90$ \\
\hline \multicolumn{5}{|l|}{ LICENCIAS } \\
\hline Ms Project & 12 & 66 & 5 & $3,960.00$ \\
\hline Licencia de softwares online Premium & 12 & 211 & 2 & $5,064.00$ \\
\hline Licencia de softwares online professional & 12 & 115 & 6 & $8,280.00$ \\
\hline Licencia de softwares Power BI & 12 & 39 & 3 & $1,404.00$ \\
\hline \multirow[t]{2}{*}{ Licencia de software project online } & 12 & 33 & 15 & $5,940.00$ \\
\hline & & & Total: & $361,602.90$ \\
\hline COSTO DE INVERSION 2019 & MESES & $\begin{array}{c}\text { COSTO } \\
\text { MENSUAL }\end{array}$ & $\begin{array}{c}\text { CANT. } \\
\text { USUARIOS }\end{array}$ & SUBTOTAL \\
\hline \multicolumn{5}{|l|}{ RRHH } \\
\hline Jefe de Prog. Y Control de Proyecto & 12 & 12000 & 1 & $144,000.00$ \\
\hline Ingeniera de Programación y Control de Proyectos & 12 & 3500 & 1 & $42,000.00$ \\
\hline Coordinador de Control Documentario de Proyectos & 12 & 5000 & 1 & $60,000.00$ \\
\hline Asistente de Control Documentario & 12 & 3500 & 1 & $42,000.00$ \\
\hline \multicolumn{5}{|l|}{ LICENCIAS } \\
\hline Ms Project & 12 & 66 & 5 & $3,960.00$ \\
\hline Licencia de softwares online Premium & 12 & 211 & 3 & $7,596.00$ \\
\hline Licencia de softwares online professional & 12 & 115 & 6 & $8,280.00$ \\
\hline Licencia de softwares Power BI & 12 & 39 & 3 & $1,404.00$ \\
\hline \multirow[t]{2}{*}{ Licencia de software project online } & 12 & 33 & 20 & $7,920.00$ \\
\hline & & & Total: & $317,160.00$ \\
\hline COSTO DE INVERSION 2020 en adelante & MESES & COSTO & $\begin{array}{l}\text { CANT. } \\
\text { CAUIOS }\end{array}$ & SUBTOTAL \\
\hline \multicolumn{5}{|l|}{ RRHH } \\
\hline Jefe de Prog. Y Control de Proyecto & 12 & 12000 & 1 & $144,000.00$ \\
\hline Ingeniera de Programación y Control de Proyectos & 12 & 4000 & 1 & $48,000.00$ \\
\hline Coordinador de Control Documentario de Proyectos & 12 & 5000 & 1 & $60,000.00$ \\
\hline Asistente de Control Documentario & 12 & 3500 & 1 & $42,000.00$ \\
\hline Ingeniero de Planificación & 12 & 4500 & 1 & $54,000.00$ \\
\hline \multicolumn{5}{|l|}{ LICENCIAS } \\
\hline Ms Project & 12 & 66 & 10 & $7,920.00$ \\
\hline Licencia de softwares online Premium & 12 & 211 & 3 & $7,596.00$ \\
\hline Licencia de softwares online professional & 12 & 115 & 6 & $8,280.00$ \\
\hline Licencia de softwares Power BI & 12 & 39 & 3 & $1,404.00$ \\
\hline \multirow[t]{2}{*}{ Licencia de software project online } & 12 & 33 & 30 & $11,880.00$ \\
\hline & & & Total: & $385,080.00$ \\
\hline
\end{tabular}

Elaboración propia. 


\subsubsection{Actividades y cronograma de implementación de la solución}

Para poder desarrollar el sistema de gestión para los estudios de ingeniería, se realizó un Diagrama de Gantt con la lista de actividades.

Figura 5.12

Cronograma de Actividades para desarrollar el Sistema de Gestión de Estudios de Ingeniería
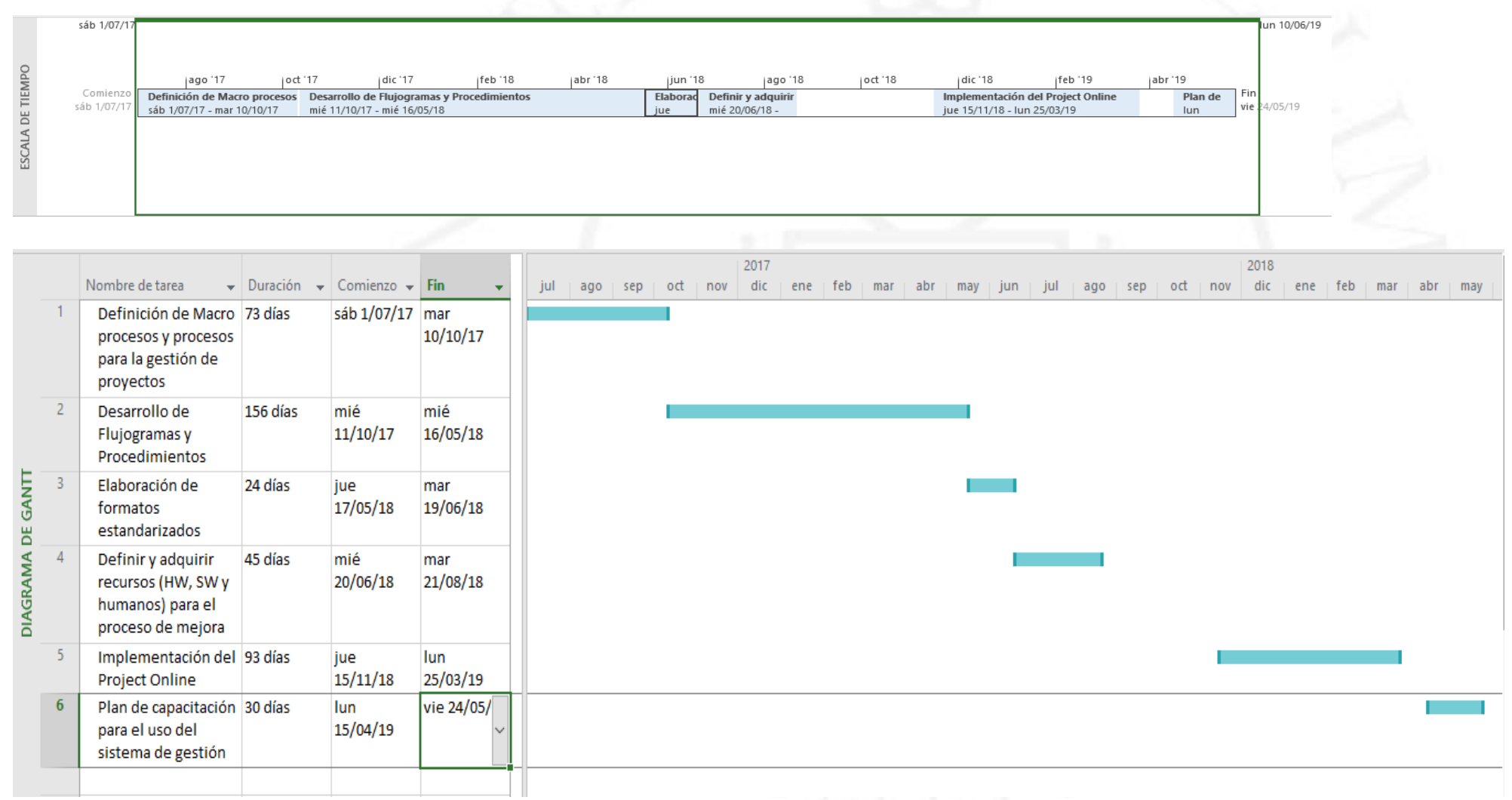

Elaboración propia 


\subsection{Evaluación económica de la solución}

Se realizó un análisis para identificar el Beneficio del uso del Sistema de Gestión desarrollando en la Tabla 5.2 y 5.3, la cual contiene la cartera de proyectos que se realizaran durante el periodo 2017 al 2020, detallando el costo y tiempo de elaboración para cada uno de ellos.

Para identificar el beneficio mediante la aplicación del sistema de gestión se realizó una diferenciación entre el monto de inversión mediante el uso del sistema vs. El monto de inversión sin el uso del sistema

Se ha determinado que el uso del sistema de gestión considera el desarrollo de los estudios previos, como los Términos de Referencia (TdR), sean elaborados de manera interna en la organización.

La evaluación económica realizada mediante el análisis Costo - Beneficio (B/C) como se muestra en la Tabla 5.4, dio como resultado un valor de 1.66 veces por lo cual esto indica que los beneficios por la implementación del sistema de gestión son mayores a los costos, en consecuencia, el proyecto es viable. 
Tabla 5.2

Beneficio

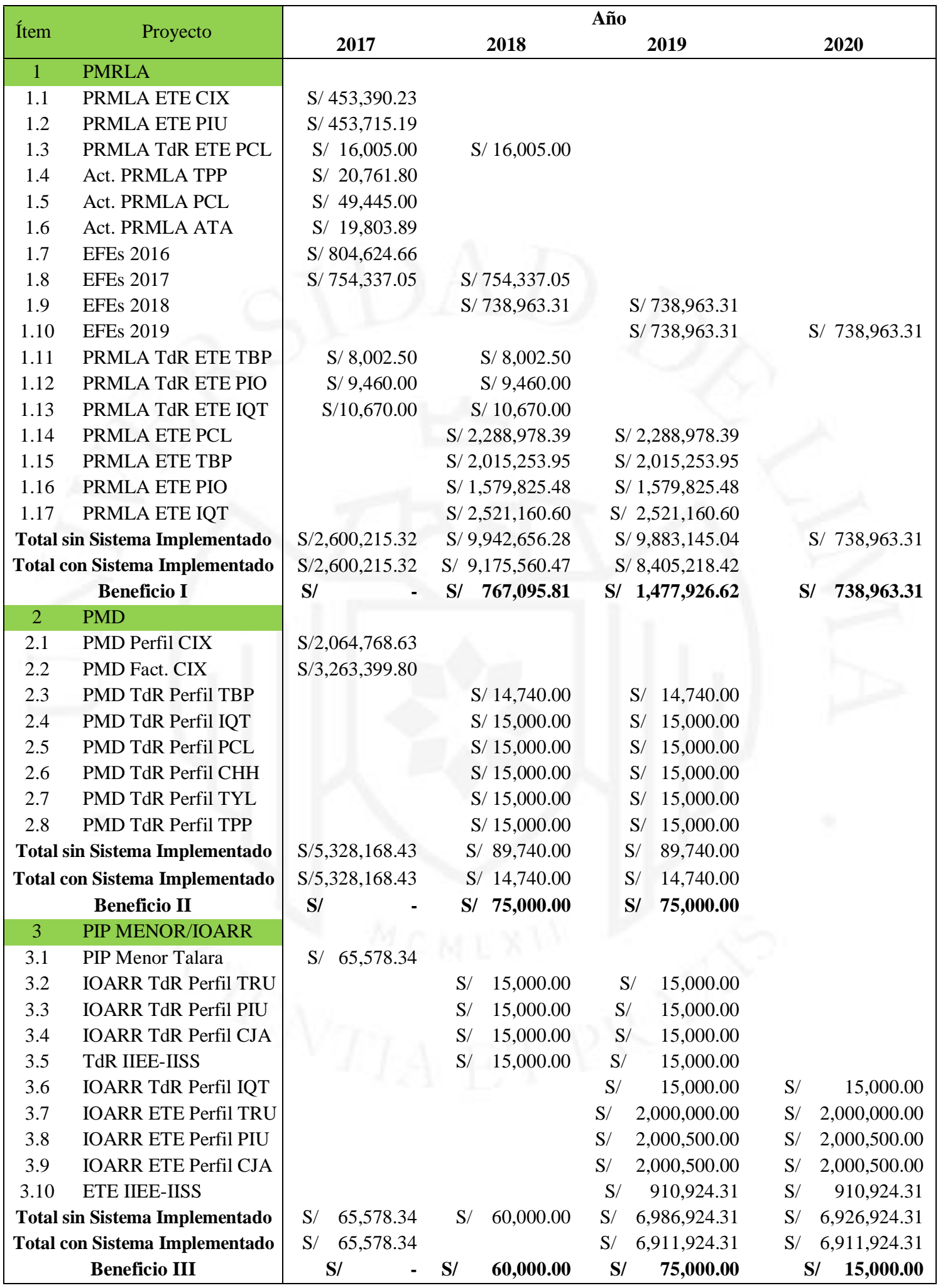

Elaboración propia. 
Tabla 5.3

Resumen de Beneficios

\begin{tabular}{|c|c|c|c|c|c|c|c|}
\hline & \multicolumn{7}{|c|}{ Año } \\
\hline & 2017 & & 2018 & & 2019 & & 2020 \\
\hline Beneficio Total & & S/ & $902,095.81$ & $\mathbf{S} /$ & $1,627,926.62$ & S/ & $753,963.31$ \\
\hline
\end{tabular}

Elaboración propia.

Tabla 5.4

Costo-Beneficio

\begin{tabular}{|c|ccrrr|}
\hline Año & COSTO & \multicolumn{2}{c|}{ BENEFICIO } & \multicolumn{2}{c|}{ Flujo } \\
\hline 2017 & S/ $136,584.00$ & & - & -S/ & $136,584.00$ \\
2018 & S/ $361,602.90$ & S/ $902,095.81$ & S/ & $540,492.91$ \\
2019 & S/ $317,160.00$ & S/ $1,627,926.62$ & S/ $1,310,766.62$ \\
2020 & S/ $385,080.00$ & S/ $753,963.31$ & S/ & $368,883.31$ \\
\hline
\end{tabular}

Elaboración propia. 


\section{CONCLUSIONES}

- Se identificaron y definieron procesos, formatos, flujogramas y procedimientos los cuales aportaron para la implementación del sistema de gestión para el desarrollo de los estudios de ingeniería, en la Gerencia de Ingeniería para la sub área de control de los proyectos.

- Incrementó el número de recursos en cada sub área, es por ello que el equipo de la Gerencia de Ingeniería tiene un total de 27 colaboradores actualmente.

- Por medio de la herramienta Matriz Cuantitativa de Planificación Estratégica (MCPE) de la Ingeniería Industrial, de acuerdo al análisis, se pudo identificar el mejor sistema de gestión.

- La implementación del Project Online como Software para la gestión de los proyectos incidió positivamente en las fases de cada gestión de los proyectos del 2018 en adelante, porque definió plantillas en base a las necesidades detectadas y/o requeridas por cada proyecto.

- Se determinó que la capacitación del Project Online influyó en los procesos establecidos como un lenguaje unificado para conocimiento de todo el equipo de la Gerencia de Ingeniería, obteniendo una visión detallada de los requisitos definidos, especificando su funcionamiento de acuerdo a los nuevos procesos y procedimientos.

- La construcción del sistema de gestión propuesto acorde con las necesidades de la Gerencia de Ingeniería se debió al incremento de proyectos en la gestión de Estudios de Ingeniería. A continuación, se muestra un cuadro Comparativo de Análisis de Indicadores de las Fases de los Estudios de Ingeniería. 


\section{Aeropuerto Chiclayo (PRMLA)}
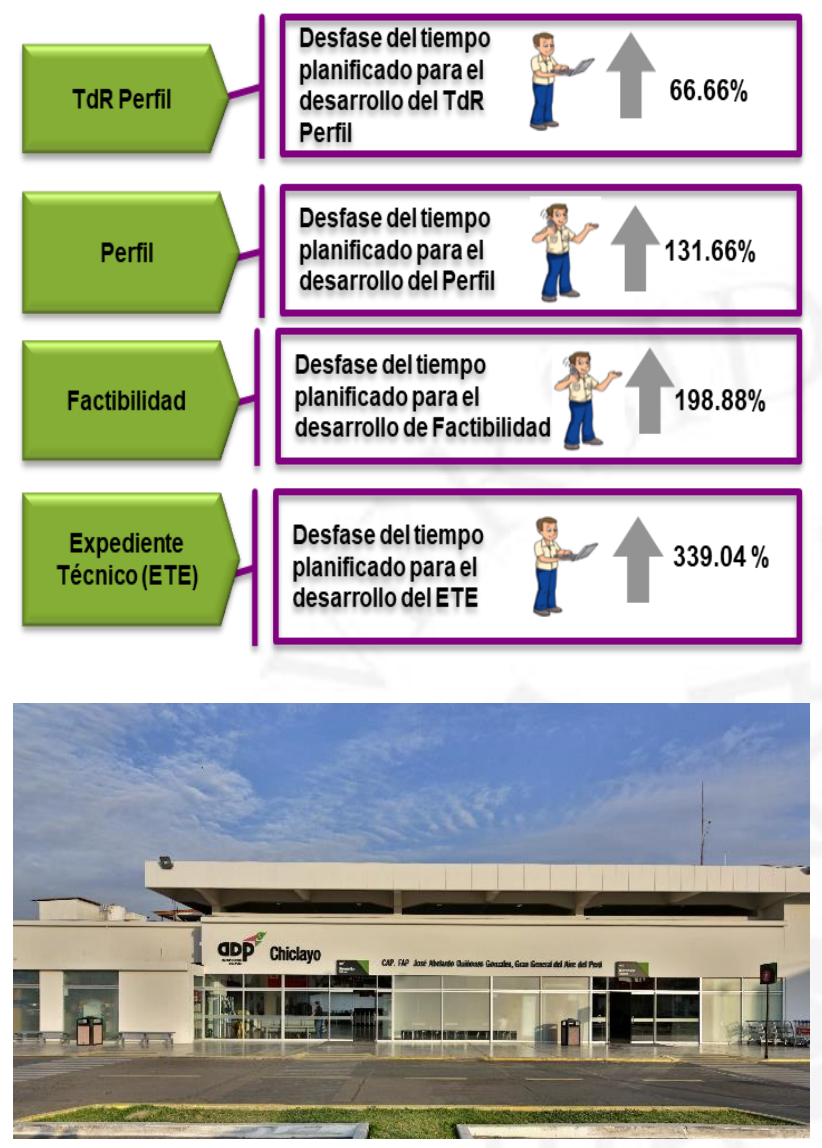

\section{Aeropuerto Pucallpa (PRMLA)}
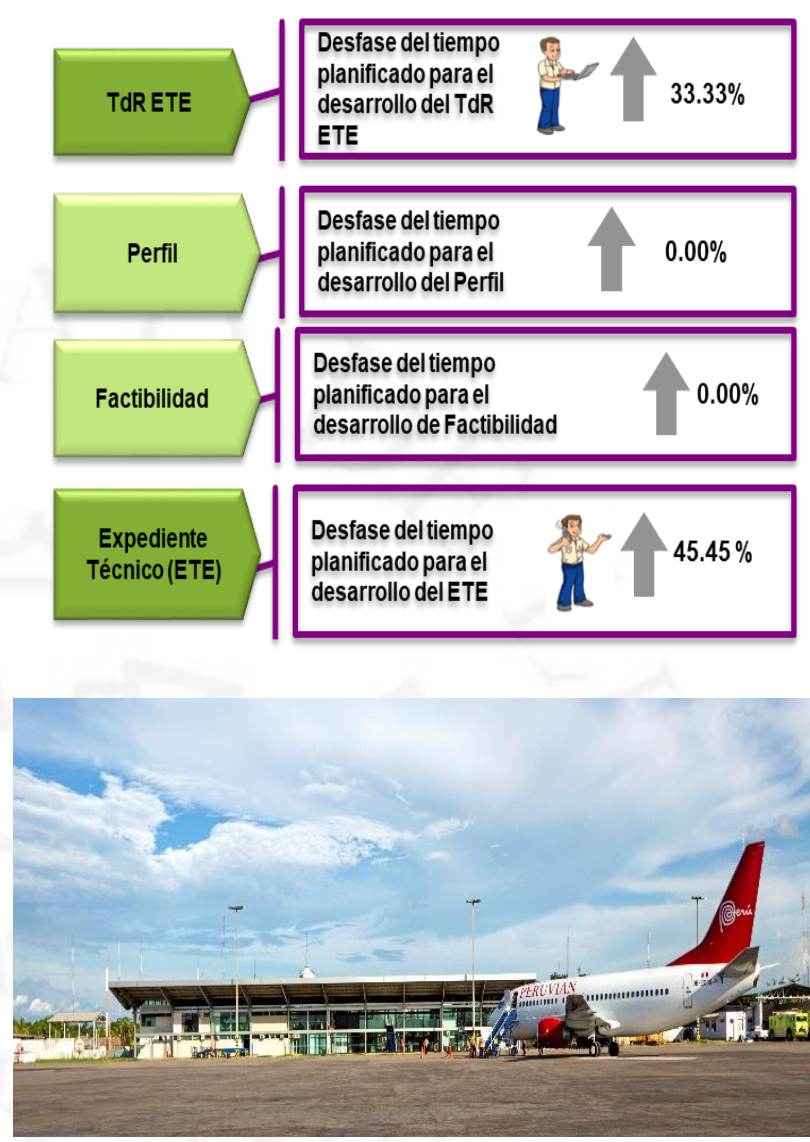


\section{RECOMENDACIONES}

Al centrarse en optimizar tiempo y costo de un proyecto, se busca obtener todas las mejoras continuas. Por lo tanto, habiendo implementado un sistema de gestión como mejora, se recomienda finalizar la aprobación e inclusión de los procesos faltantes ya definidos como necesarios para la gestión de los proyectos, en el Sistema de Gestión Integral de la empresa aeroportuaria.

Para brindarle mayor beneficio a optimizar tiempo y costo según los diferentes alcances de los proyectos. La segunda estrategia que resultó como una de las tres primeras ganadoras, debido a su puntaje alto de 4.83 en el análisis de la "Matriz Cuantitativa de Planificación Estratégica (MCPE)", se recomienda que se desarrolle "Canales Virtuales de Distribución de Entregables de los Estudios de Ingeniería", este sistema se utilizaría de manera adecuada durante toda la gestión e interacción con la Entidad y Consultores, ya que no se cuenta con un control documentario sistematizado. 


\section{REFERENCIAS}

Barrantes Cáceres, Roxana (2012). Desarrollo de la Infraestructura de Aeropuertos en el Perú. Revista Círculo de Derecho Administrativo. Lima - Perú.

Barletta, F., Pereira, M., Robert, V., y Yoguel, G. (2013). Argentina: dinámica reciente del sector de software y servicios informáticos. Revista de la CEPAL(110), 137155. Recuperado de http://www.cepal.org/publicaciones/xml/1/50511/RVE110Yoqueletal.pdf

Choy, M., y Chang, G. (2014). Medidas macroprudenciales aplicadas en el Perú. Lima: Banco Central de Reserva del Perú. Recuperado de http://www.bcrp.gob.pe/docs/Publicaciones/Documentos-deTrabajo/2014/documento-de-trabajo-07-2014.pdf

Farromeque Quiroz Rafael, (2016). Inc. Análisis de inversiones aeroportuarias en américa latina y el caribe al horizonte 2040. Corporación Andina de Fomento

Ministerio de Transporte y Comunicaciones (2019). Programación Multianual de Inversiones 2019 - 2021 (PMI). Lima - Perú.

Redacción Gestión. (26 de Agosto de 2019). Inversión para atender demanda aeroportuaria en Perú es de US\$ 5,400 millones al año 2040. Gestión. Recuperado de https://gestion.pe/economia/inversion-atender-demandaaeroportuaria-peru-us-5-400-millones-ano-2040-236901-noticia/ 


\section{BIBLIOGRAFÍA}

Aeropuertos del Perú, Contrato de Concesión para el Diseño, La construcción, mejora, mantenimiento y explotación del primer grupo de aeropuertos de provincia de la República del Perú.

Arroyo Pedro, Vásquez Ruth, (2016). Ingeniería económica. 1era edición

Bonilla Elsie, Díaz Bertha, Kleeber Fernando y Noriega María Teresa, (2010). Mejora continua de los procesos. 1era edición.

Project Management Institute, Inc. Guía De Los Fundamentos Para La Edición de Proyectos (PMBOK) 5ta edición - Pennsylvania 19073-3299 EE.UU.

Urbina, Carlos. Material del Curso de Planeamiento Estratégico Lima - Perú. 